\title{
Methodologies for Evaluation of Corrosion Protection for Ductile Iron Pipe
}

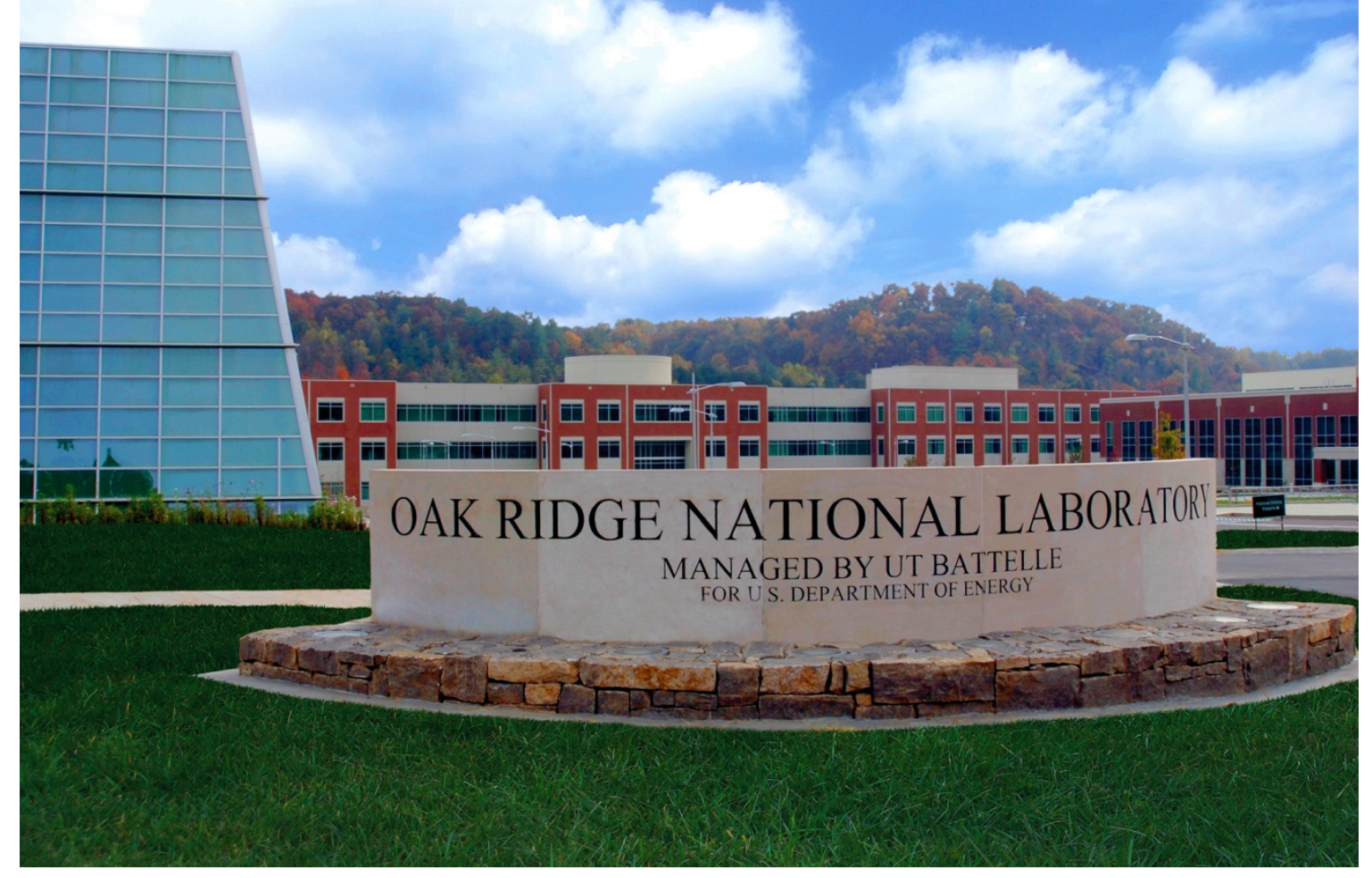

Jiheon Jun

Kinga A. Unocic

Margarita V. Petrova

Sergei A. Shipilov

Approved for public release.

Thomaz Carvalhaes

Distribution is unlimited.

Gautam Thakur

Jesse Piburn

Bruce A. Pint

June 12, 2019 


\title{
DOCUMENT AVAILABILITY
}

Reports produced after January 1, 1996, are generally available free via US Department of Energy (DOE) SciTech Connect.

\section{Website www.osti.gov}

Reports produced before January 1, 1996, may be purchased by members of the public from the following source:

\author{
National Technical Information Service \\ 5285 Port Royal Road \\ Springfield, VA 22161 \\ Telephone 703-605-6000 (1-800-553-6847) \\ TDD 703-487-4639 \\ Fax 703-605-6900 \\ E-mail info@ntis.gov \\ Website http://classic.ntis.gov/
}

Reports are available to DOE employees, DOE contractors, Energy Technology Data Exchange representatives, and International Nuclear Information System representatives from the following source:

Office of Scientific and Technical Information

PO Box 62

Oak Ridge, TN 37831

Telephone 865-576-8401

Fax 865-576-5728

E-mail reports@osti.gov

Website http://www.osti.gov/contact.html

This report was prepared as an account of work sponsored by an agency of the United States Government. Neither the United States Government nor any agency thereof, nor any of their employees, makes any warranty, express or implied, or assumes any legal liability or responsibility for the accuracy, completeness, or usefulness of any information, apparatus, product, or process disclosed, or represents that its use would not infringe privately owned rights. Reference herein to any specific commercial product, process, or service by trade name, trademark, manufacturer, or otherwise, does not necessarily constitute or imply its endorsement, recommendation, or favoring by the United States Government or any agency thereof. The views and opinions of authors expressed herein do not necessarily state or reflect those of the United States Government or any agency thereof. 
Materials Science and Technology Division

\title{
METHODOLOGIES FOR EVALUATION OF CORROSION PROTECTION FOR DUCTILE IRON PIPE
}

\author{
Jiheon Jun \\ Kinga A. Unocic \\ Margarita V Petrova \\ Sergei A. Shipilov \\ Thomaz Carvalhaes \\ Gautam Thakur \\ Jesse Piburn \\ Bruce A. Pint
}

June 12, 2019

Prepared by

OAK RIDGE NATIONAL LABORATORY

Oak Ridge, TN 37831-6283

managed by

UT-BATTELLE, LLC

for the

US DEPARTMENT OF ENERGY

under contract DE-AC05-00OR22725 



\section{CONTENTS}

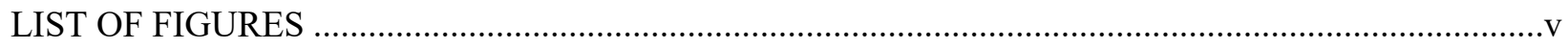

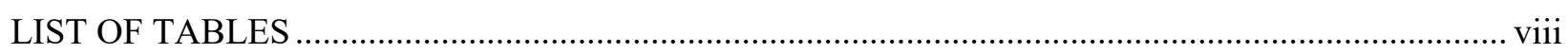

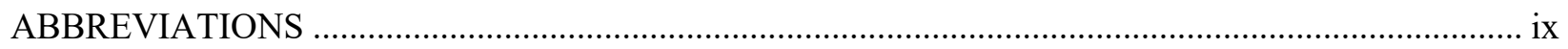

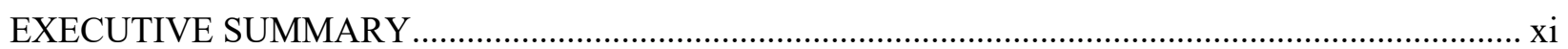

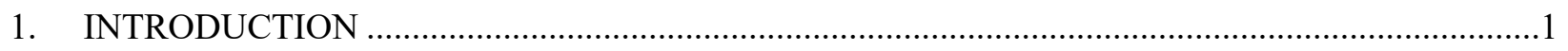

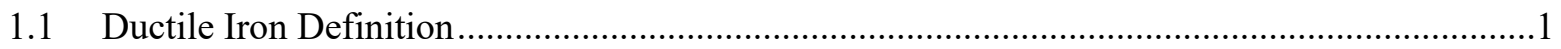

1.2 Review of the 2004 Bureau of Reclamation Technical Memorandum and the 2009

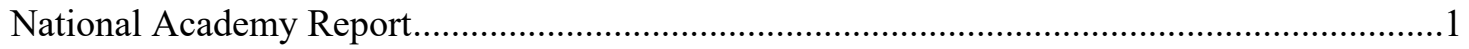

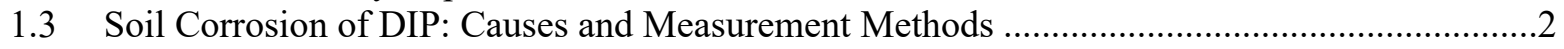

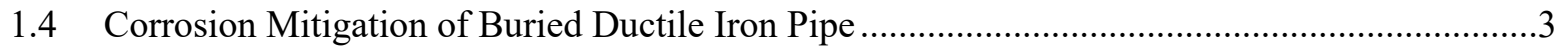

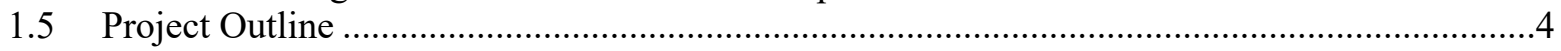

2. TASK 1: CHARACTERIZE COMMERCIAL COATING SYSTEMS

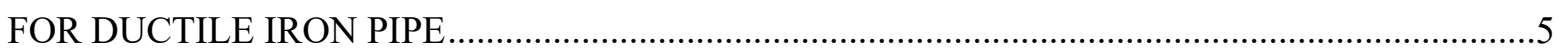

2.1 Characterization of As-Received Ductile Iron Pipe ................................................................

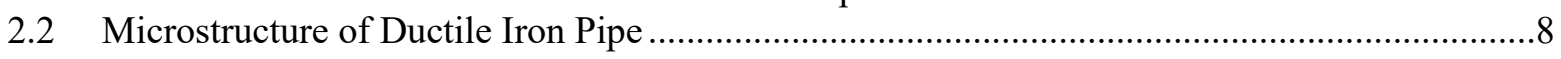

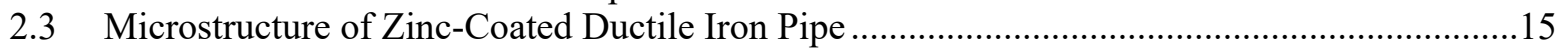

2.4 Replication of Oxide Layer Formed on As-Received DIP ...............................................16

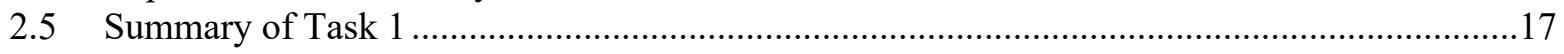

3. TASK 2: CONSOLIDATE AVAILABLE CORROSION DATA …...............................................18

3.1 Studies of Soil Corrosivity and Corrosion Protection...........................................................18

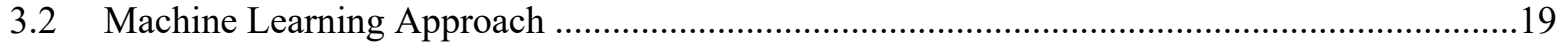

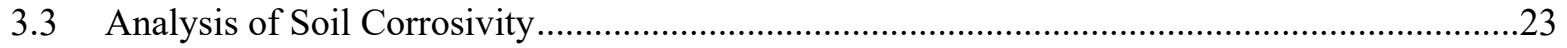

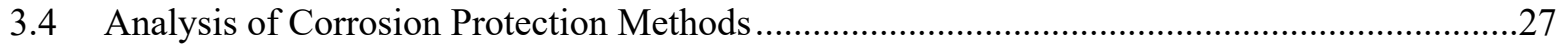

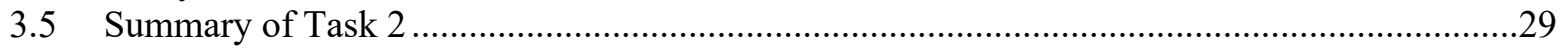

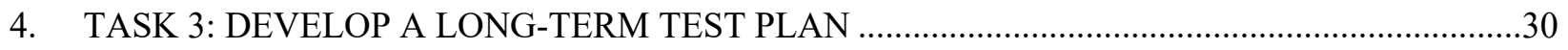

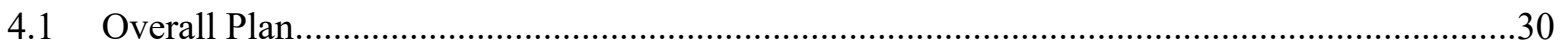

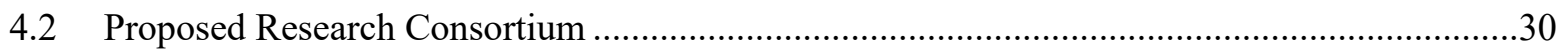

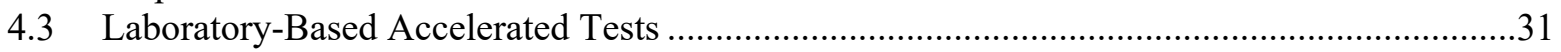

4.4 Examples of Suggested Experimental and Computer-Based Analyses .................................32

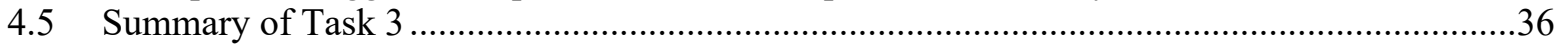

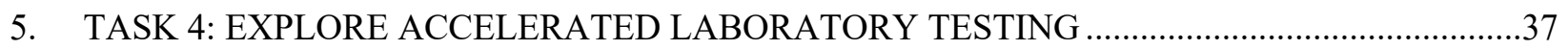

5.1 Consideration of Accelerating Factors in Soil Corrosion .......................................................37

5.2 Preparation of DIP Samples with Oxide Layer and Zn Coating ..............................................

5.3 Accelerated Corrosion Test in Aggressive Soil Mixture: Experimental and Corrosive

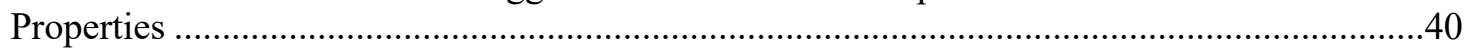

5.4 Accelerated Corrosion Test in Aggressive Soil Mixture: Mass Loss ......................................48

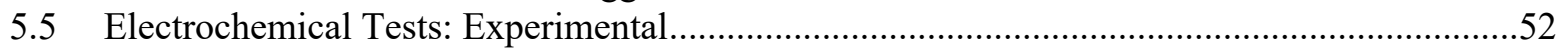

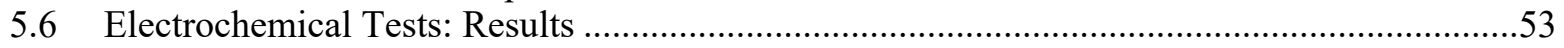

5.7 Comparison of Field and Laboratory-Simulated Soil Corrosion ............................................64

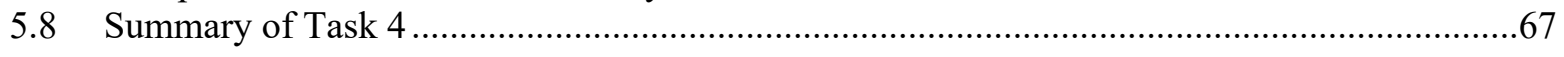

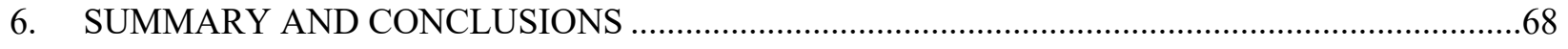

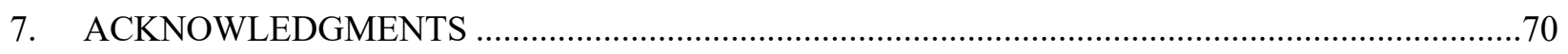

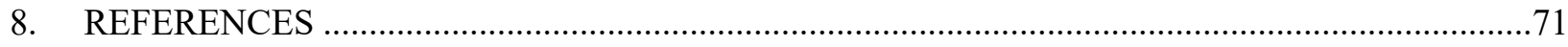

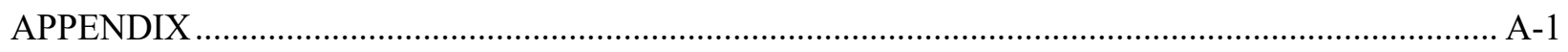





\section{LIST OF FIGURES}

Figure 1.1. Classification of corrosion measurements, the ${ }^{*}$ symbol indicates the measurement was conducted on real pipes buried in soil.

Figure 1.2. Classification of corrosion protection methods. .............................................................

Figure 2.1. Photo images of sectioned 4 in. DIP: $(a, b)$ Manufacturer B and (c,d) Manufacturer

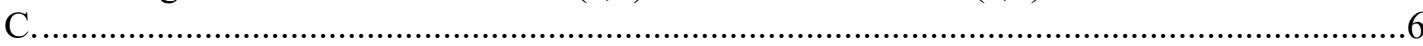

Figure 2.2. Photo images of sectioned DIP (Manufacturer A): (a,b,c) 4 in. and (d) 12 in.

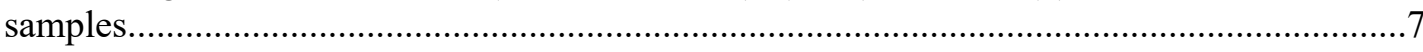

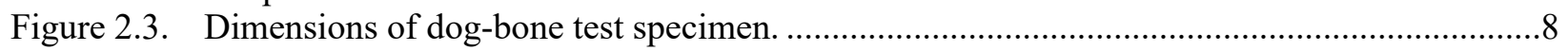

Figure 2.4. Tensile properties of DIP and steel samples from 4, 6, and 36 in. pipes.............................8

Figure 2.5. Light microscopy image of 2\% Nital etched DIP (Manufacturer A) sample........................9

Figure 2.6. SEM images of cross-sectioned DIP in as-received condition from DIP manufacturers $(\mathrm{a}, \mathrm{d}) \mathrm{C},(\mathrm{b}, \mathrm{e}) \mathrm{A}$, and $(\mathrm{c}, \mathrm{f}) \mathrm{B}$.

Figure 2.7. Measured thickness of (a) total and (b) inner/outer oxide layers on as-received DIP samples.....

Figure 2.8. SEM/EDS elemental mapping on cross-sectioned DIP (Manufacturer C) in the asreceived condition.

Figure 2.9. SEM/EDS elemental mapping on cross-sectioned DIP (Manufacturer A) in the asreceived condition.

Figure 2.10. SEM/EDS elemental mapping on cross-sectioned DIP (Manufacturer B) in the asreceived condition.

Figure 2.11. EPMA line scan on the cross section of as-received DIP (Manufacturer A): (a) BSE image with the arrow indicating the direction and length of the line scan; (b) elemental compositions along the distance of linear scan; and (c) $\mathrm{Zn}, \mathrm{O}$, and $\mathrm{Fe}$ compositions of asphalt layer in the broken line box of (b).

Figure 2.12. BF and HAADF S/TEM images (left and middle) of inner/outer oxide interface in as-received DIP (Manufacturer A).

Figure 2.13. BF and HAADF S/TEM images at the same location shown in Figure 2.12 (left and middle), TEM-based EDS mapping for $\mathrm{O}, \mathrm{Fe}, \mathrm{C}, \mathrm{Si}$, and $\mathrm{Zn}$ (right)...

Figure 2.14. HAADF S/TEM image and TEM-based EDS mapping of inner oxide/substrate interface in as-received DIP (Manufacturer A).

Figure 2.15. BF and HAADF S/TEM images of asphalt layer (top) and TEM-based EDS mapping for $\mathrm{C}, \mathrm{Fe}, \mathrm{O}, \mathrm{Si}$, and $\mathrm{Zn}$ (bottom) in as-received DIP (Manufacturer A)

Figure 2.16. BF and HAADF S/TEM images of asphalt/outer oxide interface (top) and TEMbased EDS mapping for $\mathrm{C}, \mathrm{Fe}, \mathrm{Si}$, and $\mathrm{O}$ (bottom) in as-received DIP (Manufacturer A).

Figure 2.17. Light microscopy of a zinc-coated specimen from a domestic DIP manufacturer. 15

Figure 2.18. BSE SEM images of laboratory-fabricated oxide on DIP (substrate from Manufacturer A) after ambient oxidation at $930^{\circ} \mathrm{C}$ for $(\mathrm{a}, \mathrm{b}) 0.5 \mathrm{~h},(\mathrm{c}, \mathrm{d}) 1 \mathrm{~h},(\mathrm{e}, \mathrm{f}) 2 \mathrm{~h}$, and $(\mathrm{g}, \mathrm{h})$ at $900{ }^{\circ} \mathrm{C}$ for $8 \mathrm{~h}$.

Figure 2.19. Light microscopy images of laboratory-fabricated oxide on DIP (substrate from Manufacturer A) after ambient oxidation at $950^{\circ} \mathrm{C}$ for (a) $1 \mathrm{~h}$, (b) $2 \mathrm{~h}$, and (c) $4 \mathrm{~h}$.

Figure 2.20. Measured thickness of laboratory-fabricated oxide on DIP (substrate from Manufacturer A) after oxidation at $900^{\circ}, 930^{\circ}$, and $950^{\circ} \mathrm{C}$ : (a) total oxide thickness (shaded region is the distribution of oxide thickness on as-received DIP), (b) inner, and (c) outer oxide thickness.

Figure 3.1. Quantified influences of 20 factors on corrosion mass loss using two RF methodologies: (a) average mean squared error (MSE) increase and (b) average total decrease in node impurities. 
Figure 3.2. Comparison of daily precipitation records from NBS study (average annual precipitation divided by 365 days) and NCEI daily summaries at Dallas, Texas.

Figure 3.3. Comparison of annual precipitation at Dallas, Texas: the average value of NBS study and the derived values from NCEI weather data.

Figure 3.4. Mass loss vs. time plots for eight ferrous pipes buried in soil, showing (a) large and (b) small scatters in mass loss data in 1934.

Figure 3.5. Normalized mass loss vs. soil $\mathrm{pH}$ plot from 36 data selected from the NBS corrosion dataset.

Figure 3.6. Normalized mass loss vs. soil resistivity plot from 36 data selected from the NBS corrosion dataset.

Figure 3.7. Normalized deepest penetration vs. soil $\mathrm{pH}$ plot from 14 data selected from the NBS corrosion dataset.

Figure 3.8. Normalized deepest penetration vs. soil resistivity plot from 14 data selected from the NBS corrosion dataset.

Figure 3.9. Normalized penetration of iron pipes (ductile and cast) measured for different surface conditions.

Figure 3.10. Normalized penetration of iron pipes (ductile and cast) measured under different protections (including PE and $\mathrm{Zn}+$ top coat). .28

Figure 4.1. Dominant soil orders in the US including more than 10 major soil types...........................31

Figure 4.2. Measurable and controlled parameters in laboratory and field corrosion tests. ....................32

Figure 4.3. Suggested design of a soil corrosion testing frame..........................................................33

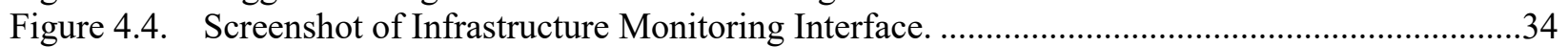

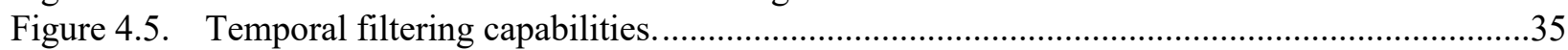

Figure 4.6. Temporal distribution of issues recorded for a 2 month period.............................................35

Figure 4.7. Spatial distribution of issues recorded for a 2 month period. ..............................................36

Figure 5.1. Appearance of laboratory-oxidized DIP samples: $(a, b)$ partial spallation of black scale with reddish oxide surface underneath and (c) full spallation of black scale

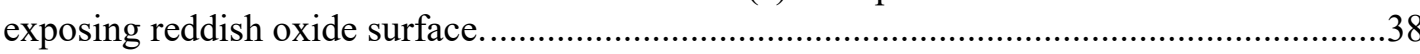

Figure 5.2. Light microscopy cross-section images of oxidized DIP samples (a) without oxide

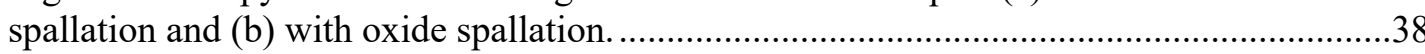

Figure 5.3. Laboratory-oxidized DIP with sandblast: (a) appearance of dark-gray oxide on a DIP sample measuring approximately $3.5 \times 4.5 \mathrm{~cm}^{2}$ and (b) cross-section light microscopy image of oxide layer formed on a sandblasted surface.

Figure 5.4. Zn coating formed by thermal spray on laboratory-oxidized DIP (substrate from Manufacturer C): (a) circular 1 in. diameter coupon, (b) DIP sample with each side measuring $\sim 4.5 \mathrm{~cm}$.

Figure 5.5. Cross-section light microscopy image of $\mathrm{Zn} /$ laboratory oxide layers formed on DIP...........39

Figure 5.6. Cross-section light microscopy images of Zn layer coated on (a) bare DIP, (b) sandblasted DIP.

Figure 5.7. Cross-section light microscopy images of $\mathrm{Zn}$ coating formed by $(\mathrm{a}, \mathrm{b})$ a manufacturer and (c) this work.

Figure 5.8. Images of DIP samples with each side 3.5-5 cm long: (a) bare surface, (b) manufacturer oxide, and (c) asphalt topcoat.

Figure 5.9. Zinc-coated DIP with a linear scribe ( $\sim 5 \mathrm{~mm}$ wide) exposing DI substrate: (a) appearance of a sample with sides 3.5 and $5.5 \mathrm{~cm}$ long and (b) schematic of scribe cross section.

Figure 5.10. Liquid epoxy coated DIP samples: (a) appearance of epoxy (green) coated DIP samples, (b) schematic of cross section, and (c) light microscopy image of crosssectioned sample.

Figure 5.11. Simulated polyethylene encasement of DIP samples: (a) appearance of DIP samples in sealed polybag and (b) schematic of encased DIP sample. 
Figure 5.12. Schematic of DIP samples buried in a saturated soil mixture.

Figure 5.13. Accelerated corrosion testing in saturated soil: (a) soil bucket placed outdoors and

(b) saturated soil with excessive solution layer.

Figure 5.14. Monitoring of measured (a) resistivity and (b) $\mathrm{pH}$ in saturated soil and excessive solution with increasing testing time.

Figure 5.15. Schematic of immersion test for DIP and steel samples; the samples were immersed for 30 days.

Figure 5.16. DIP samples after non-acid cleaning: (a) bare and (b) asphalt-coated; the sides of DIP samples are 3.5 to $5 \mathrm{~cm}$ long.

Figure 5.17. Manufacturer A DIP samples (pre-test condition: bare) cleaned by (a) non-acid cleaning and (b) non-acid + acid cleaning.

Figure 5.18. Normalized mass loss of bare DIP and steel samples with increasing test duration.

Figure 5.19. Normalized mass loss of bare DIP and steel samples after 30 day tests in different conditions.

Figure 5.20. Normalized mass loss of Manufacturer A DIP with manufacturer (annealing) oxide. ..........50

Figure 5.21. Normalized mass loss of DIP (Manufacturer C) in bare and as-manufactured (asphalt + oxide) conditions.

Figure 5.22. Normalized mass loss of DIP with pristine and damaged $\mathrm{Zn}$ coatings.

Figure 5.23. Normalized mass loss of DIP protected by simulated polyethylene encasement (PE) and liquid epoxy coating after the 10 day test; mass losses of DIP in bare and pristine $\mathrm{Zn}$-coating conditions are also plotted/designated for comparison.

Figure 5.24. Schematic of epoxy-mounted ductile iron/steel electrode..................................................53

Figure 5.25. Configuration of electrochemical cell.

Figure 5.26. Linear polarization curves of DIP samples from all three manufacturers in soilsimulating solution; zero current potential and anodic slopes of each curve are denoted.

Figure 5.27. Two-step cyclic polarization with different sequence of performance: (a) anodic cyclic scan first and (b) cathodic cyclic scan first with peak potentials $150 \mathrm{mV}$ above and below OCP.

Figure 5.28. Comparison of cyclic polarization curves of DIP and steel in soil-simulating solution from performing the (a) anodic cyclic scan first and (b) cathodic cyclic scan first.

Figure 5.29. Full polarization curve with after cathodic polarization for Tafel analysis: (a) applied potential vs time plot showing initial and full polarizations, (b) full polarization curves of DIP and steel in soil-simulating solution, and (c) snapshot of Tafel analysis assisted by EC-Lab software.

Figure 5.30. Anodic and cathodic Tafel slopes for DIP and steel in soil-simulating solution...................57

Figure 5.31. Anodic and cathodic slopes of DIP in soil-simulating solution and soil extract..........

Figure 5.32. Corrosion currents of DIP and steel estimated by Tafel analysis in soil-simulating solution and soil extract.

Figure 5.33. A snapshot of software-assisted estimation of polarization resistance in a full polarization curve of DIP in soil-simulating solution.

Figure 5.34. Estimated polarization resistance and corrosion current of DIP and steel in soilsimulating solution and soil extract.

Figure 5.35. Comparison of corrosion currents estimated by Tafel- and polarization resistancebased analyses in soil-simulating solution and soil extract (data in the broken box)............60

Figure 5.36. Nyquist plots of DIP and steel in soil-simulating solution.

Figure 5.37. Randle circuit with constant phase element of double layer.

Figure 5.38. Software-assisted fitting of Nyquist plot: (a) a snapshot of fitted plot and (b) fitted values of circuit element. 
Figure 5.39. Polarization resistance of DIP and steel in soil-simulating solution determined by fitting: (a) Nyquist plots and (b) polarization curves from EIS and potentiodynamic (P.dyn) techniques

Figure 5.40. Fitted values of (a) solution and (b) polarization resistances with increasing immersion time.

Figure 5.41. Mass loss vs soil resistivity plot of 17 data selected from the NBS corrosion dataset.

Figure 5.42. Comparison of 30 day mass loss values measured in this work (ORNL accelerated test) and estimated from NBS corrosion database.

Figure 5.43. Comparison of mass loss rates measured in this work (ORNL solution-based test) and estimated from the NBS corrosion database.

\section{LIST OF TABLES}

Table 1.1. Corrosivity of soil rated by measured resistivity (from Calhoun 2004) .................................2

Table 1.2. Classification (corrosivity rating) based on soil resistivity (from Calhoun 2004)......................2

Table 2.1. Specification of DIP samples characterized in this task .........................................................

Table 2.2. Elemental compositions of three ductile iron pipes (weight percentage) ..................................7

Table 2.3. List of characterization techniques for DIP microstructure analysis .......................................9

Table 3.1. Twenty environmental and material factors considered for machine learning analysis.............19

Table 3.2. The five core weather values in NCEI daily summaries......................................................21

Table 3.3. Weather metrics calculated from NCEI daily summary data ................................................22

Table 4.1. Three categories of parameters associated with soil-buried corrosion .....................................32

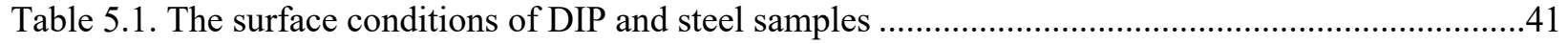

Table 5.2. Preparation details for six different test conditions ..............................................................41

Table 5.3. Preparation details of laboratory-formulated soils and accelerated testing conditions...............43

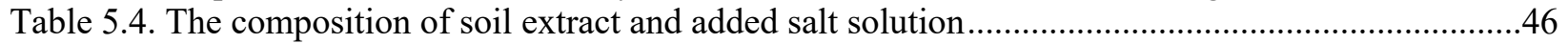

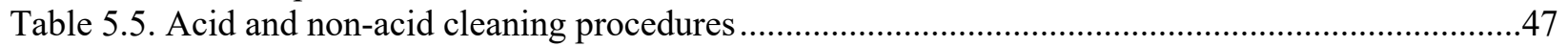

Table 5.6. Correction of mass loss for different sample conditions. ........................................................48

Table 5.7. Ionic concentrations of soil-simulating solution and soil extract ..........................................53 


\section{ABBREVIATIONS}

ASCE

ASTM

AWWA

BF STEM

BSE

$\mathrm{CP}$

CPE

DI

DIP

EDS

EIS

EPMA

ER

FBE

FIB

HAADF STEM

ICP-OES

IGF

LP

mmpy

MSE

NACE

NBS

NCEI

NIST

NOAA

OCP

OCP

ORNL

PE

RF

SCE

SE

SEM

STEM

TEM

USBR

USDA

UTS

X-FEG

YS

ZCP

ZRA
American Society of Civil Engineers

ASTM International (formerly American Society for Testing and Materials)

American Water Works Association

bright-field STEM

backscattered electron

cathodic protection

constant phase element

ductile iron; or deionized (as in DI water)

ductile iron pipe

energy dispersive spectroscopy

electrochemical impedance spectroscopy

electron probe microanalysis

electric resistance

fusion-bonded epoxy

focused ion beam

high angle annual dark field STEM

inductively coupled plasma-optical emission spectrometry

inert gas fusion

linear polarization

millimeter per year

mean squared error

National Association of Corrosion Engineers International

National Bureau of Standards (now NIST)

National Center for Environmental Information

National Institute of Standards and Technology (formerly NBS)

National Oceanic and Atmospheric Administration

open circuit potential

open circuit potential

Oak Ridge National Laboratory

polyethylene encasement

Random Forests

saturated calomel electrode

secondary electron

scanning electron microscopy

scanning/transmission electron microscopy

transmission electron microscopy

US Bureau of Reclamation

US Department of Agriculture

ultimate tensile strength

extreme field emission gun

yield strength

zero current potential

zero current ammeter 



\section{EXECUTIVE SUMMARY}

Repairing the nation's infrastructure and ensuring its future durability are key issues facing the United States. It is important that these critical issues are addressed with appropriate and economical solutions based on the best modern scientific information. For example, in 2013 the American Society of Civil Engineers (ASCE), in its Report Card for America's Infrastructure, gave the state of the critical water/wastewater infrastructure an overall grade of "D." According to the ASCE, 6 billion gallons of drinking water disappear every day, mostly due to leaks in old pipes. Corrosion of water pipes plays a role in their durability and, for external pipe corrosion, the corrosivity of soils varies by location and is based on several factors, including soil resistivity. There is universal agreement that water pipes require some type of corrosion mitigation strategy (i.e., bare pipe is not installed). However, in specifying which strategy to employ for ductile iron pipe (DIP) in different soil types, the recommendations of the US Bureau of Reclamation (USBR) Technical Memorandum 8140-CC-2004-1 were subject to considerable debate. So much so that in 2009, this report was the subject of a study by the National Academy, which did not resolve the debate about the most effective and affordable solutions. Zinc-coatings have been explored in other parts of the world. Despite being widely used in Europe for almost 60 years, zinc coating was barely mentioned in either the 2004 or 2009 studies, which appeared to focus on North American data.

To begin to address some of the outstanding questions, the goal of this project was to evaluate the performance of zinc-coated DIP in severely corrosive soils. Based on the $<1$-year duration of this project, tasks were identified to characterize commercial DIP with and without zinc coating, look at and consolidate historical data on the subject, suggest a long-term plan to fully address this subject, and to explore accelerated testing methods on relevant commercial zinc-coated pipe.

Unfortunately, commercially made zinc-coated DIP was not received from vendors for evaluation until near the end of this project, as this material is only made in limited quantities in the US. Therefore, an attempt was made to produce similar coatings in the laboratory for evaluation in the accelerated testing task and begin to address the viability of this corrosion protection strategy in relevant environments. The laboratory-made material had a remarkably similar microstructure to commercial zinc-coated DIP, but a direct comparison of the corrosion behavior of commercial material remains to be completed.

The other supporting activities were completed and provide future value for testing in more representative materials. For example, in the $20^{\text {th }}$ century, a significant pipeline corrosion study ( $\sim 40$ years, 95 different kinds of soil at 128 sites across the country) was conducted by the National Bureau of Standards (now the National Institute of Standards and Technology) which may be useful in developing a better definition of soil corrosivity. However, the study was concluded before the introduction of DIP in $~ 1970$ and before the introduction of polyethylene encasement (PE) for external DIP protection. Nevertheless, the database may be useful in developing a better definition of corrosive soils. Initial computational work was done using machine learning to process the large amount of information and variables. Rather than waiting decades for modern pipeline corrosion control solution to be evaluated, several laboratory tests were explored using accelerated testing protocols. However, further work is needed to validate these results compared to traditional long-term buried pipe studies. In 10- to 60-day laboratory experiments, the accelerated testing did show the effectiveness of both PE, preferred by the DIP industry, and a bonded dielectric coating required under the 2004 memorandum.

The current standards for DIP corrosion control in highly and severely corrosive soils are outlined in the 2004 memo and require the use of bonded dielectric coatings with cathodic protection and corrosion monitoring. A subsequent National Academy advisory committee review of corrosion data and standards for soil-buried DIP did not consider zinc-coatings as an option. There is an open question as to whether a zinc coating alone or a zinc coating in conjunction with another form of protection, such as polyethylene 
encasement and/or cathodic protection, could enable the 50-year reliability required by the USBR. Based on the information gathered in this study, it is not clear if the current standards are consistent with the DIP manufacturing process or amenable for qualification of zinc-coated DIP. It is recommended that the USBR form an independent research team consisting of universities and independent laboratories not associated with any of the competing pipe manufacturers to examine key issues and the use of this standard for zinc-coated DIP. Team members should be strategically located to enable soil testing in numerous conditions across the country, and the team should be advised by a committee of manufacturers, industry experts, and water utilities to conduct research to address fundamental issues such as

1. developing an improved definition of corrosive soils not based solely on resistivity,

2. evaluating various coating strategies to determine their effectiveness,

3. developing predictive modeling capabilities that would be available to the entire water utility industry, and

4. conducting long-term studies of pipeline corrosion to validate the model in a variety of soils.

The suggested structure would have the added benefits of educating the next generation of corrosion scientists for this industry and bringing scientific rigor to this important issue. An initial goal of this future effort would be a more detailed examination of the existing standards, the evaluation of combinations of zinc coating, PE, and cathodic protection to determine which, if any, combinations meet the 50 -year goal required by the USBR. 


\section{INTRODUCTION}

\subsection{DUCTILE IRON DEFINITION}

Ductile iron (DI) is a type of cast iron developed in the $20^{\text {th }}$ century (ca. 1943). It began to replace cast iron in water pipelines in about 1970 (Bell 2017). Generically, cast irons are a class of ferrous alloys with carbon contents above $2.14 \mathrm{wt}$.\%; in practice, however, most cast irons contain between 3.0 and $4.5 \mathrm{wt} . \%$ carbon as well as other alloying elements. The tendency to form graphite in the iron is regulated by the composition and rate of cooling. Graphite formation is promoted by the presence of silicon in concentrations greater than about $1 \mathrm{wt} . \%$. Also, slower cooling rates during solidification favor graphitization (the formation of graphite). For most cast irons, the carbon exists as graphite, and both microstructure and mechanical behavior depend on composition and heat treatment. The most common cast iron types are gray, ductile (or nodular), white, malleable, and compacted graphite.

The common defining characteristic of DI is the shape of the graphite. In DI, the graphite is in the form of nodules (see Section 2.2) rather than flakes as in grey iron. The rounded shape of the nodules inhibits the creation of cracks and provides the enhanced ductility that gives the alloy its name. The formation of nodules is achieved by the addition of specific alloying elements, most commonly magnesium. Graphite still forms, but as nodules or sphere-like particles instead of flakes. The matrix phase surrounding these particles is either pearlite or ferrite, depending on the heat treatment. It is normally pearlite as-cast. However, a heat treatment for several hours at about $700^{\circ} \mathrm{C}\left(1300^{\circ} \mathrm{F}\right)$ will yield a ferrite matrix. Castings are stronger and much more ductile than gray iron. In fact, DI has mechanical characteristics approaching those of steel. For example, ferritic DI has tensile strengths ranging between 380 and $480 \mathrm{MPa}$ (55 and 70 ksi) and ductility (as percent elongation) from 10 to 20\%. Typical applications for this material include valves, pump bodies, crankshafts, gears, and other automotive and machine components. As noted earlier, DI also is used for manufacturing ductile iron pipe (DIP). Cast iron (56\%) and DIP (16\%) dominate the water pipelines in service in the US. More information about DI specifications and manufacturing can be found in the Appendix.

\subsection{REVIEW OF THE 2004 USBR TECHNICAL MEMORANDUM AND THE 2009 NATIONAL ACADEMY REPORT}

In 2004, the US Bureau of Reclamation (USBR) published technical memorandum 8140-CC-2004-1, which provides a measure of soil corrosivity and recommends protections for various pipe materials, including DIP, in soils with different levels of corrosivity (Calhoun 2004). In the document, the measured soil resistivity was considered the main criterion for corrosivity, as summarized in Table 1.1.

Recommended protections for DIP according to soil corrosivity were also found in the document as summarized in Table 1.2. For the most corrosive soil (i.e., soil resistivity $<2000 \mathrm{ohm} \cdot \mathrm{cm}$ ), a bonded dielectric coating along with cathodic protection (CP) was suggested, while polyethylene encasement (PE) with and without CP were recommended for less-corrosive soils. The effectiveness of PE, however, has not been fully proven for long-term corrosion protection due to a lack of corrosion data reported for DIP with PE protection. The combination of $\mathrm{PE}$ and $\mathrm{CP}(\mathrm{PE}+\mathrm{CP})$ for synergetic protection was not investigated either. 
Table 1.1. Corrosivity of soil rated by measured resistivity

(from Calhoun 2004)

\begin{tabular}{ll}
\hline \multicolumn{1}{c}{$\begin{array}{c}\text { Soil resistivity } \\
(\mathbf{o h m} \cdot \mathbf{c m})\end{array}$} & \multicolumn{1}{c}{ Classification } \\
\hline$<1000$ & Very corrosive \\
$1,000-5,000$ & Moderately corrosive \\
$5,000-10,000$ & Mildly corrosive \\
$>10,000$ & Slightly corrosive \\
\hline
\end{tabular}

Table 1.2. Classification (corrosivity rating) based on soil resistivity (from Calhoun 2004)

\begin{tabular}{cccc}
\hline $\begin{array}{c}\text { Soil resistivity } \\
(\mathbf{o h m} \cdot \mathbf{c m})\end{array}$ & Minimum external protection & $\begin{array}{c}\text { Cathodic } \\
\text { protection }\end{array}$ & $\begin{array}{c}\text { Corrosion } \\
\text { monitoring }\end{array}$ \\
\hline$\leq 2000$ & Bonded dielectric & Yes & Yes \\
$>2000, \leq 3000$ & Polyethylene encasement & Yes & Yes \\
$>3000$ & Polyethylene encasement & No & Yes \\
\hline
\end{tabular}

Because of the limited data available, USBR later requested the advisory committee of the National Academy to review the effectiveness of PE + CP for corrosion reliability of DIP over 50 years. USBR also asked the committee to suggest alternative corrosion protection strategies for the 50 -year corrosion reliability of DIP if PE $+\mathrm{CP}$ were not expected to provide proper protection.

In response to BoR's request, the advisory committee of the National Academy investigated available corrosion data and standards for soil-buried DIP and concluded:

- $\mathrm{CP}+\mathrm{PE}$ effectively reduced corrosion compared to non-protected DIP.

- $\mathrm{CP}+\mathrm{PE}$ was not likely to provide 50-year corrosion reliability of DIP.

- No alternative protection could be suggested due to a lack of corrosion data.

It is worth noting that in the report the advisory committee did not consider zinc coating as an alternative. However, zinc coatings are suggested with or without other protection methods for buried pipe corrosion in Europe and have been used for over 50 years (Paris 1975, Drew 1995, ISO 2007). An initial search did not locate any standards or reports on the use of zinc-coated DIP in the US. Thus, there is an open question as to whether a zinc coating alone or a zinc coating in conjunction with another form of protection, such as $\mathrm{PE}$ and/or CP, could enable the 50-year reliability required by the USBR. While domestic commercial production of zinc-coated DIP started in the 1980s, it was not widely deployed in the US until recently and only limited corrosion data on the performance of zinc-coated DIP with PE and/or CP are publicly available (Horton 2014).

\subsection{SOIL CORROSION OF DIP: CAUSES AND MEASUREMENT METHODS}

\section{Soil-derived solution}

Ingress of water into soil can create an aqueous solution that contains soluble salts, organic matter and gases. This soil-derived solution exists as moisture (a very small volume of aqueous solution), which enables the measurement of soil humidity, conductivity and $\mathrm{pH}$. This solution is also the direct cause of pipe corrosion: once an aqueous solution is in contact with an unprotected or poorly protected surface of DIP, corrosion can initiate and proceed, particularly accelerated by aggressive species (e.g., S, Cl) in the solution. The concentration of dissolved species in the solution is an indicator of soil corrosivity; however, it is not constant over time due to changes in the amount of water in the soil which is controlled 
by the environment (e.g., weather). This fluctuation of solution concentration changes the corrosion rate of DI over time, implying that the soil properties related to corrosivity need to be monitored to assess the progress of pipe corrosion. Corrosion and corrosion rate are also highly dependent on the nature of the surrounding soil, which may vary considerably across the nation and even across local municipalities.

\section{Direct measurement of corrosion damage on DIP}

The most common and direct way to evaluate corrosion damage is to visually inspect the DIP after removing it from the soil. Once DIP is extracted from the soil, the corrosion mass loss of DIP can be measured along with the maximum penetration depth. For a fixed value of mass loss, the maximum penetration depth would increase if the corrosion attack were localized but decrease if the corrosion were uniform. In most cases, localized corrosion would not be as easy to detect because the attack would be narrow and deep, resulting in a small opening on the surface of the corroded metal. The main drawbacks of these on-site inspections include service outages and costs for soil excavation and inspection. This direct method measures the accumulated corrosion damage over the entire exposure period but does not provide real-time corrosion damage for specific time frames, so it is classified as an ex situ measurement in Figure 1.1.

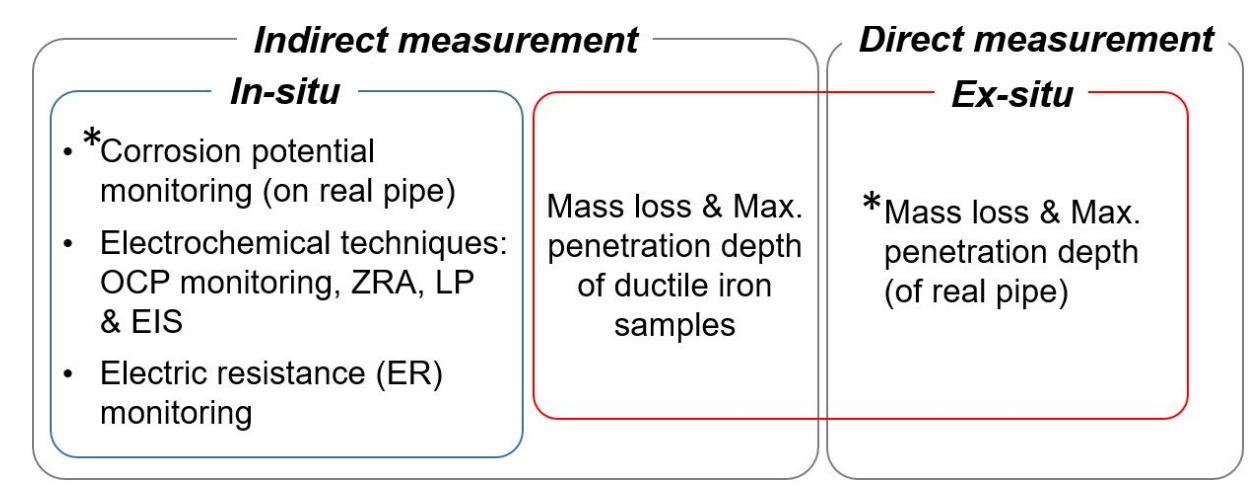

Figure 1.1. Classification of corrosion measurements, the * symbol indicates the measurement was conducted on real pipes buried in soil.

\section{Indirect measurement of corrosion damage on DIP}

Any evaluation of corrosion without direct inspection of real pipes is considered an indirect measurement and would include all laboratory tests and corrosion monitoring on DI samples and pipes. These indirect analyses of corrosion can be divided into in situ and ex situ measurements depending on whether the corrosion rate can be recorded in real time. Most in situ (or real-time) measurements monitor electrochemical potential, current and impedance associated with corrosion with or without perturbation of the system by an applied potential and current. These measurements include open-circuit potential (OCP) monitoring, zero current ammeter (ZRA), linear polarization (LP), and electrochemical impedance spectroscopy (EIS). Another method for in situ corrosion monitoring makes use of the change of electrical resistance (ER) in corroding metals (e.g., Bell and Romer 2004). On the other hand, for ex situ measurements, the maximum penetration depth and mass loss of a DI sample (not a pipe specimen) exposed to laboratory or field environments can be used to estimate corrosion damage of DIP. The classification of in situ and ex situ indirect corrosion measurements is shown in Figure 1.1.

\subsection{CORROSION MITIGATION OF BURIED DUCTILE IRON PIPE}

Choosing proper protections for DIP is crucial to minimize corrosion and ensure service reliability. In soil-buried DIP, the corrosion interface is defined by the DI surface in contact with soil-derived solution. One branch of corrosion mitigation utilizes physical protection to prevent or minimize the formation of 
the corrosion interface by barrier materials. This type of protection includes epoxy coating and polyethylene encasement (PE). The other branch of corrosion mitigation reduces electrochemical dissolution (corrosion) of metal by lowering the electrode potential of DIP in the cathodic direction, which is referred to as cathodic protection. To polarize DIP cathodically, imposed current from external power sources or galvanic anodes can be used. Magnesium is a common galvanic (or sacrificial) anode connected to steel and cast iron pipes by conducting wires. On the other hand, zinc can be directly coated on pipes and provide both barrier and cathodic protections: a pristine zinc layer can physically impede the permeation of soil-derived solution to the pipe surface. In cases in which both zinc and the pipe surface are exposed, a zinc coating can still provide galvanic current, which would reduce the corrosion of the underlying pipe (Gulec 2011). The classification of corrosion mitigation is shown in Figure 1.2.

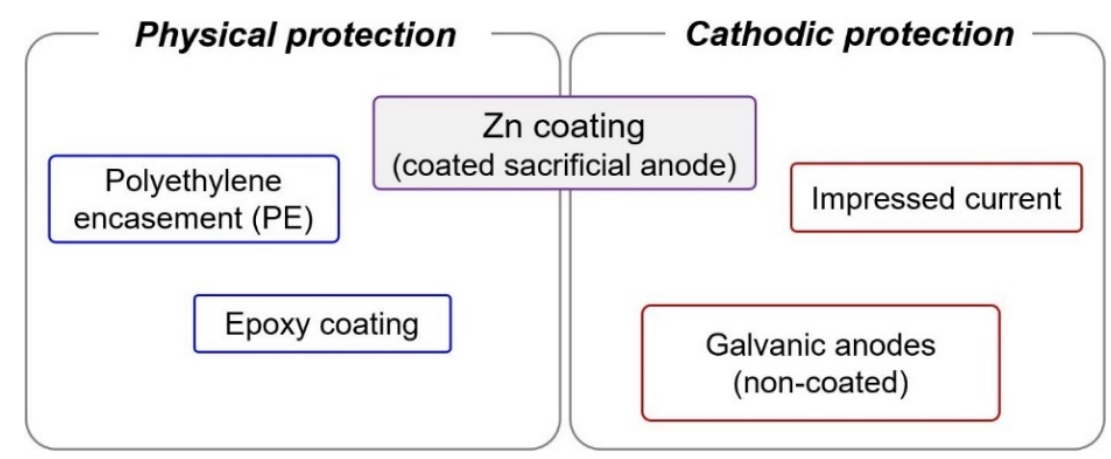

Figure 1.2. Classification of corrosion protection methods.

As mentioned previously, International Organization for Standardization (ISO) Standard 8179 for zinc coated DIP (ISO 2007) was first issued in 1985 (U.S. Pipe 2017). Zinc-coated DIP has been used commercially in Europe for almost 60 years. However, the large US studies of buried pipe did not include zinc coatings (or PE or CP) (e.g., Romanoff 1957). Since only limited data are available on zinc-coated DIP relative to PE alone or epoxy coatings on DIP, a study is needed to address this gap and quantify the reliability of coated DIP in service.

\subsection{PROJECT OUTLINE}

The stated goal of this project was to evaluate and develop performance data for zinc-coated DIP applications in highly or severely corrosive soils. This information was to be used to evaluate whether or not zinc-coated DIP meets the requirements of the 2004 USBR technical memorandum.

A research plan was developed with four tasks:

- Characterize commercial coating systems for DIP

- Consolidate the available corrosion data

- Develop a long-term test plan

- Explore accelerated laboratory testing

The project was led by the Corrosion Science and Technology Group of the Materials Science and Technology Division at Oak Ridge National Laboratory (ORNL). The team included researchers from the Electron Microscopy Group, the Mechanical Properties and Mechanics Group, as well as the Geographic Information Science and Technology Group from the Computational Sciences and Engineering Division.

Unfortunately, the project was complicated by the lack of available commercial zinc-coated DIP. Considerable effort was made to study the zinc content of coating on conventional DIP and to prepare zinc-coated DIP in the laboratory. 


\section{TASK 1: CHARACTERIZE COMMERCIAL COATING SYSTEMS FOR DUCTILE IRON PIPE}

This task was intended to characterize the thickness, composition, and microstructure of zinc coatings fabricated on DIP from the three major US DIP manufacturers (American Pipe 2017, McWane 2017 and U.S. Pipe 2017). However, since commercially fabricated zinc-coated DIP was not available, this task characterized conventional DIP without a zinc coating. Without commercial zinc-coated material to study, the project focused on creating zinc coatings in the laboratory. This strategy necessitated the replication of the thick oxide layer formed during annealing of DIP after casting. The process of recreating that oxide layer on DIP is discussed. Some commercially made coatings deposited on witness substrates are shown in Section 5 along with characterization of DIP after accelerated corrosion exposures.

\subsection{CHARACTERIZATION OF AS-RECEIVED DUCTILE IRON PIPE}

Three DIP manufacturers are located near Birmingham, AL:

- American Ductile Iron Pipe

- McWane Ductile

- U.S. Pipe and Foundry Company

To obtain samples for this task, several DIP pipe samples (without zinc coatings) were purchased through third-party vendors. The specifications of the DIP samples are summarized in Table 2.1. The first column contains manufacturer information, inner diameter, and batch number of each DIP sample; for example, A04-1 indicates the first batch of 4" DIP sample manufactured by Manufacturer A.

Table 2.1. Specification of DIP samples characterized in this task

\begin{tabular}{|c|c|c|c|c|c|}
\hline Label & Third-party vendor & $\begin{array}{c}\text { DIP } \\
\text { manufacturer }\end{array}$ & $\begin{array}{c}\text { Pipe size } \\
(\text { ID [in] } \times \text { L [ft] })\end{array}$ & Description & Received \\
\hline A04-1 & $\begin{array}{l}\text { ORNL Utilities } \\
\text { Division }\end{array}$ & A & $4 \times 3$ & Asphalt coated, mortar lined & $8 / 10 / 2016$ \\
\hline A12-1 & Blalock \& Sons Inc. & A & $12 \times 2$ & $\begin{array}{l}\text { Standard mortar lining with } \\
\text { bituminous seal coat and } \\
\text { bituminous exterior }\end{array}$ & $9 / 23 / 2016$ \\
\hline B04-1 & $\begin{array}{l}\text { Consolidated Pipe } \\
\text { and Supply Co. }\end{array}$ & B & $4 \times 18$ & $\begin{array}{l}\text { Asphalt coated, mortar lined } \\
\text { slip joint pipe }\end{array}$ & $8 / 11 / 2016$ \\
\hline B36-1 & $\begin{array}{l}\text { Valley Pipe and } \\
\text { Fittings }\end{array}$ & B & $36 \times 22$ & bituminous exterior & 9/9/2016 \\
\hline $\mathrm{C} 04-1$ & $\begin{array}{l}\text { Valley Pipe and } \\
\text { Fittings }\end{array}$ & $\mathrm{C}$ & $4 \times 1 / 2$ & $\begin{array}{l}\text { Class } 53 \text { ( } 4.8 " \text { OD); asphalt } \\
\text { coated, mortar lined }\end{array}$ & 9/8/2016 \\
\hline $\mathrm{C} 06-1$ & $\begin{array}{l}\text { Valley Pipe and } \\
\text { Fittings }\end{array}$ & $\mathrm{C}$ & $6 \times 20$ & Tyton joint pipe & $\begin{array}{l}\text { Stock in } \\
\text { Knoxville }\end{array}$ \\
\hline $\mathrm{C} 06-2$ & $\begin{array}{l}\text { Valley Pipe and } \\
\text { Fittings }\end{array}$ & $\mathrm{C}$ & $6 \times 20$ & Tyton joint pipe & $\begin{array}{l}\text { Stock in } \\
\text { Knoxville }\end{array}$ \\
\hline
\end{tabular}

\section{Visual insepction}

As-received DIP samples were cut for surface and cross-section inspection, and images of sectioned DIP samples are shown in Figures 2.1 and 2.2. All DIP samples were finished with an asphalt coating (Figures 2.1a,c and 2.2a,d) and lined inside with mortar (Figures 2.1b,d and 2.2b,c). As an example, the thickness 
of a 4" (102 mm) pipe wall was $\sim 8.5 \mathrm{~mm}(0.33$ "), and the thickness of the mortar lining was $\sim 5.5 \mathrm{~mm}$ $(0.22 ”)$ (Figure 2.2b,c).

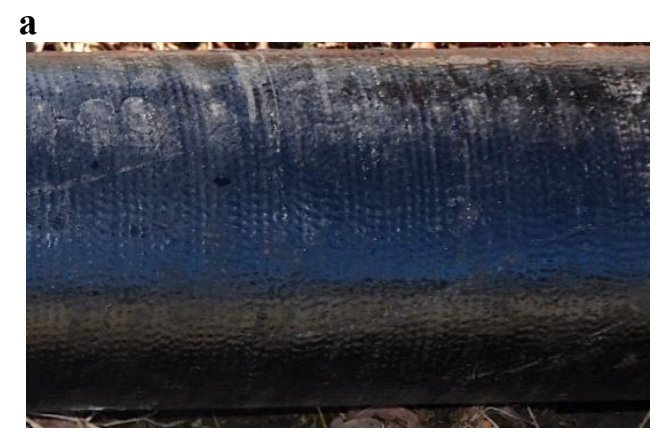

b

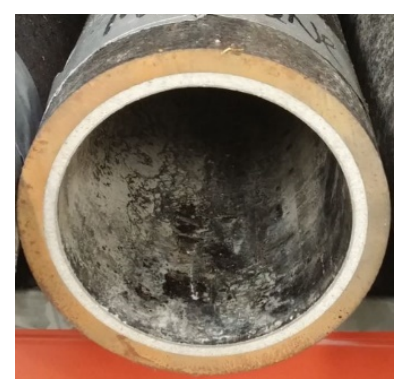

c

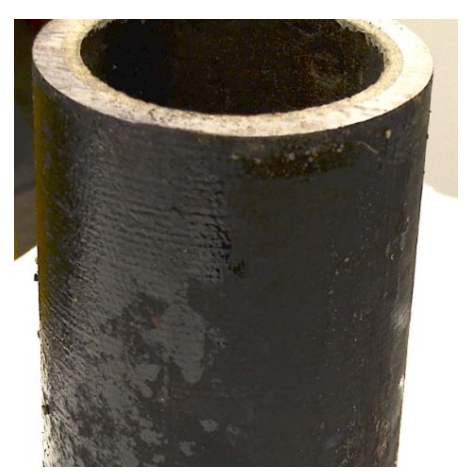

d

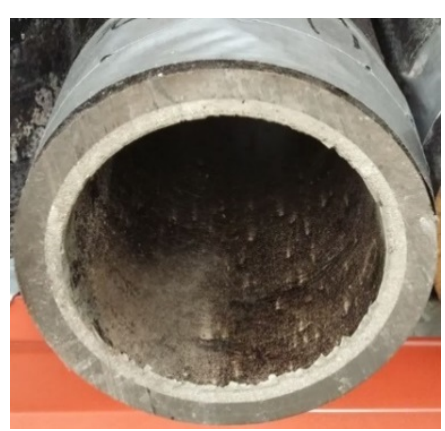

Figure 2.1. Photo images of sectioned 4" DIP: (a,b) Manufacturer B and (c,d) Manufacturer C.

\section{Compositional analyses on DIP}

Inductively coupled plasma, optical emission spectrometry (ICP-OES), inert gas fusion (IGF), and combustion analyses were used to analyze the composition of DIP samples. The compositions of three DIP samples are summarized in Table 2.2. The contents of carbon and other alloying elements were not significantly different in all DIP samples. However, the Si level was less than $0.1 \mathrm{wt} . \%$ in one sample. This is considered a measurement error because Si content comparable to other DIP was repeatedly detected in the oxide layer of Manufacturer A DIP with energy dispersive spectroscopy (EDS) described in Section 2.2. 
b
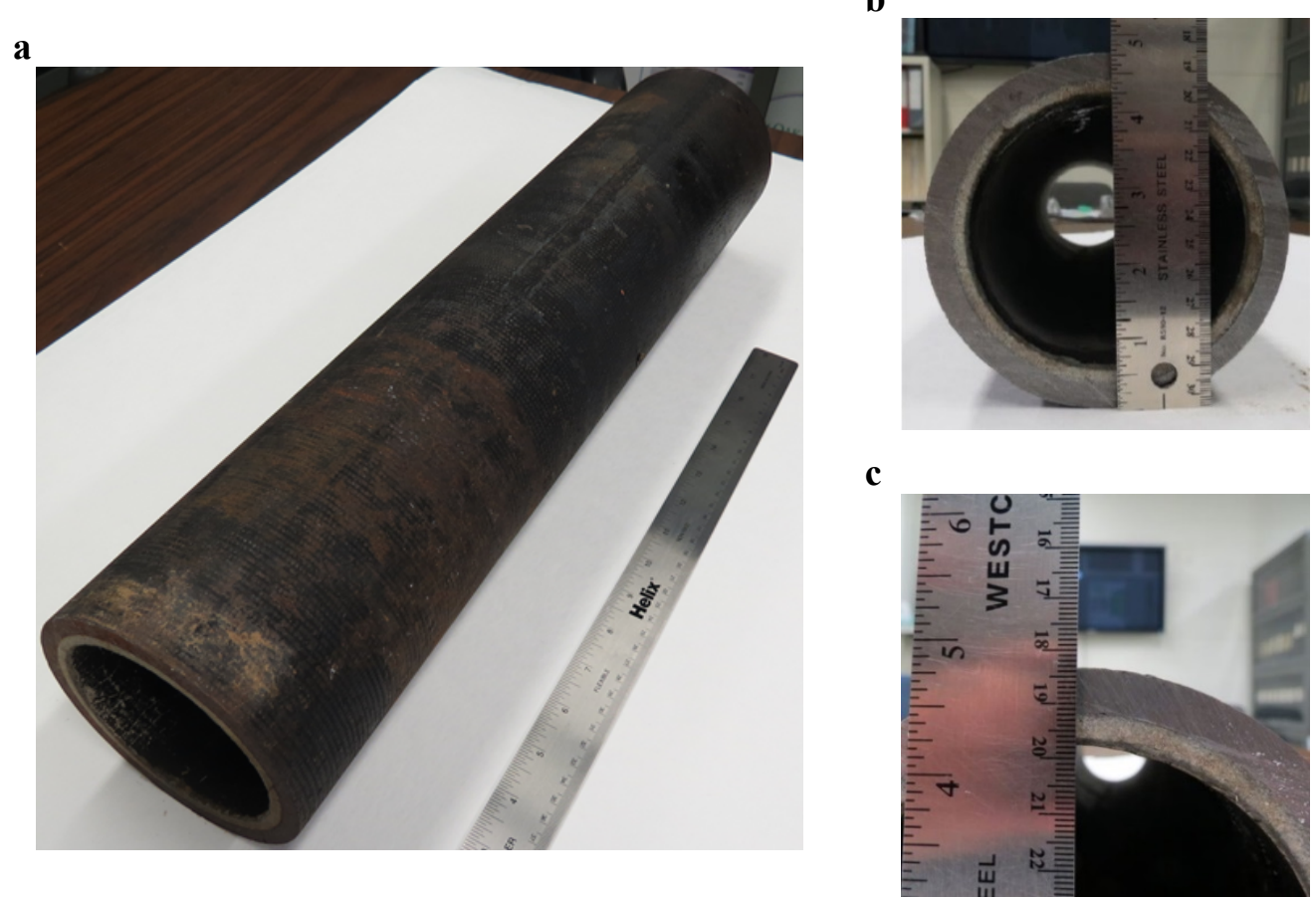

d

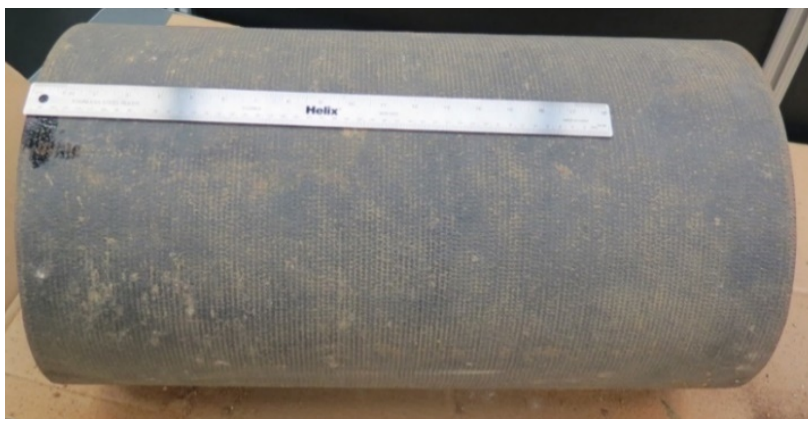

Figure 2.2. Photo images of sectioned DIP (Manufacturer A): (a,b,c) 4" and (d) 12" samples.

Table 2.2. Elemental compositions of three ductile iron pipes (weight percentage)

\begin{tabular}{lccc}
\hline Element & Pipe A & Pipe B & Pipe C \\
\hline $\mathrm{Fe}$ & 95.44 & 93.53 & 92.78 \\
$\mathrm{C}$ & 3.53 & 3.38 & 3.96 \\
$\mathrm{Si}$ & $<0.01$ & 2.19 & 2.27 \\
$\mathrm{Mn}$ & 0.35 & 0.31 & 0.54 \\
$\mathrm{Cu}$ & 0.28 & 0.23 & 0.14 \\
$\mathrm{Cr}$ & 0.16 & 0.19 & 0.12 \\
$\mathrm{Mg}$ & 0.02 & 0.02 & 0.04 \\
$\mathrm{P}$ & 0.042 & 0.032 & 0.025 \\
$\mathrm{~S}$ & 0.005 & 0.003 & 0.007 \\
Minor elements & $\mathrm{Co}, \mathrm{Mo}, \mathrm{Ni}, \mathrm{Ti}, \mathrm{Sn}$, & $\mathrm{Al}, \mathrm{As}, \mathrm{Co}, \mathrm{Mo}, \mathrm{Ti}$, & $\mathrm{As}, \mathrm{Ce}, \mathrm{Co}, \mathrm{Mo}, \mathrm{Ti}$, \\
$(<0.03$ wt.\%) & $\mathrm{V}, \mathrm{O}, \mathrm{N}$ & $\mathrm{Nb}, \mathrm{Ni}, \mathrm{Sn}, \mathrm{O}, \mathrm{N}$ & $\mathrm{Nb}, \mathrm{Sn}, \mathrm{V}, \mathrm{O}, \mathrm{N}$ \\
\hline
\end{tabular}




\section{Tensile Properties}

DIP pipes from Manufacturer $\mathrm{C}$ and steel pipes from Manufacturer $\mathrm{D}$ were machined into dog-bone specimens for tensile testing. The detailed dimensions of the dog-bone specimens are shown in Figure 2.3. The measured yield strength and ultimate tensile strength (YS and UTS) as well as total elongation are plotted in Figure 2.4. The standard mechanical properties of 60-42-10 grade DI defined in ASTM A536 are also designated as broken lines in the plots.

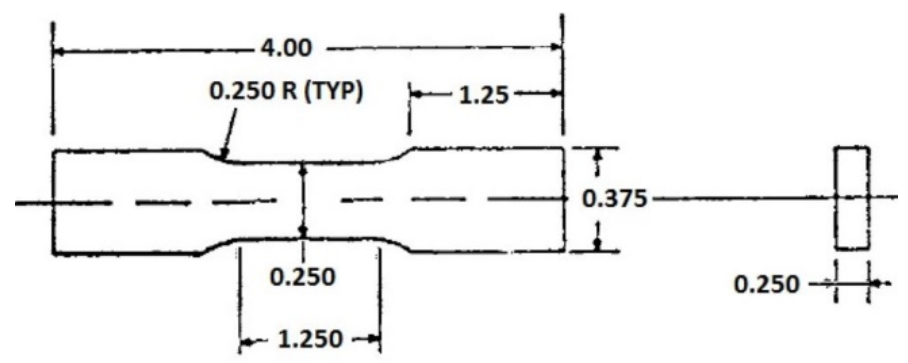

Figure 2.3. Dimensions of dog-bone test specimen.

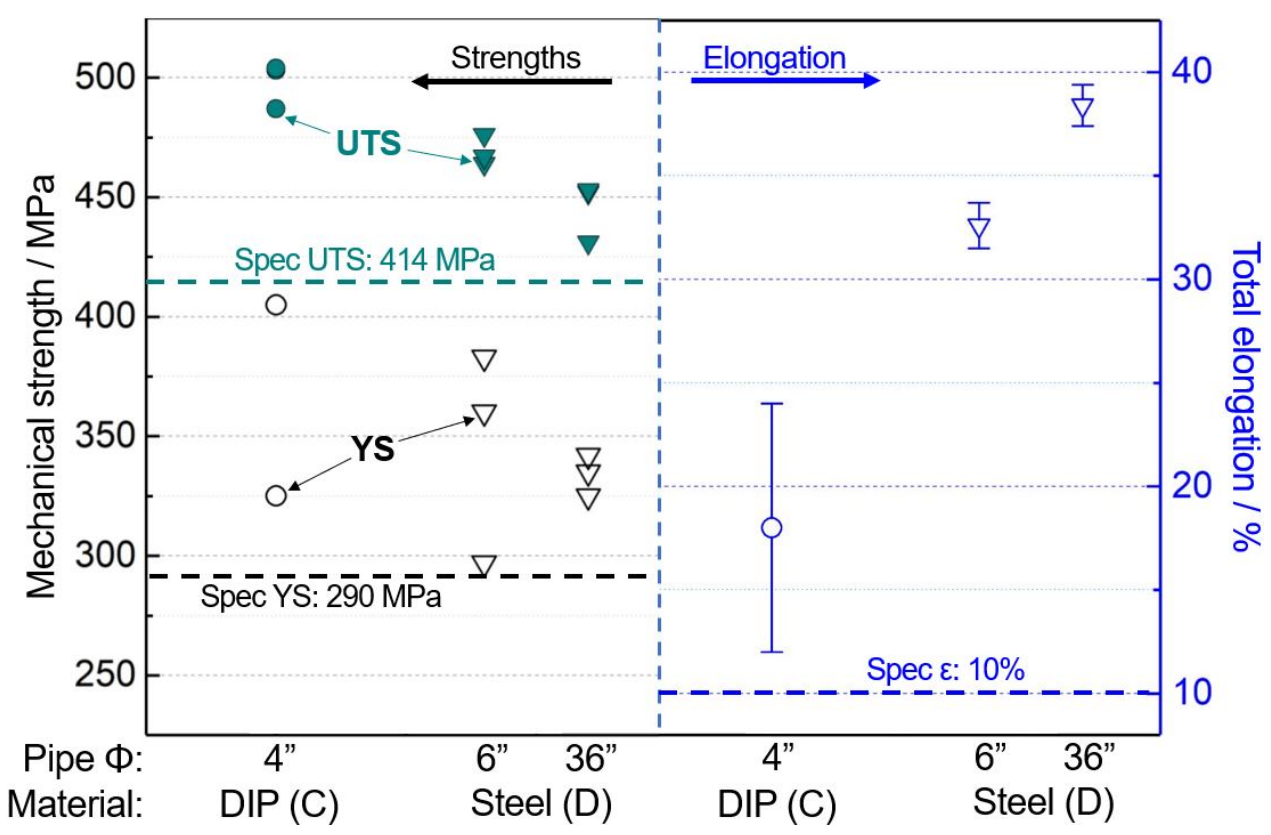

Figure 2.4. Tensile properties of DIP and steel samples from 4, 6 and 36" pipes. The manufacturers of DIP and steel are C and D, respectively. The standard properties of 60-42-10 grade DIP in ASTM A536 are shown as dashed lines.

\subsection{MICROSTRUCTURE OF DUCTILE IRON PIPE}

Microstructures of DIP samples were analyzed using multiple characterization techniques as summarized in Table 2.3. Acronyms for the various characterization techniques are shown in the table. A light microscopy image with a 2\% Nital etchant of the Manufacturer A DIP is shown in Figure 2.5. Both ferrite (bright phases) and pearlite (lamellar phases) were observed in the matrix along with spheroidal graphite. In general, pearlite is not as ductile as ferrite, so DIP with an increased content of pearlite would exhibit higher mechanical strength but lower elongation. This is in good agreement with the tensile results in Figure 2.4. 
Table 2.3. List of characterization techniques for DIP microstructure analysis

\begin{tabular}{lll}
\hline Characterization instrument & Model (brand) & Notes \\
\hline Light microscopy & - & Initial evaluation \\
\hline $\begin{array}{l}\text { Scanning electron microscopy } \\
\text { (SEM) }\end{array}$ & S3400 and S4800 (Hitachi) & $\begin{array}{l}\text { SEM-based energy dispersive spectroscopy } \\
\text { (EDS) available }\end{array}$ \\
\hline $\begin{array}{l}\text { Electron probe microanalysis } \\
\text { (EPMA) }\end{array}$ & JEOL 8200 (JEOL) & $\begin{array}{l}\text { Chemical analysis with improved standards } \\
\text { compared to SEM EDS }\end{array}$ \\
\hline $\begin{array}{l}\text { Scanning/transmission electron } \\
\text { microscopy (STEM) }\end{array}$ & STEM Talos F200X (FEI) & $\begin{array}{l}\text { Operation voltage: 200 kV, equipped with } \\
\text { extreme field emission gun (X-FEG) and } \\
\text { Super-X EDS for TEM-based EDS }\end{array}$ \\
\hline Focused ion beam (FIB) & NB5000 FIB-SEM (Hitachi) & \begin{tabular}{l} 
Used to prepare thin-foil samples for TEM \\
\hline
\end{tabular}
\end{tabular}

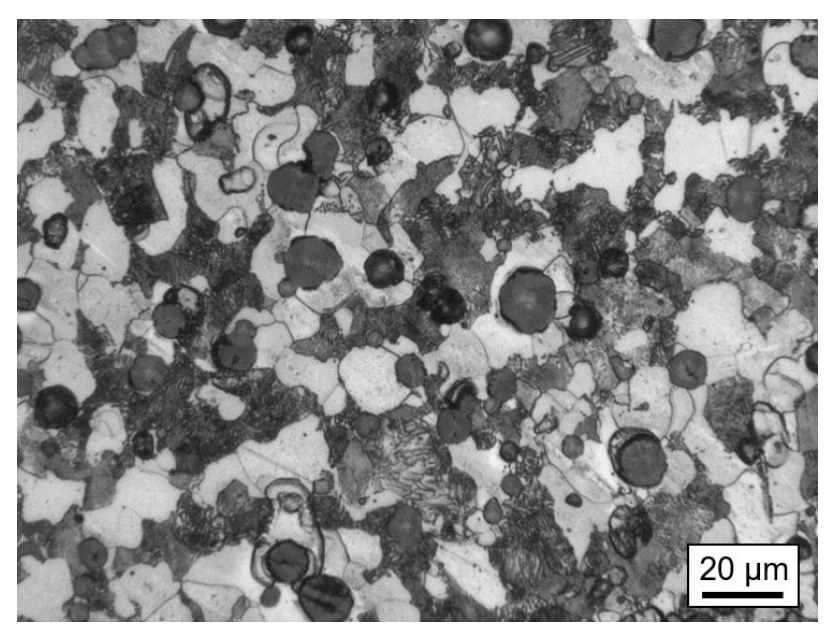

Figure 2.5. Light microscopy image of 2\% Nital etched DIP (Manufacturer A) sample.

As-received DIP samples were cross-sectioned for further characterization, and six SEM images of the cross-sectioned samples are shown in Figure 2.6. In all DIP samples, the top asphalt layer and bi-layer oxide were observed (Figure 2.6a). The thickness of the outer asphalt layer was not uniform, $\sim 50 \mu \mathrm{m}$ at the thickest spot. The oxide layer formed during thermal annealing of the as-cast DIP and the outer and inner oxide layers are distinguished by contrast in the images (e.g., Figure 2.6d). The outer oxide (typically outward-growing haematite) generally contained voids and cracks, while the inner oxide layer (typically inward-growing magnetite or another spinel-type oxide) is more compact. The thicknesses of the inner, outer, and total oxide layers are shown in Figure 2.7. The total oxide thickness in the three asreceived DIP samples ranged from $60-100 \mu \mathrm{m}$. The thickness of the outer oxide layer was larger than the inner oxide layer in all cases. 

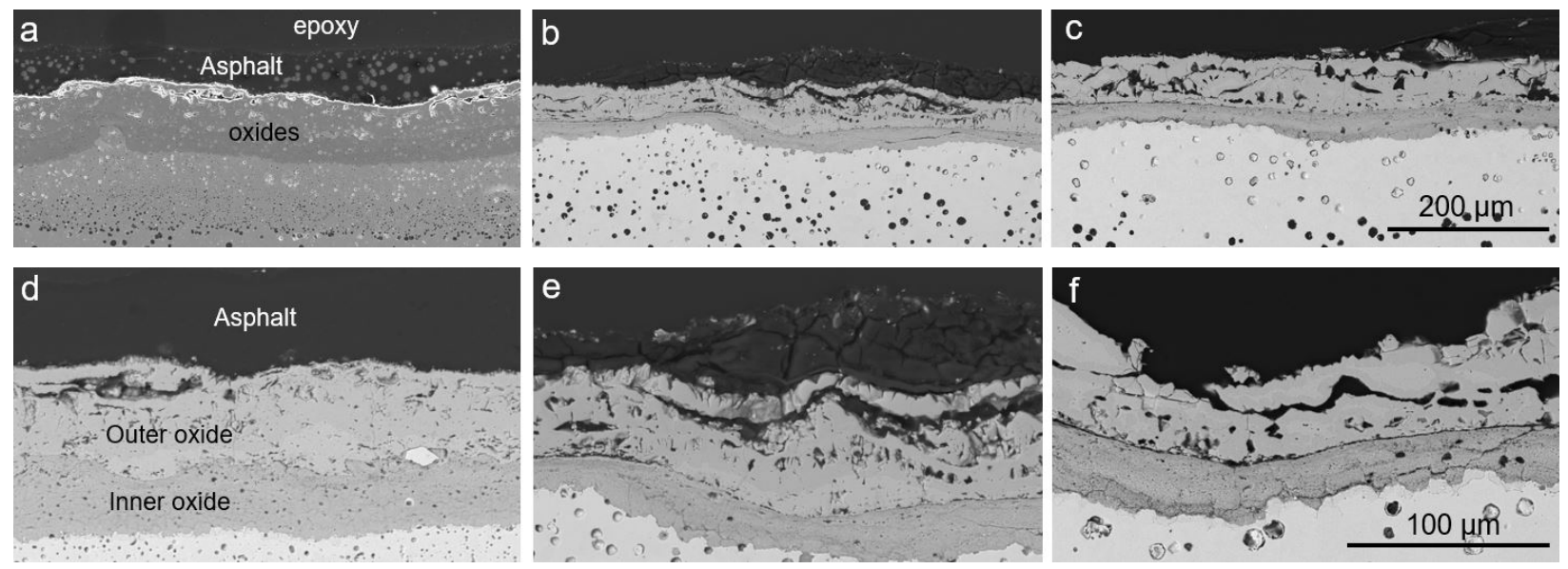

Figure 2.6. SEM images of cross-sectioned DIP in as-received condition from DIP manufacturers (a,d) C, $(\mathbf{b}, \mathbf{e}) \mathbf{A}$ and (c,f) B. Image (a) is a secondary electron (SE) image, while (b-f) are back-scattered electron (BSE) images.

a

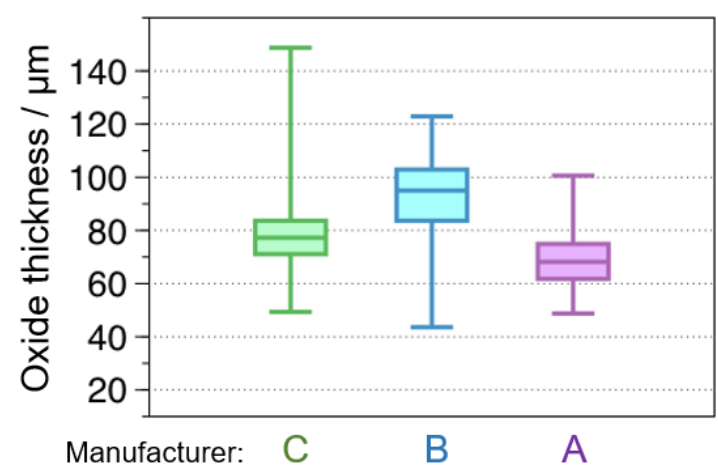

b

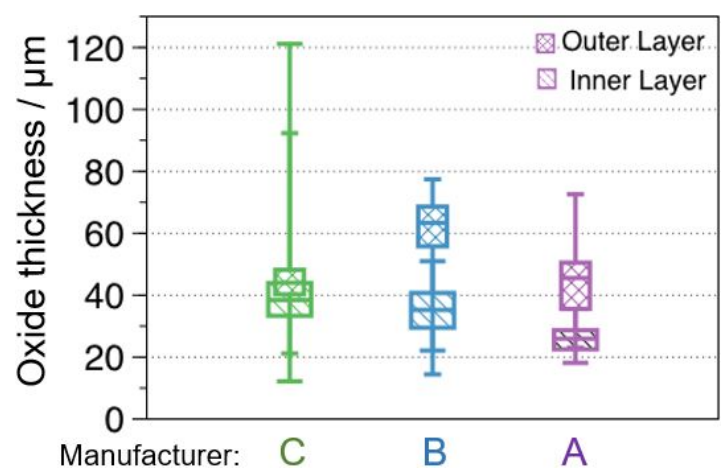

Figure 2.7. Measured thickness of (a) total and (b) inner/outer oxide layers on as-received DIP samples. Box plots show the $25 \%$ and $75 \%$ measurements with the median value inside the box. Whiskers show the minimum and maximum values measured.

The compositions of the bi-layer oxide on as-received DIP samples were analyzed by EDS, and the elemental mapping results are shown in Figures 2.8, 2.9, and 2.10 for each of the US manufacturers. The main constituents of the outer and inner layers are iron $(\mathrm{Fe})$ and oxygen $(\mathrm{O})$, but silicon $(\mathrm{Si})$ is additionally detected in the inner layer. Conventional DIP does not have a zinc coating, and the zinc maps occasionally show some signal; however, this is likely noise. Nevertheless, additional characterization was conducted on the Manufacturer A DIP sample (Figure 2.9). 

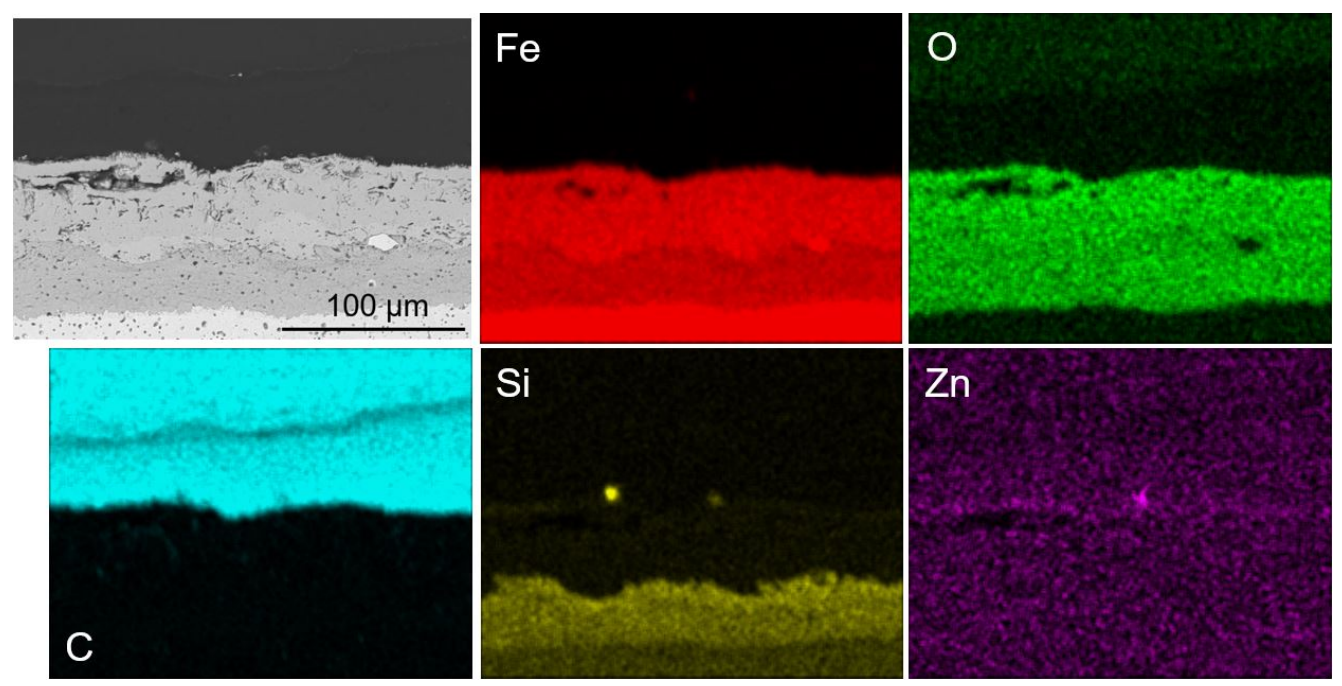

Figure 2.8. SEM/EDS elemental mapping on cross-sectioned DIP (Manufacturer $\mathrm{C}$ ) in the as-received condition. Upper left is the SE image along with five maps from that region.
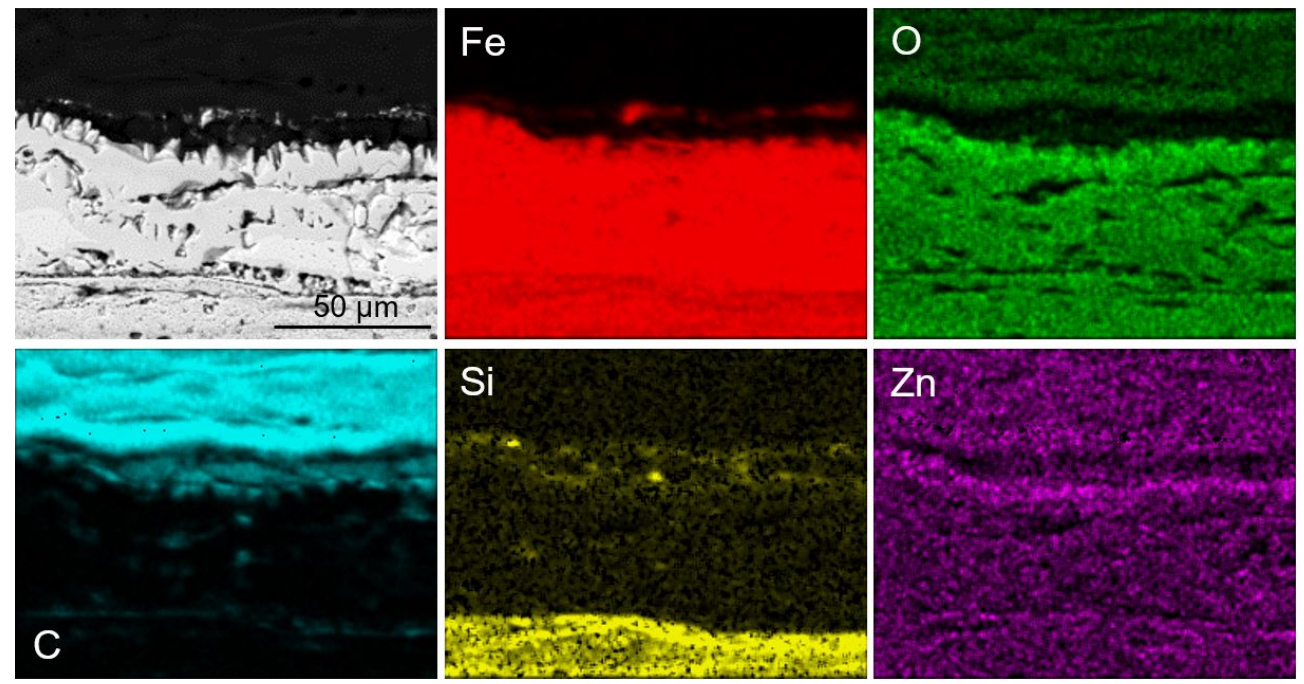

Figure 2.9. SEM/EDS elemental mapping on cross-sectioned DIP (Manufacturer $\mathrm{A}$ ) in the as-received condition. Upper left is the SE image along with five maps from that region.

A linear composition profiling of as-received Manufacturer A DIP was conducted by EPMA and shown in Figure 2.11. The EPMA line scan was initiated in the top asphalt layer and continued through the outer and inner oxide layers to the DI substrate (Figure 2.11a). The elemental composition (in atom \%) vs. distance profile (Figure 2.11b) shows high $\mathrm{O}$ and Fe contents in the oxide layer with small amount $(<10$ atom \%) of Si detected for the region closer to the substrate. This agrees well with EDS mapping results in Figure 2.9. In the asphalt layer, a high carbon content was detected. The non-carbon elements in the asphalt layer (Figure 2.11c) contain a small amount ( $<10$ atom \%) of Zn. Again, this could be noise in the measurement. 

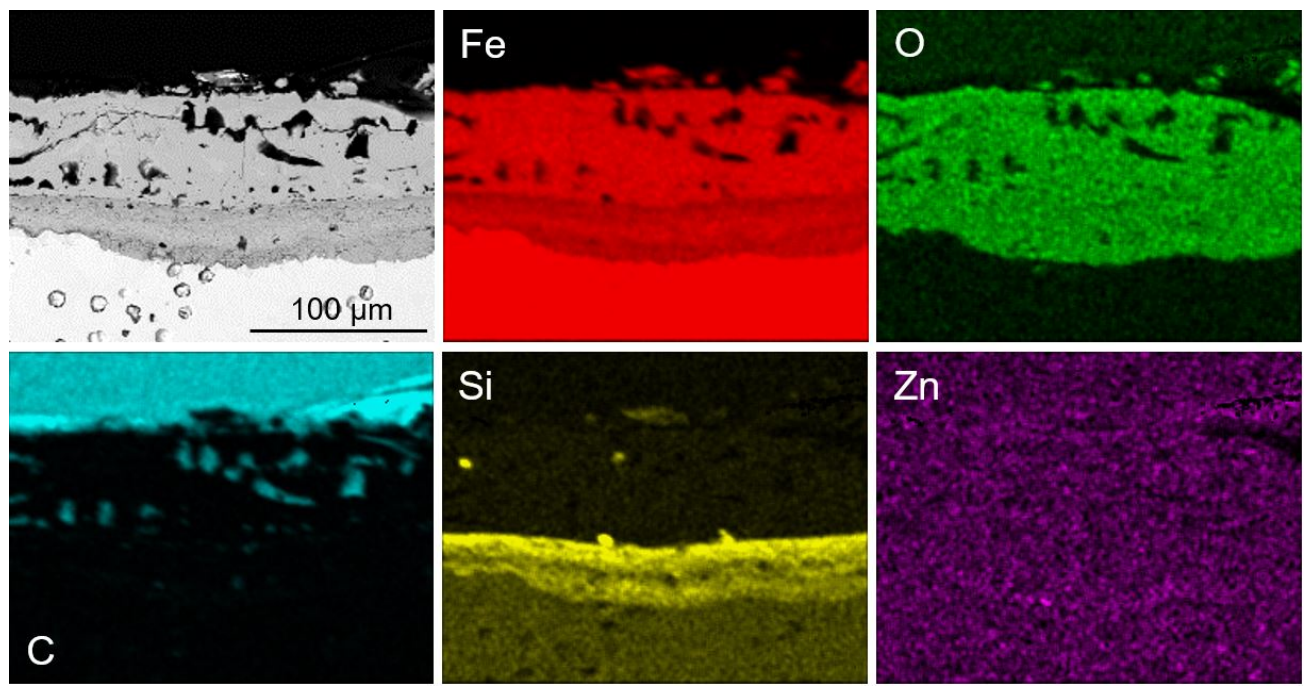

Figure 2.10. SEM/EDS elemental mapping on cross-sectioned DIP (Manufacturer B) in the as-received condition. Upper left is the SE image along with five maps from that region.

a

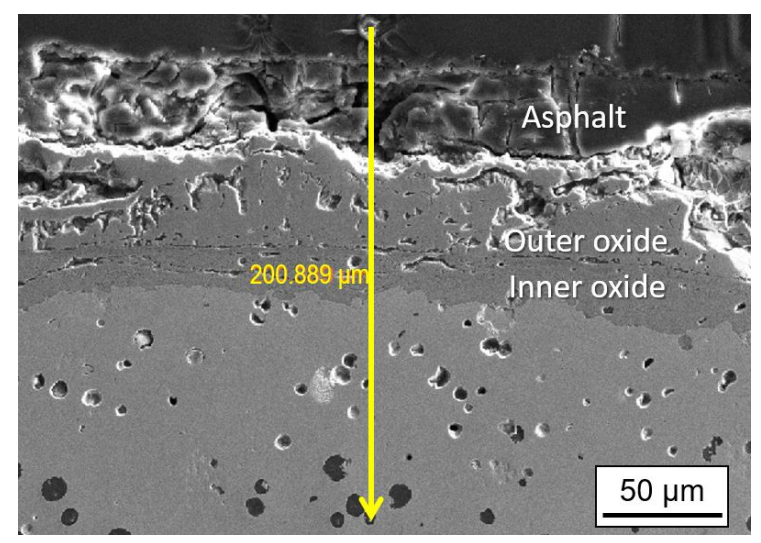

$\mathbf{b}$

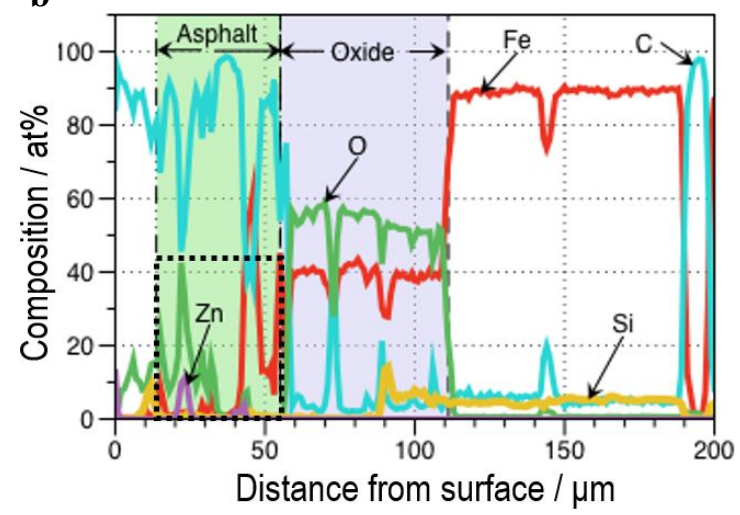

c

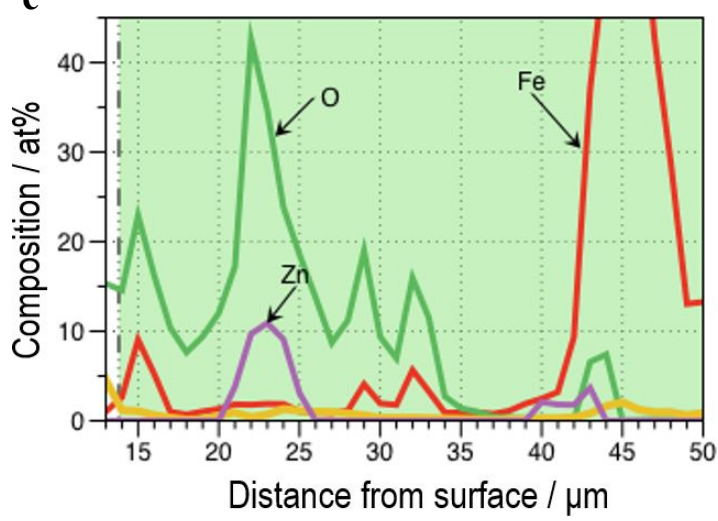

Figure 2.11. EPMA line scan on the cross section of as-received DIP (Manufacturer A): (a) BSE image with the arrow indicating the direction and length of the line scan; (b) elemental compositions along the distance of linear scan; and (c) Zn, O, and Fe compositions of asphalt layer in the broken line box of (b).

Bright-field and high-angle annular dark field (BF and HAADF) STEM as well as BSE SEM images of an inner/outer oxide interface are shown in Figure 2.12. In the STEM images, individual grains are 
identified by contrast differences. Both oxides are constructed of equiaxed grains with a smaller grain size in the inner oxide layer. STEM EDS elemental maps generated for the location shown in the STEM images in Figure 2.12 are presented in Figure 2.13. The oxides were identified as Fe oxides with $\mathrm{Si}$ content present in the inner oxide. These results agree well with the compositional analyses by SEMbased EDS and EPMA.

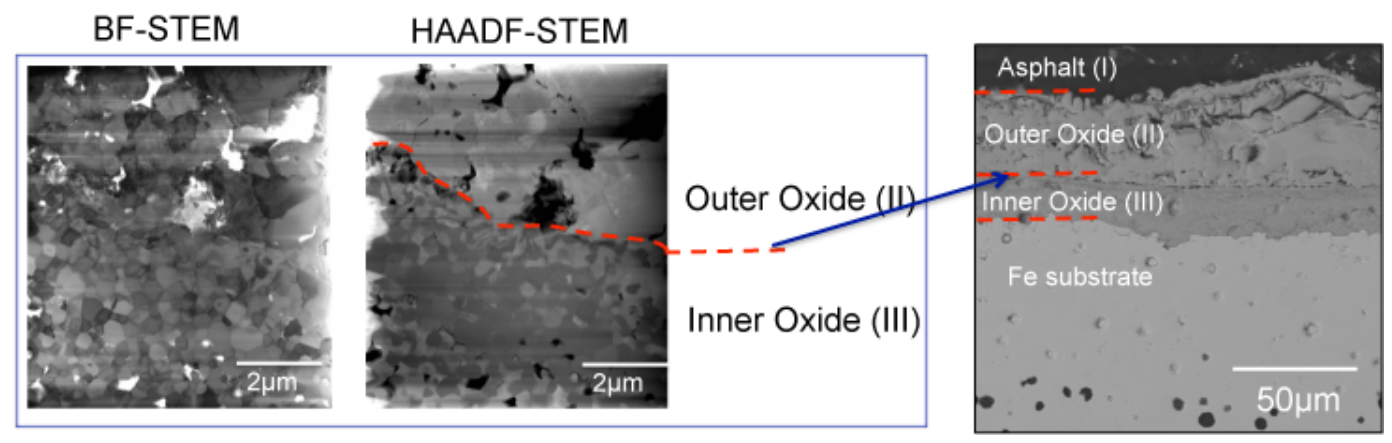

Figure 2.12. BF and HAADF S/TEM images (left and middle) of inner/outer oxide interface in as-received DIP (Manufacturer A). The boundary of two oxides is outlined by red broken line in the HAADF image, and both S/TEM images were taken from the location pointed in SEM-BSE image (right).
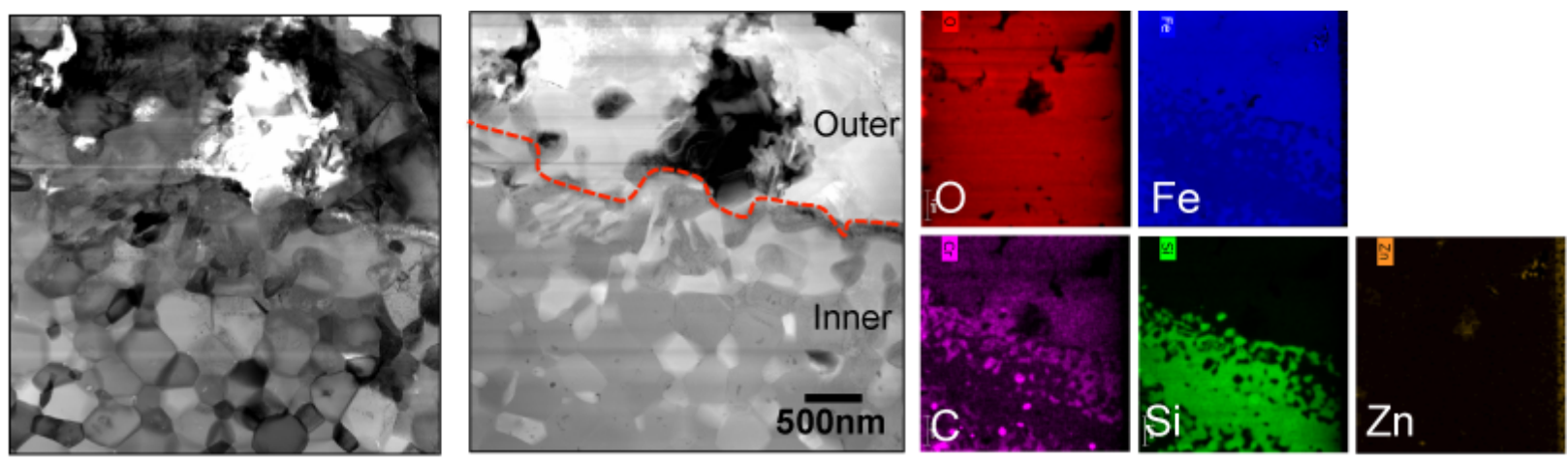

Figure 2.13. BF and HAADF S/TEM images at the same location shown in Figure 2.12 (left and middle), TEM-based EDS mapping for $\mathrm{O}, \mathrm{Fe}, \mathrm{C}, \mathrm{Si}$, and $\mathrm{Zn}$ (right).

A HAADF STEM image of the inner oxide/iron substrate interface is shown with STEM EDS maps in Figure 2.14. Oxides rich in $\mathrm{Si}$ were observed in this location along with some $\mathrm{C}$ enrichment, perhaps due to oxidation of an adjacent graphite particle. Unlike the low magnification image (Figure 2.5), the carbonrich graphite precipitates in the substrate are not spherical but elongated. Perhaps these small precipitates formed after the heat treatment. At the surface of these precipitates at the metal-oxide interface, a thin $\mathrm{Si}$ rich oxide has formed. Figure 2.15 shows STEM images and EDS maps from the asphalt layer. Oxide particles at the surface of the asphalt appeared to contain zinc. Figure 2.16 shows STEM images and EDS maps of the asphalt/outer oxide interface. 

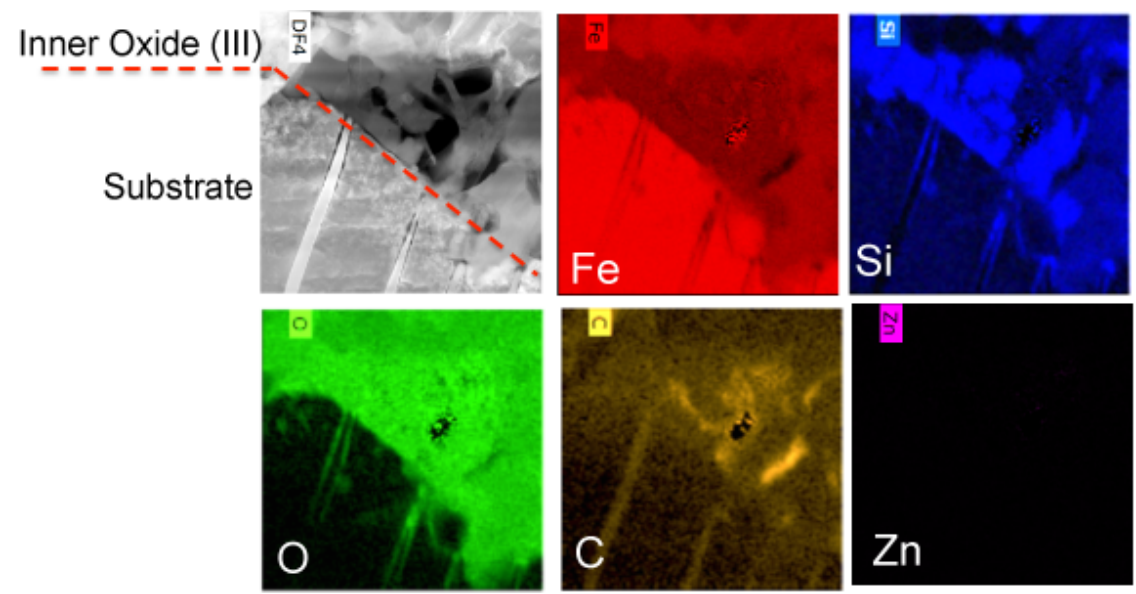

Figure 2.14. HAADF S/TEM image and TEM-based EDS mapping of inner oxide/substrate interface in asreceived DIP (Manufacturer A). The interface is outlined by a broken red line in the HAADF image.

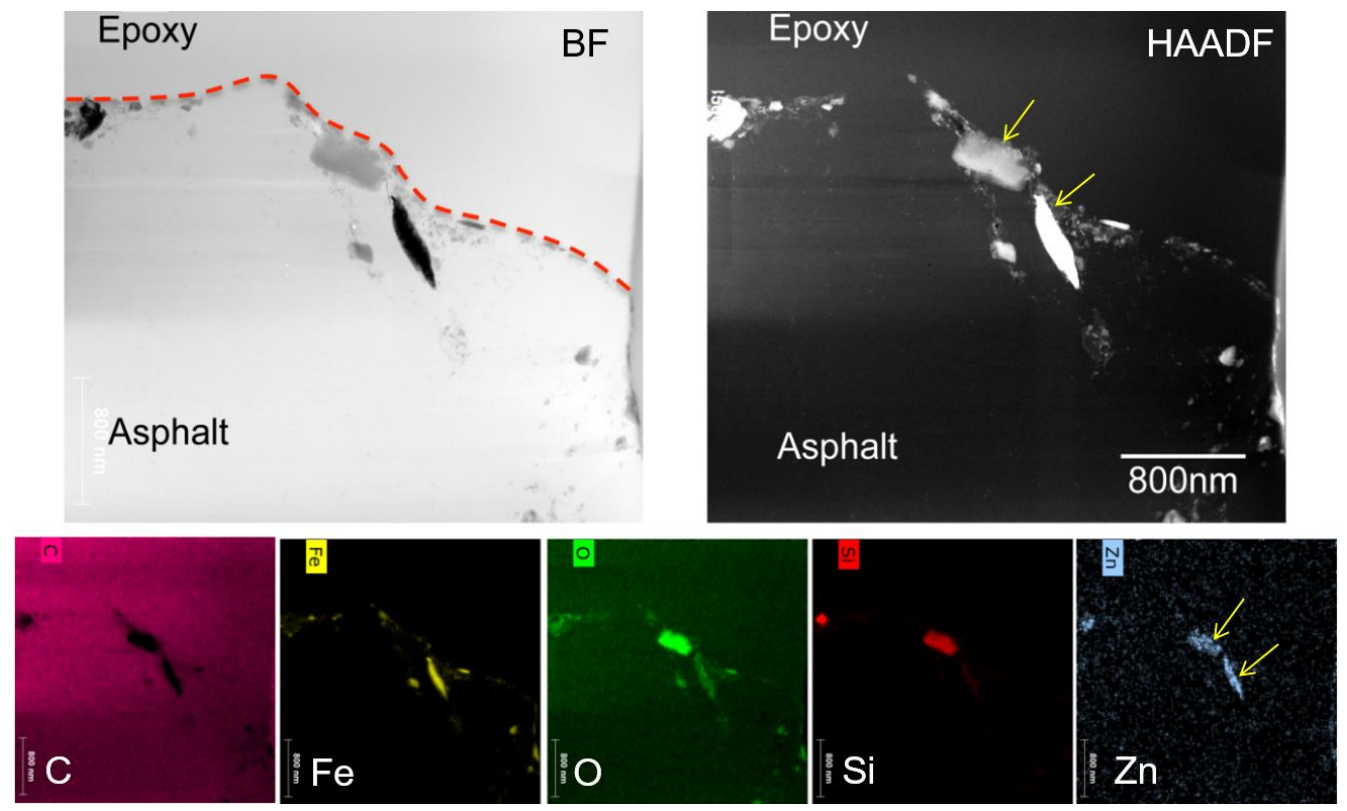

Figure 2.15. BF and HAADF S/TEM images of asphalt layer (top) and TEM-based EDS mapping for C, Fe, $\mathrm{O}, \mathrm{Si}$, and Zn (bottom) in as-received DIP (Manufacturer A). 

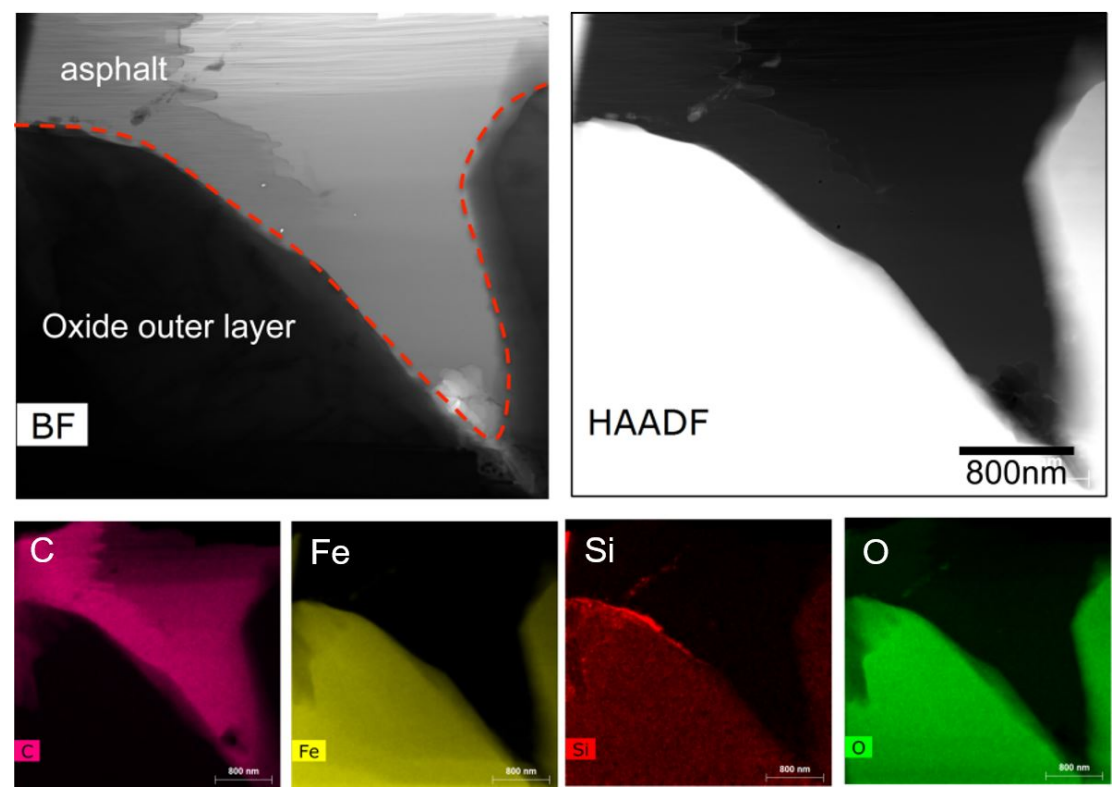

Figure 2.16. BF and HAADF S/TEM images of asphalt/outer oxide interface (top) and TEM-based EDS mapping for C, Fe, Si and $\mathrm{O}$ (bottom) in as-received DIP (Manufacturer A).

\subsection{MICROSTRUCTURE OF ZINC-COATED DUCTILE IRON PIPE}

In March and April 2017, pieces of a Zn-coated specimen were obtained for characterization. Figure 2.17 shows three different locations from the same 6" pipe. The coating was applied over the oxide layer that formed during annealing of the pipe. The coating is reported to be applied by an arc spray process in which small droplets of molten zinc are propelled onto the pipe surface by compressed air. The microstructures in Figure 2.17 are consistent with such a process where liquid droplets are applied. The zinc layer is then protected by the further application of an outer asphalt layer.
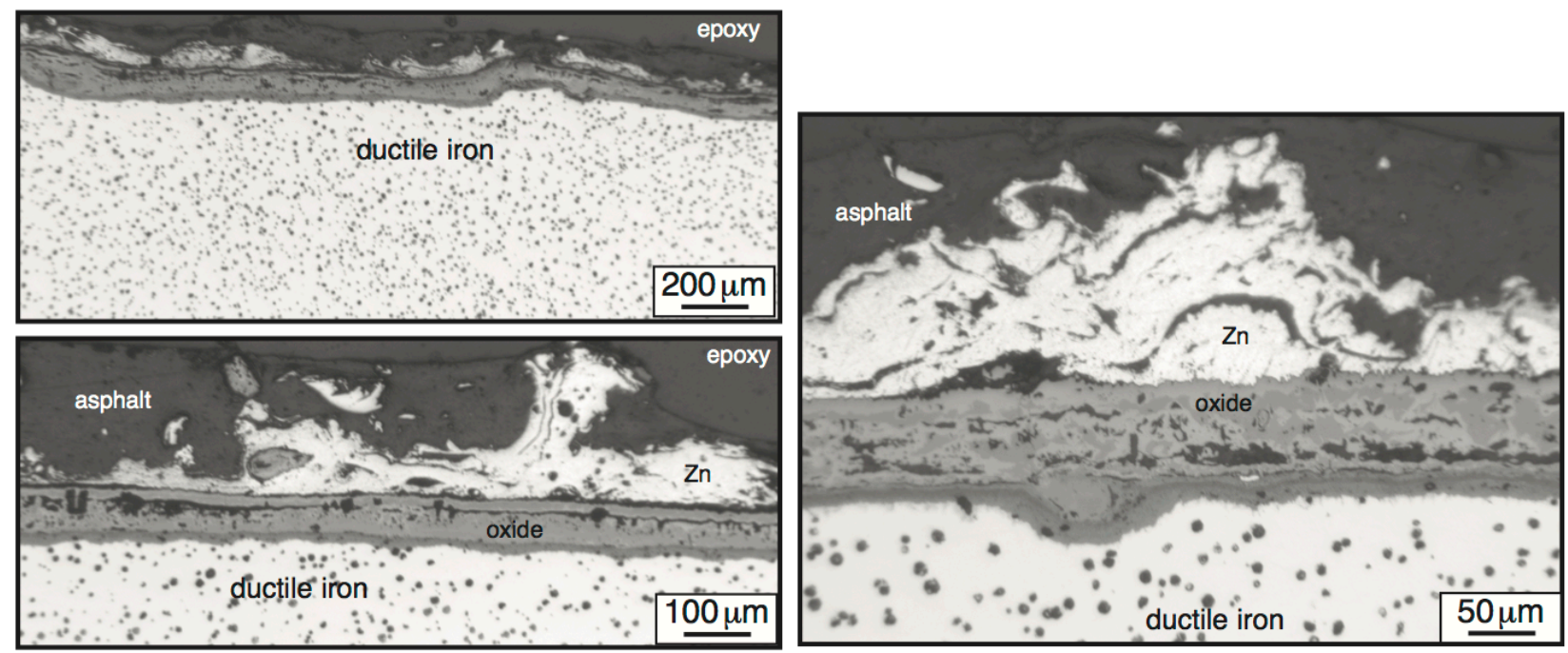

Figure 2.17. Light microscopy of a zinc-coated specimen from a domestic DIP manufacturer. Three different locations are shown from one pipe at different magnifications. 


\subsection{REPLICATION OF OXIDE LAYER FORMED ON AS-RECEIVED DIP}

As it became clear that zinc-coated DIP would not be easily available for this project, a decision was made to recreate the DIP surface in the laboratory and add a laboratory zinc coating. Typically, a galvanic zinc coating would be in direct contact with the iron substrate. However, the oxide on DIP formed during the heat treatment is not easily removed, and, therefore, the zinc coating is typically applied on top of this oxide (see Figure 2.17). To create the oxide, oxidation of DIP was performed in the laboratory with different temperatures and times. Prior to heat treatment, bare DIP was prepared by sandblasting to remove the preexisting asphalt and oxide layers. Specimens $(\sim 10 \times 20 \mathrm{~mm})$ were machined and hand ground to produce a rough ( 80 to 120 grit) surface somewhat similar to the as-cast DIP surface finish. (It was later determined that this finish was insufficient to achieve good oxide adhesion for larger $(\sim 50 \times 50$ $\mathrm{mm}$ ) specimens, and sandblasting was used to further roughen the surface; see Section 5). Oxidation of DIP coupons was conducted in a box furnace in laboratory air to mimic the industrial DIP heat treatment.

SEM images of the laboratory-formed oxide layers on DIP are shown in Figure 2.18. The laboratoryformed oxides showed a bi-layer structure similar to the $60-100 \mu \mathrm{m}$ thick oxide on the as-received DIP (see Figure 2.6). For exposures up to $2 \mathrm{~h}$ at $930^{\circ} \mathrm{C}\left(1706^{\circ} \mathrm{F}\right)$, the laboratory-formed oxides were thinner than those on commercial DIP (Figure 2.18). A longer exposure of $8 \mathrm{~h}$ at $900^{\circ} \mathrm{C}\left(1652^{\circ} \mathrm{F}\right)$ produced a thicker oxide, but it contained numerous voids and internal penetrations (Figure $2.18 \mathrm{~g}, \mathrm{~h}$ ). Laboratory oxidation of DIP was also examined at $950^{\circ} \mathrm{C}\left(1742^{\circ} \mathrm{F}\right)$ for 1,2 and $4 \mathrm{~h}$, and light microscopy images of the fabricated oxide layers are shown in Figure 2.19. The metal-oxide interface was smoother at higher temperature.
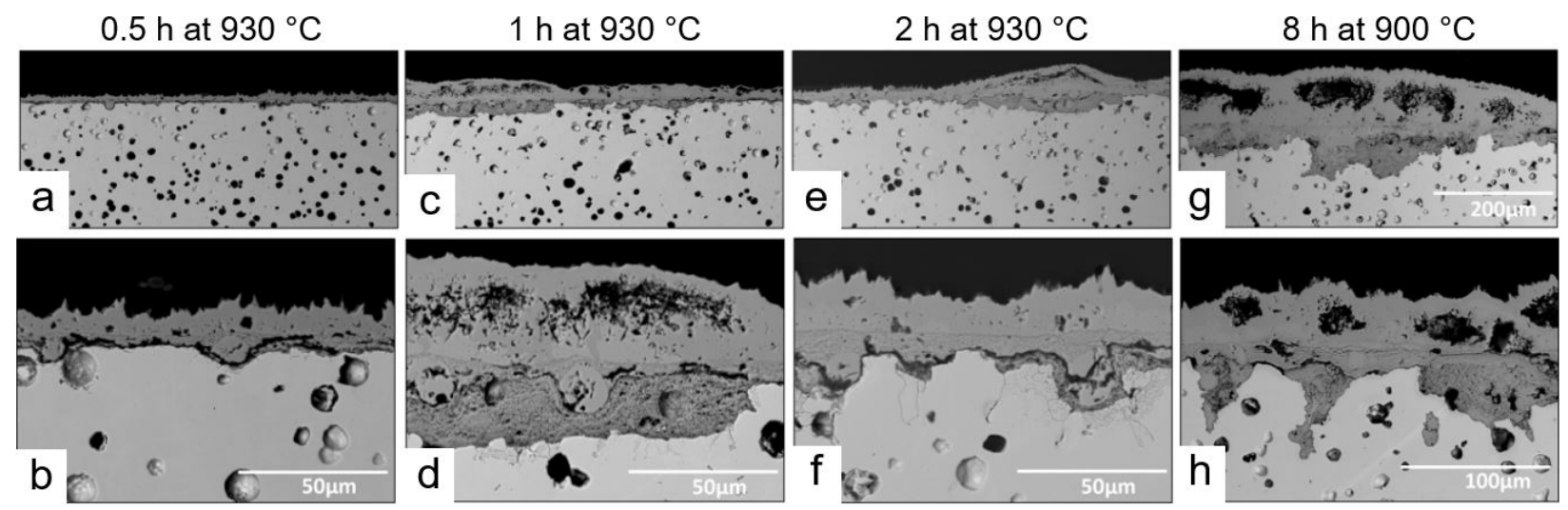

Figure 2.18. BSE SEM images of laboratory-fabricated oxide on DIP (substrate from Manufacturer A) after ambient oxidation at $930^{\circ} \mathrm{C}$ for $(\mathrm{a}, \mathrm{b}) 0.5 \mathrm{~h},(\mathrm{c}, \mathrm{d}) 1 \mathrm{~h},(\mathrm{e}, \mathrm{f}) 2 \mathrm{~h}$, and $(\mathrm{g}, \mathrm{h})$ at $900{ }^{\circ} \mathrm{C}$ for $8 \mathrm{~h}$.

a

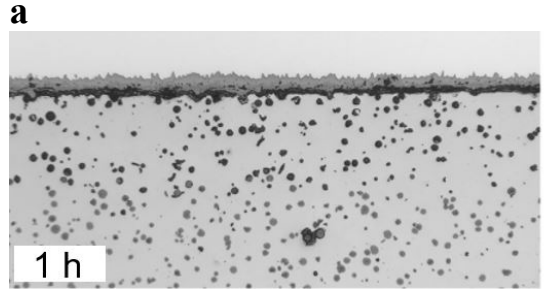

b

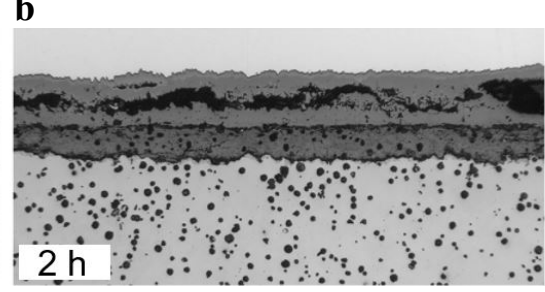

c

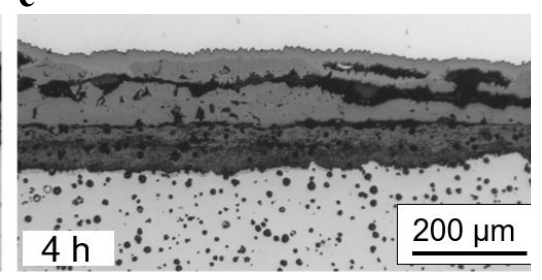

Figure 2.19. Light microscopy images of laboratory-fabricated oxide on DIP (substrate from Manufacturer A) after ambient oxidation at $950^{\circ} \mathrm{C}$ for (a) $1 \mathrm{~h}$, (b) $2 \mathrm{~h}$, and (c) $4 \mathrm{~h}$.

The total laboratory-formed oxide thickness and the values for the inner and outer layers are shown in Figure 2.20. At $950^{\circ} \mathrm{C}\left(1742^{\circ} \mathrm{F}\right)$, the thickness values almost tripled between 2 and $4 \mathrm{~h}$, suggesting that the oxidation rate increased rapidly under these conditions. The oxide thickness after $2 \mathrm{~h}$ at $950^{\circ} \mathrm{C}$ 
$\left(1742^{\circ} \mathrm{F}\right.$ ) was a reasonable match to the commercially formed oxide on DIP (shaded in Figure 2.20a), and these conditions were selected for laboratory evaluations.

a

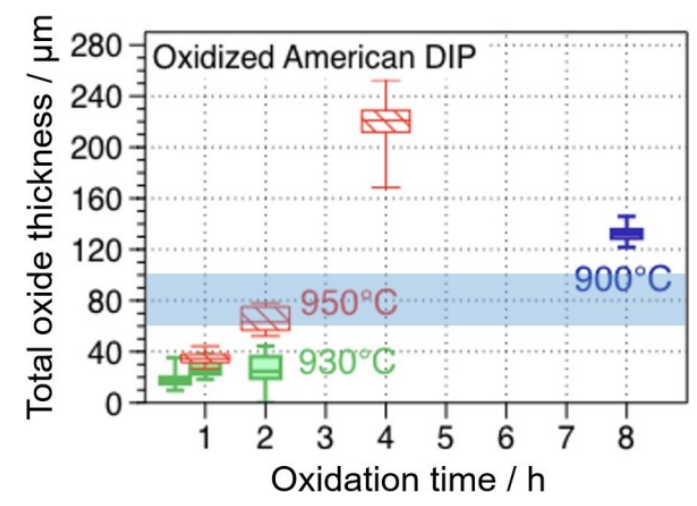

b

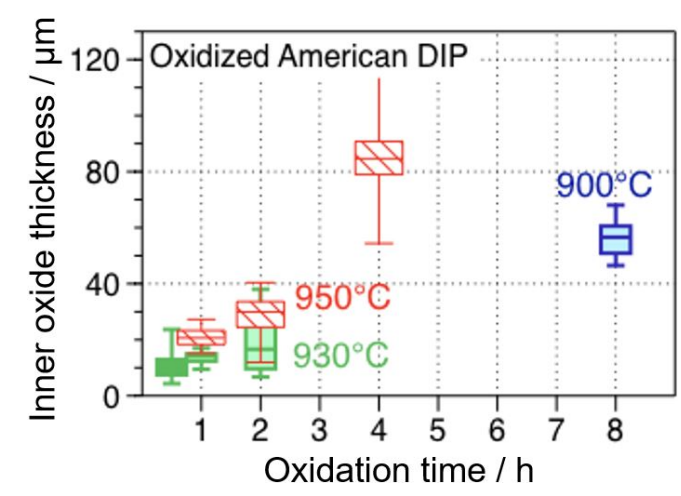

c

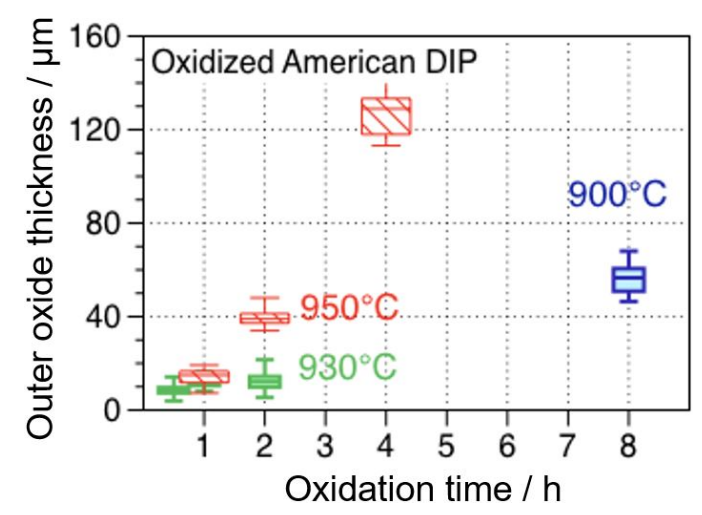

Figure 2.20. Measured thickness of laboratory-fabricated oxide on DIP (substrate from Manufacturer A) after oxidation at $900^{\circ}, 930^{\circ}$, and $950^{\circ} \mathrm{C}$ : (a) total oxide thickness (shaded region is the distribution of oxide thickness on as-received DIP), (b) inner, and (c) outer oxide thickness.

\subsection{SUMMARY OF TASK 1}

- Specimens of DIP from all three US manufacturers were characterized, including measurement of the chemical composition, tensile properties and microstructure.

- The products all had a thick surface oxide $(60-100 \mu \mathrm{m})$ and no zinc coating.

- One commercial zinc-coated tube was obtained at the end of the project. The microstructure of the commercial coating was examined and compared to those produced as part of this study.

- Because commercial zinc-coated DIP was not readily available, there was an extensive effort to recreate the commercial microstructure, including forming the thick oxide layer in the laboratory. The laboratory conditions for oxide formation were $2 \mathrm{~h}$ at $950^{\circ} \mathrm{C}$ (similar to those for commercially formed oxide). 


\section{TASK 2: CONSOLIDATE AVAILABLE CORROSION DATA}

The goal of this task was to create a baseline of information about the performance of coated DIP in corrosive soils. One of the obstacles was that the extensive older studies of buried pipeline corrosion by the National Bureau of Standards (NBS) were conducted before the commercialization of DIP and the use of polyethylene encasement (PE), zinc coating, or combinations with and without cathodic protection (CP). However, the NBS dataset may be useful in developing a better definition of corrosive soils by using machine learning techniques to explore the extensive, multifactor corrosion dataset on buried pipe. Such an analysis was beyond the scope and timeframe of the current project. Furthermore, it was found that external factors - such as soil properties, precipitation, and temperature - had a major influence but were typically measured at a very coarse resolution. The NBS dataset could be enhanced by pairing it with available external datasets on rainfall and temperature. A broader search of the corrosion literature also was conducted to further understand the current state of knowledge of DIP corrosion. Further analysis focused on the effects of soil resistivity and $\mathrm{pH}$ on corrosion mass loss and penetration with a group of selected data. Corrosion mass loss and penetration were also compared for different surface conditions with and without PE.

\subsection{STUDIES OF SOIL CORROSIVITY AND CORROSION PROTECTION}

Most soil-related corrosion data on ferrous materials are available in technical reports and journal publications from the American Water Works Association (AWWA), the National Association of Corrosion Engineers (NACE) International and the National Bureau of Standards (NBS). In this work, these corrosion data were analyzed to evaluate the soil properties associated with corrosion damage and the effectiveness of protection methods for soil-buried ferrous pipes.

From 1910 to 1952, NBS (now the National Institute of Standards and Technology, NIST) conducted a broad investigation on corrosion mass loss and maximum penetration of soil-buried water pipes, exposed at 125 US test sites, which included a wide range of soil conditions (Logan 1928, Logan 1945, Romanoff 1957). The focus was typically on ferrous pipes (e.g., Bessemer steel, wrought and open-hearth iron) with carbon contents of only 0.02 to 0.12 wt. $\%$, i.e., well below the $2.5 \%$ in cast iron. Nevertheless, the dataset still can provide insight into the role of soil properties at the numerous sites, which varied in ionic concentration, $\mathrm{pH}$, and resistivity (see Appendix). Previous studies have attempted to apply linear regression and other techniques to extract more meaningful relationships between environmental factors and corrosion damage (Rossum 1969, Ricker 2010, Munson 2016, Jyrkama 2017). However, to cite one example, none of the environmental data exhibited a strong correlation with the measured corrosion damage (Ricker 2010). This implies that soil corrosivity cannot be predicted by a single environmental factor. Nonetheless, soil resistivity is frequently considered an important measure of corrosivity and is adopted in different standard and technical documents (Spickelmire 2002, AWWA 2004, AWWA 2009, NACE 2013, DIN 1985, DoD 2003). Other soil properties such as $\mathrm{pH}$, redox potential, sulfide content, and moisture content are also considered to assess soil corrosivity and adopted in 10- and 25-point scoring systems to estimate corrosion risk of buried ferrous pipes (AWWA 2009, Spickelmire 2002). The rating criteria of soil corrosivity used in several technical documents and standards are summarized in the Appendix.

Several studies on ferrous pipes and samples under different protection strategies reported the maximum penetration and corrosion rate available for comparison analysis (Bonds 2005, Horton 2014, Paris 1975, Collins and Padley 1983, Ellis 1998, Bell 2007, Bell 2012). The corrosion protection strategies tested in these studies include a zinc coating plus a topcoat (coal-tar varnish or asphalt), PE, and a combination of zinc coating and topcoat with PE. Documented instructions of PE application are outlined in US, European, British, and Australian standards (AWWA 2010, ISO 2006, BS 1996, AS 2008a, AS 2008b), and a summary of these standards is found in a previous report (Marney and De Silva 2010). The 
application of a $\mathrm{Zn}$ coating with topcoat finish is documented in a European standard, ISO 8179-1 (ISO 2007).

Some previous studies found that the corrosion penetration depth of DIP decreased by applying PE, which supports the effectiveness of PE to mitigate corrosion (Collins and Padley 1983, Ellis 1998). In other studies, the effectiveness of PE was questioned (Caproco 1985, DIPRA 1985), which is well summarized in other studies (Rajani and Kleiner 2003, Marney and De Silva 2010). Application of a zinc coating and topcoat layer on DIP was extremely successful in some cases where the penetration depth was close to zero (Paris 1975, Horton 2014). The combination of PE and zinc coating with a topcoat for DIP tested for 11 years or less showed no evidence of corrosion attack in all cases (Horton 2014), suggesting that the corrosion protection provided by a zinc coating with a topcoat could be further enhanced by the additional of PE. More comparison analyses on these corrosion data under different protection are discussed in Sections 3.3 and 3.4.

\subsection{MACHINE LEARNING APPROACH}

\section{Machine learning analysis on soil corrosivity}

The NBS corrosion dataset published in 1957 included environmental conditions of test sites and material specification of pipes along with corrosion mass loss and penetration depth for eight different ferrous pipes. The measured mass loss and the deepest penetration of ferrous pipes were plotted by time of burial at 47 sites. From these environmental and material data, 20 factors, which were assumed to influence corrosion mass loss, were chosen for machine learning analysis. The details of the selected factors are summarized in Table 3.1.

Table 3.1. Twenty environmental and material factors considered for machine learning analysis

\begin{tabular}{|c|c|c|}
\hline & $\begin{array}{c}\text { Number } \\
\text { of } \\
\text { factors }\end{array}$ & Factors \\
\hline Soil condition & 7 & $\begin{array}{l}\text { Resistivity, } \mathrm{pH} \text {, moisture content, major soil type, } \\
\text { internal drainage, muck, silt loam }\end{array}$ \\
\hline Weather condition & 2 & Precipitation, mean temperature \\
\hline Material condition & 9 & $\begin{array}{l}\text { Elemental component }(\mathrm{C}, \mathrm{P}, \mathrm{Cu}, \mathrm{Si}, \mathrm{Mn}, \mathrm{S}) \text {, } \\
\text { nominal pipe diameter, wall thickness, } 8 \text { ferrous } \\
\text { alloys }\end{array}$ \\
\hline Other condition & 2 & Burial depth, experiment time \\
\hline Total & 20 & \\
\hline
\end{tabular}

The quantified influence of material, soil, and test conditions on the total mass loss of ferrous pipes was generated using two methodologies of Random Forests (RF), which are presented in Figure 3.1. The factors with high importance (shown on the $\mathrm{x}$-axis) indicate a greater influence on the total mass loss. These RF analyses suggest that the corrosion damage on buried ferrous pipes is highly dependent on weather and soil conditions, but the effect of material factors (material composition and pipe size) is insignificant, as expected. It is also evident that soil resistivity, moisture and $\mathrm{pH}$ are ranked in the top 5 of influential factors, emphasizing the importance of soil properties to estimate the corrosion damage. For this reason, further analyses to correlate soil resistivity, $\mathrm{pH}$ and corrosion damage were conducted, which is discussed in Section 3.3. 

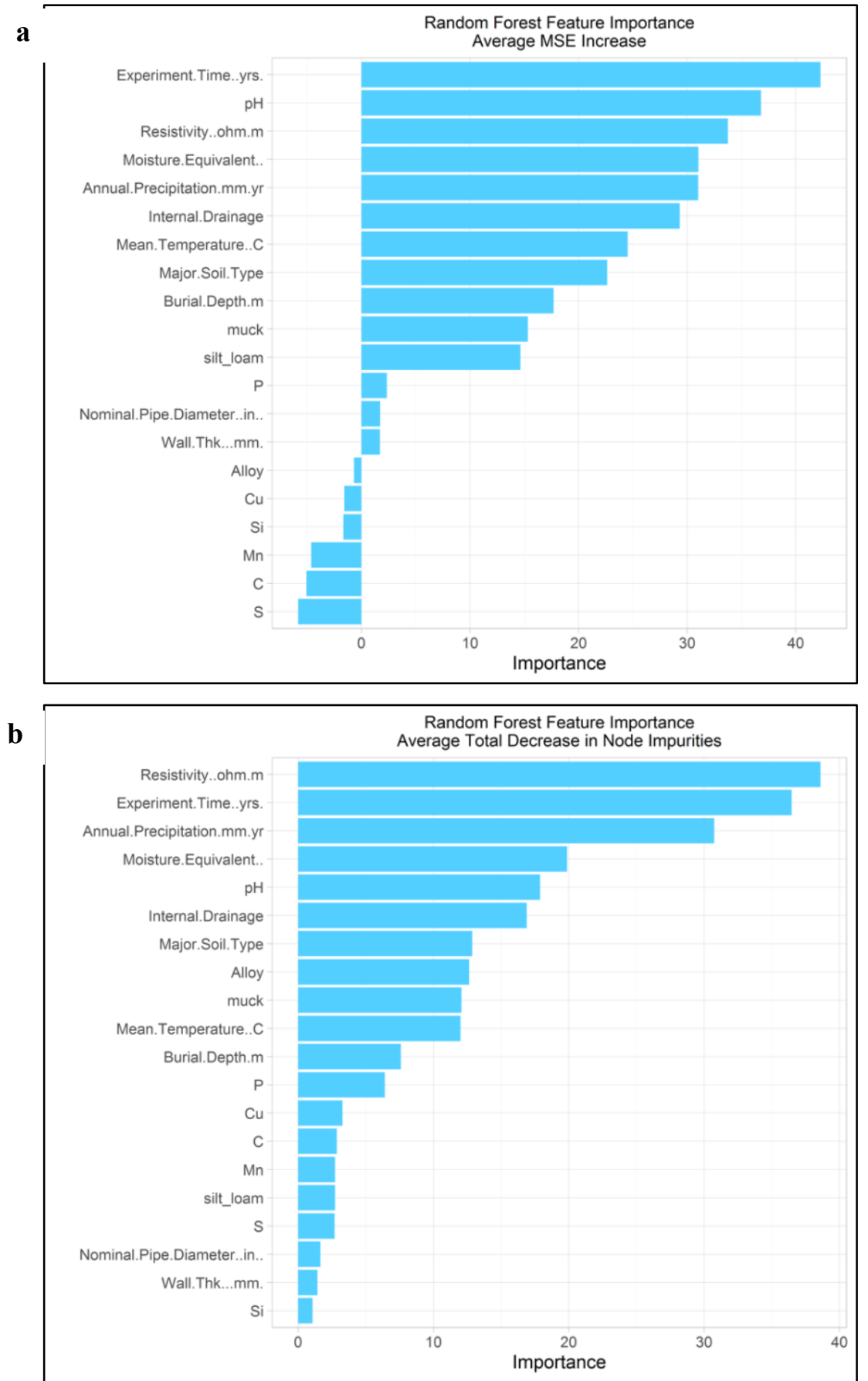

Figure 3.1. Quantified influences of 20 factors on corrosion mass loss using two RF methodologies: (a) average mean squared error (MSE) increase and (b) average total decrease in node impurities.

Annual precipitation is ranked as the third and fifth most influential factor in the two RF machine learning analyses. This result seems reasonable because precipitation is considered a primary source of water for the soil's formation of a soil-derived solution. As discussed in Section 1.2, soil-derived solution plays a crucial role in the corrosion of buried pipes and affects the measured moisture content and soil resistivity. In a relatively uniform soil texture, soil resistivity was found to decrease with increasing moisture content (Calamita 2012), also supporting that soil resistivity, moisture content, and precipitation are interrelated. On the other hand, Cole and Marney concluded that the corrosion damage of pipes was weakly dependent 
on moisture content but not on other soil properties (Cole and Marney 2012). This conclusion could be attributed to non-uniform soil texture: soil resistivity and moisture content may not be well correlated in a non-uniform soil texture, which would also cause a weak correlation between soil resistivity and corrosion damage.

\section{Computer-based approach to process weather data}

The NBS corrosion dataset contains normalized weather data that appeared as the average annual precipitation and mean temperature. These normalized data, however, do not reflect fluctuations in precipitation and temperature, which would have affected the progress of corrosion accordingly. For example, two test sites with the same mean temperature may have had a different number of days with temperatures below the freezing point. Due to the temperature-sensitive nature of corrosion reactions, the resulting corrosion damage may have been quite different for the two sites. To address this discrepancy properly, the number of days with below-freezing temperatures can be added to the input group for machine learning, which could improve the analysis quality. Similarly, the precipitation can be considered on a yearly basis rather than the average rainfall for the entire test duration (up to 18 years). These detailed subset data can be generated by analyzing daily-recorded temperature and precipitation data.

The historical weather data for different US locations are available from the National Center for Environmental Information (NCEI) at the National Oceanic and Atmospheric Administration (NOAA). Daily NCEI data were recorded during the time of the NBS corrosion study (1922-1940), which provided five types of weather data as summarized in Table 3.2. In the NCEI on-line database, the weather data were obtained in CSV file format, which contained the most comprehensive information for several US sites and locations. Due to the large volume of the data, some download requests took up to $24 \mathrm{~h}$ to be fulfilled. In cases of unavailable weather data for a city listed in the NBS study, the next closest city was chosen for the data acquisition instead.

Table 3.2. The five core weather values in NCEI daily summaries

\begin{tabular}{|l|c|c|}
\hline Observation (NCEI field name) & Available units & Highest resolution available \\
\cline { 1 - 1 } Precipitation (PRCP) & \multirow{2}{*}{$\mathrm{mm} / \mathrm{in}$} & \\
\cline { 1 - 1 } Snowfall (SNOW) & & Daily \\
\cline { 1 - 1 } Snow depth (SNWD) & \multirow{2}{*}{${ }^{\circ} \mathrm{F} /{ }^{\circ} \mathrm{C}$} & \\
\cline { 1 - 1 } Maximum temperature (TMAX) & \\
\cline { 1 - 1 } Minimum temperature (TMIN) &
\end{tabular}

An automated process based on the R programming language was used to extract NCEI weather data for the burial period (between the beginning and end dates) of each test. For instance, if a record in the NBS table indicated a pipe was buried on 01/01/1922 and resurfaced on 03/01/1937, the program code will automatically read the daily-recorded NCEI data between those dates and calculate statistical values for each desired weather metric shown in Table 3.3. NCEI daily and annual precipitation data in Dallas, TX are compared with NBS average precipitation at the same location in Figures 3.2 and 3.3, respectively. The annual precipitation data plotted for each year were always smaller than the average precipitation from the NBS data, suggesting that the NBS data do not represent the actual precipitation at the test site. To improve the prediction of machine learning, daily weather data from NCEI could be used, but that would also increase the data volume tremendously. Based on the computer-based machine learning technique developed in this work, a larger volume of input data could easily be processed to improve the understanding of dominant corrosivity factors. 
Table 3.3. Weather metrics calculated from NCEI daily summary data

\begin{tabular}{ll}
\hline Metric & Statistical values calculated \\
\hline Precipitation (in) & Mean, sum, count $(>0)$ \\
Snowfall (in) & Mean, sum, count $(>0)$ \\
Snow depth (in) & Mean, sum, count $(>0)$ \\
Average temperature $\left({ }^{\circ} \mathrm{F}\right)$ & Mean, sum, count $(<32)^{*}$ \\
Maximum temperature $\left({ }^{\circ} \mathrm{F}\right)$ & Mean, sum, count $(<32)$ \\
Minimum temperature $\left({ }^{\circ} \mathrm{F}\right)$ & Mean, sum, count $(<32)$ \\
\hline
\end{tabular}

*Average temperature is not listed as a NCEI core value for many locations.

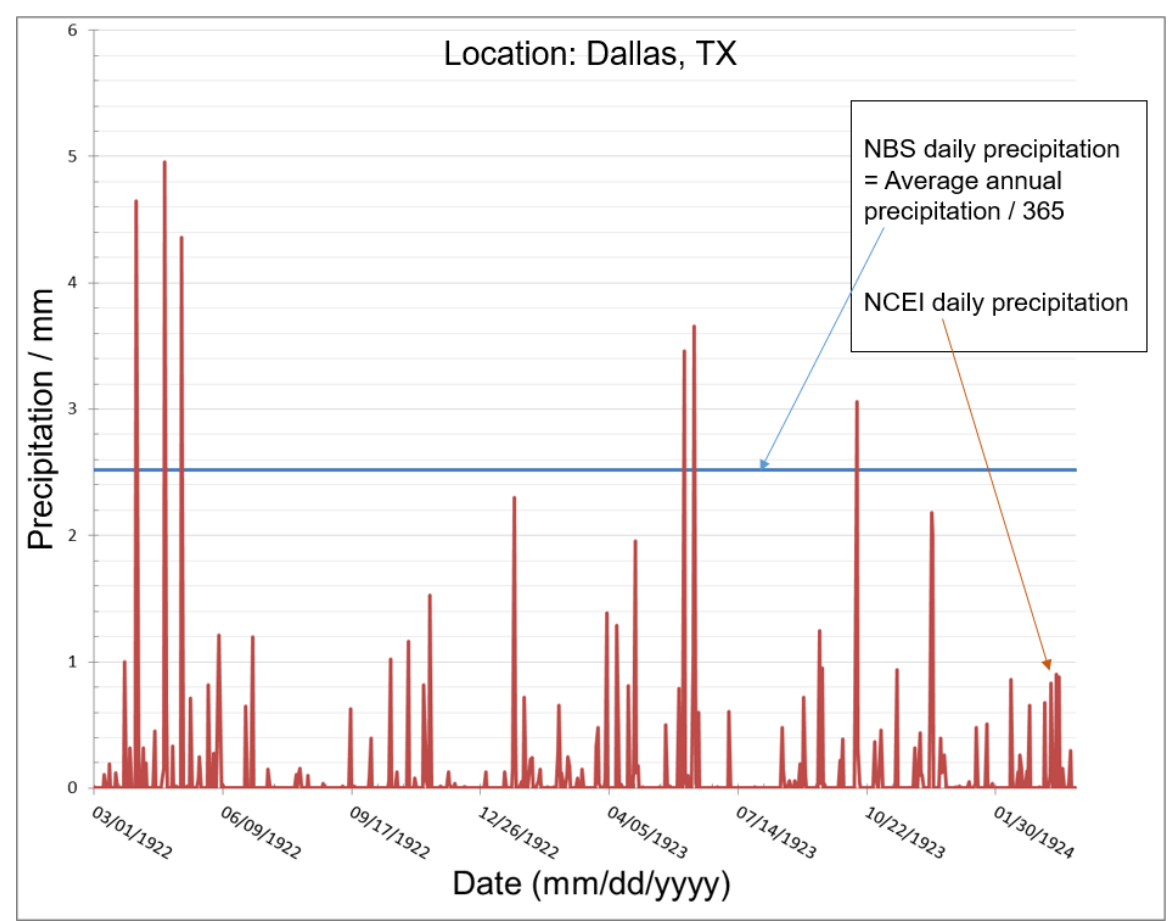

Figure 3.2. Comparison of daily precipitation records from NBS study (average annual precipitation divided by 365 days) and NCEI daily summaries at Dallas, TX. 


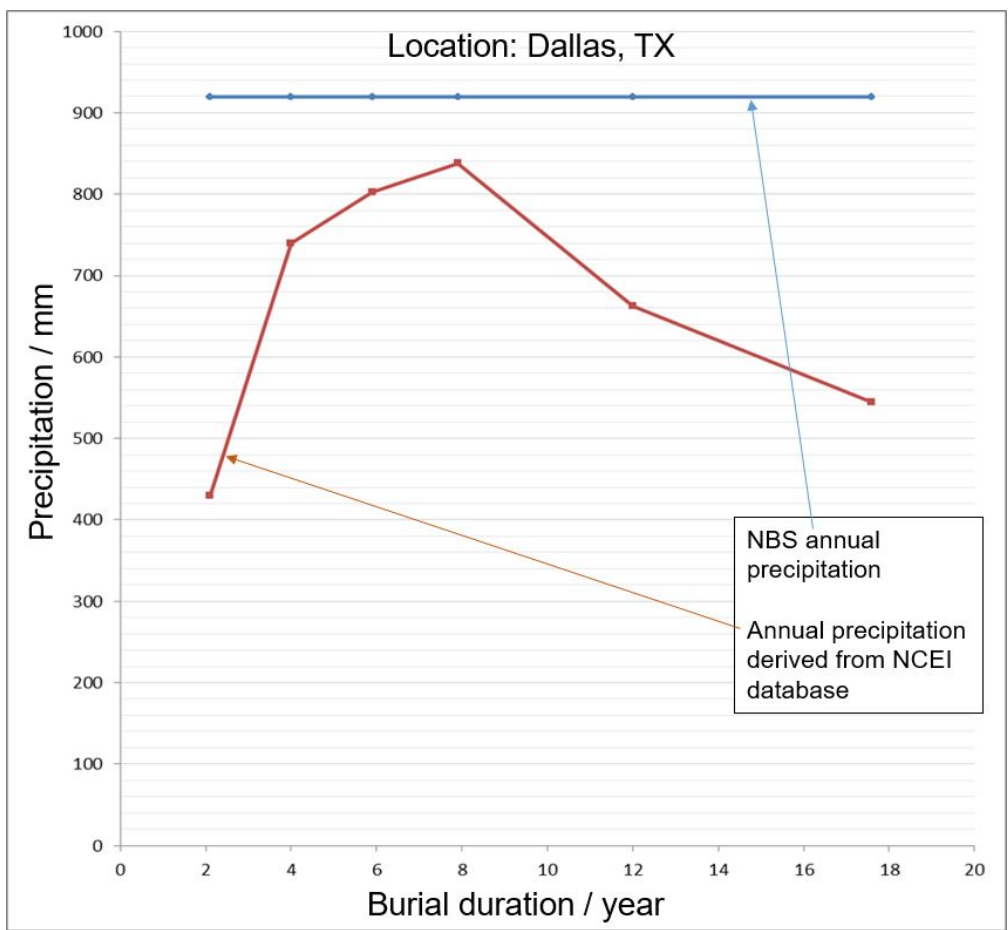

Figure 3.3. Comparison of annual precipitation at Dallas, TX: the average value of NBS study and the derived values from NCEI weather data.

\subsection{ANALYSIS OF SOIL CORROSIVITY}

The machine learning analysis of the NBS corrosion dataset indicated that the resistivity, $\mathrm{pH}$, and moisture content of soils were the core corrosivity factors for soil-buried ferrous pipes. Based on this result, further analyses were conducted to correlate the core corrosivity factors with corrosion damage of pipes using the NBS data. In the meantime, the eight types of ferrous pipes in the NBS study were considered to have similar corrosion resistance based on the machine learning result that composition variation had little or no effect on corrosion mass loss (Figure 3.1). The scatter of mass loss data between different pipes, therefore, was assumed to depend only on soil conditions and not on material compositions. Additional plots comparing soil resistivity, $\mathrm{pH}$, and ionic concentration of soils associated with the most and least corrosion damage are included in the Appendix.

\section{Effect of soil resistivity and $\mathrm{pH}$ on selected mass loss data}

The effect of soil resistivity and $\mathrm{pH}$ on corrosion mass loss was analyzed by use of a group of small scatter data selected from the NBS corrosion database. Examples of large and small scatter data are presented in Figure 3.4. The mass loss data for Meridian, MS, showed a wide distribution of mass loss among the eight ferrous pipes, which was considered large scatter data (Figure 3.4a). On the other hand, the mass loss data for Middleboro, MA was narrowly distributed and was selected for this correlation analysis (Figure 3.4b). The numerical value of scatter was defined by the difference between the minimum and maximum mass loss at the last measurement. According to this definition, the mass loss scatters in Meridian and Middleboro were approximately 2500 and $600 \mathrm{~g} / \mathrm{cm}^{2}$, respectively (Figure $3.4 a, b)$. 
a

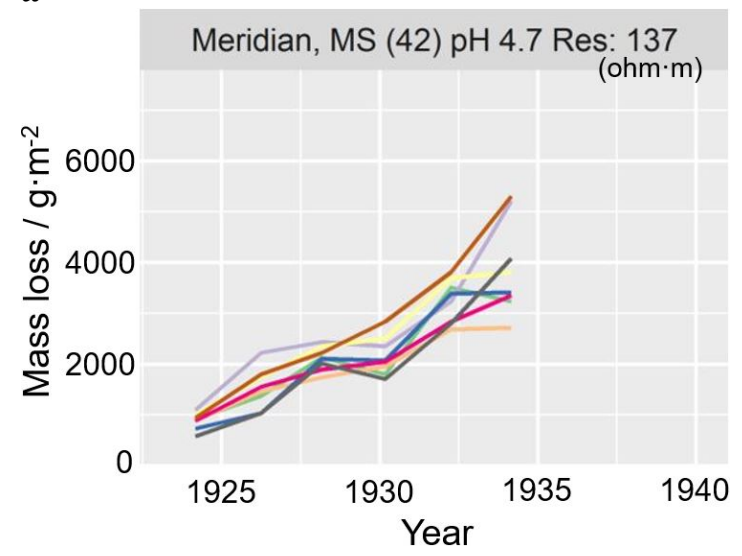

b

Middleboro, MA (10) pH 6.6 Res: 74.6

(ohm $\cdot \mathrm{m})$

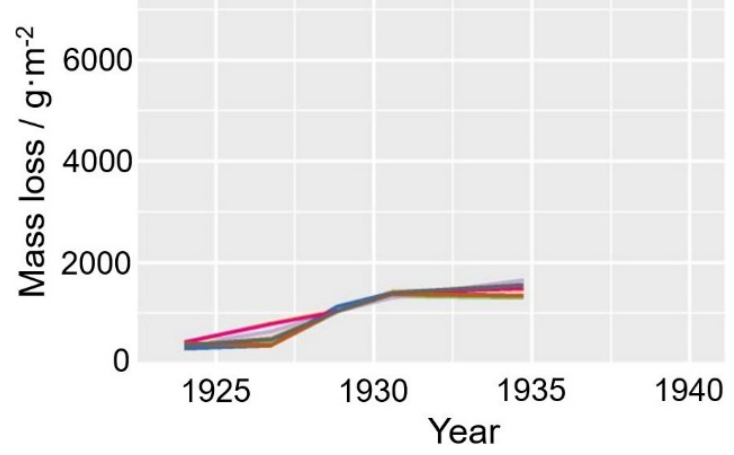

Figure 3.4. Mass loss vs. time plots for eight ferrous pipes buried in soil, showing (a) large and (b) small scatters in mass loss data in 1934. The mass loss data were collected in the NBS study, along with soil pH and resistivity (Romanoff 1957).

In the NBS corrosion dataset, the mass loss data from 36 US sites that had scatters less than $1000 \mathrm{~g} / \mathrm{cm}^{2}$ between different ferrous pipes were used for further comparison analysis. The average of the maximum and minimum mass loss in the 36 data sets was divided by the years of burial to yield a single normalized mass loss for each site:

$$
\text { Normalized mass loss }=\frac{0.5 \times(\text { Max. mass loss }+ \text { Min. mass loss })}{\text { Years of burial }}
$$

The 36 normalized mass loss values are plotted by soil $\mathrm{pH}$ in Figure 3.5. No noticeable correlation between mass loss and soil $\mathrm{pH}$ was found in this plot. An effect of $\mathrm{pH}$ increasing the mass loss was reported for $\mathrm{pH}$ lower than 4 (Jack and Wilmott 2011), but all soil $\mathrm{pH}$ in the selected dataset was higher than 4. This implies that the pipes were not exposed to low $\mathrm{pH}$ for accelerated mass loss, supporting the idea that $\mathrm{pH}$ did not affect the mass loss. The same dataset is plotted by soil resistivity in Figure 3.6. The vertical broken lines indicate the boundaries of soil corrosivity level suggested by the 2004 USBR technical memorandum (Calhoun 2004). The maximum and minimum values (denoted by the bold broken parallel lines) decrease at the lower corrosivity levels associated with high soil resistivity. It is also noted that the deviation of maximum and minimum values expands with increasing corrosivity level, implying that the prediction of corrosion mass loss would be more difficult at lower soil resistivity. This suggests that soil corrosivity based solely on resistivity is limited in estimating the resulting corrosion mass, which was also pointed out by Cole and Marney (2012). 


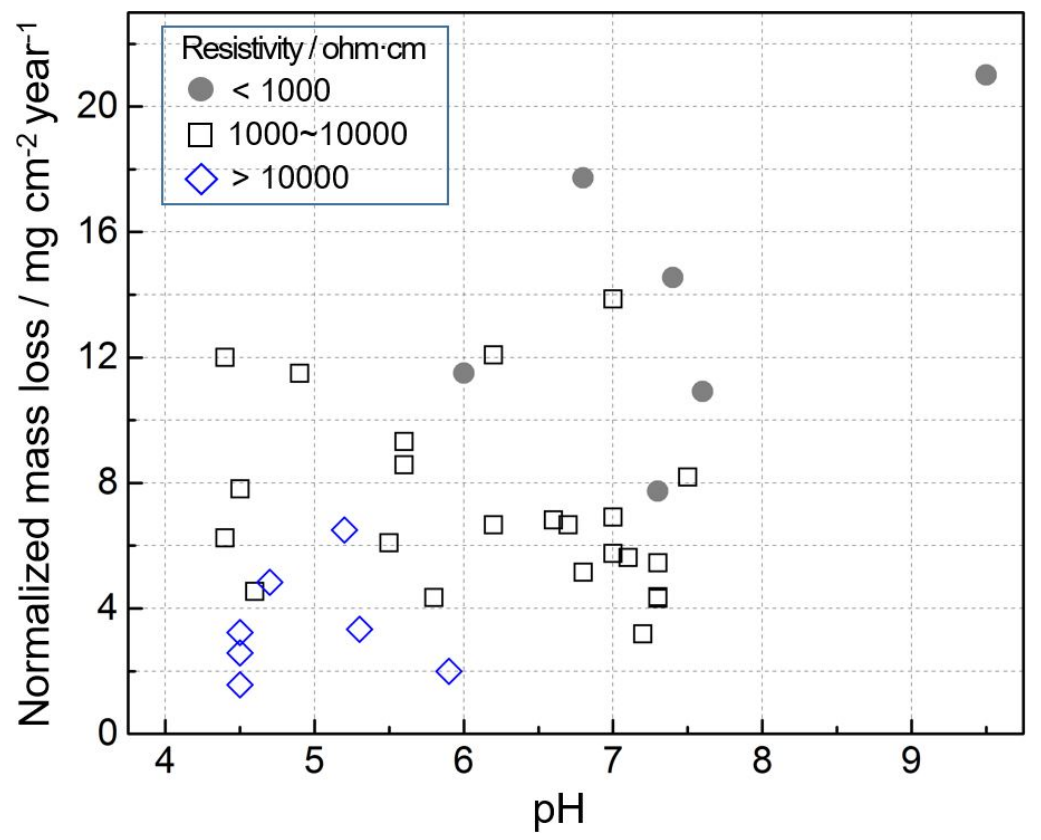

Figure 3.5. Normalized mass loss vs. soil pH plot from 36 data selected from the NBS corrosion dataset. The normalized mass loss values presented here are the average of maximum and minimum mass loss data divided by the test duration (10 to 33 years) and also marked with three symbols for different soil resistivities.

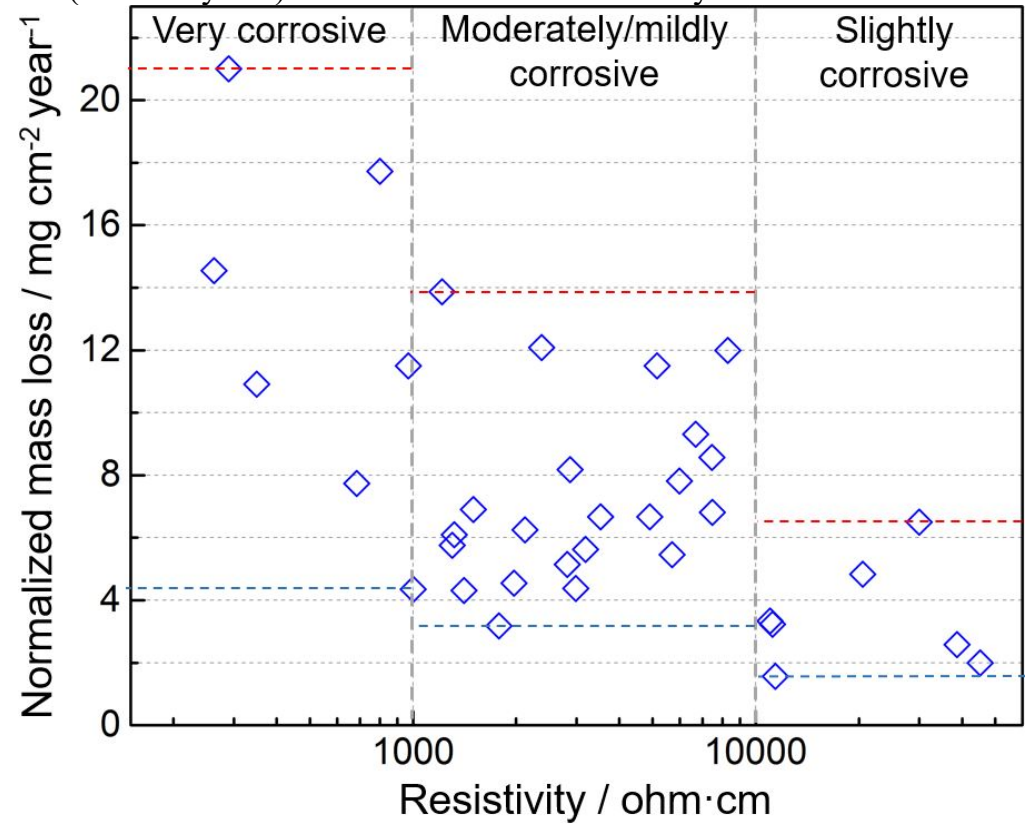

Figure 3.6. Normalized mass loss vs. soil resistivity plot from 36 data selected from the NBS corrosion dataset. Three corrosivity levels were determined by the USBR technical memorandum based on soil resistivity, and the normalized mass loss data are the same as the data presented in Figure 3.5. Effect of soil resistivity and pH on

\section{selected deepest penetration data}

The effect of soil resistivity and $\mathrm{pH}$ on the deepest corrosion penetration was also analyzed in the same manner. The penetration data from 14 US sites had scatter (the difference between minimum and maximum data) smaller than $0.8 \mathrm{~mm}$ in the NBS corrosion dataset. These small-scatter data were selected for the soil $\mathrm{pH}$ - and resistivity-based plotting. The normalized penetration for 14 data were calculated: 


$$
\text { Norm. penetration }=\frac{0.5 \times(\text { Max. deepest penetration }+ \text { Min. deepest penetration })}{\text { Years of burial }}
$$

The plot of normalized penetration vs. soil $\mathrm{pH}$ is shown in Figure 3.7. Any correlation between $\mathrm{pH}$ and the penetration values was difficult to confirm, suggesting that the measured penetration was barely affected by $\mathrm{pH}$ higher than 4 . The normalized penetration is also plotted versus soil resistivity in Figure 3.8. The vertical broken lines again indicate the boundaries of soil corrosivity levels based on the 2004 USBR technical memorandum (Calhoun 2004). As the corrosivity level increases, the maximum values of normalized penetration values and their deviation also increase, which seems similar to the trend observed in mass loss vs. resistivity plotted in Figure 3.6. This result implies that the penetration depth was not strongly dependent on soil resistivity, especially in soils with resistivity less than $1000 \mathrm{ohm} \cdot \mathrm{cm}$.

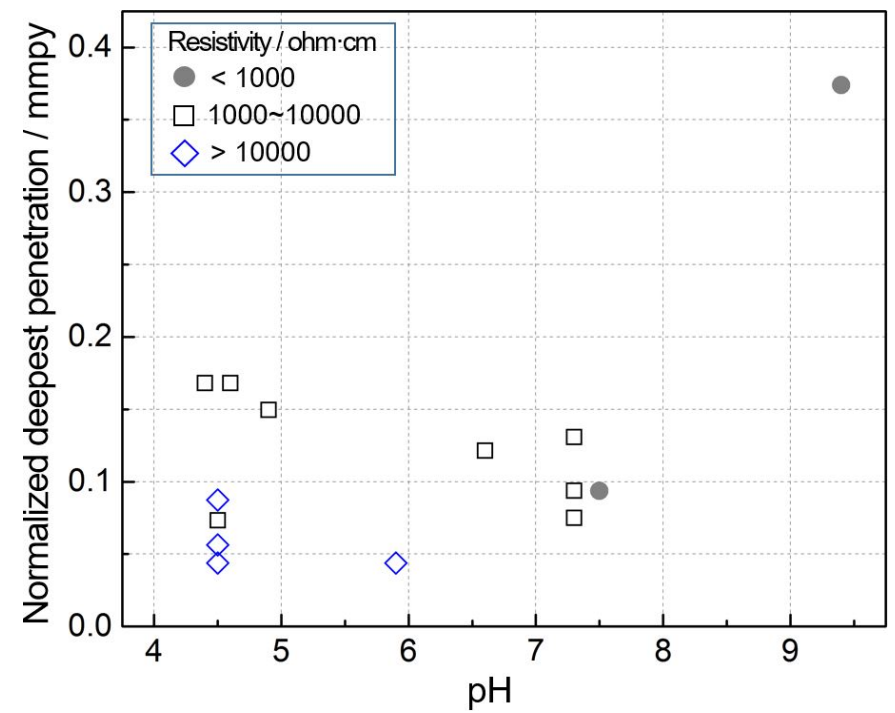

Figure 3.7. Normalized deepest penetration vs. soil pH plot from 14 data selected from the NBS corrosion dataset. The normalized penetration values presented here are the average of maximum and minimum penetration data divided by the test duration (10.7 to 16 years) and also marked with three symbols for different soil resistivities.

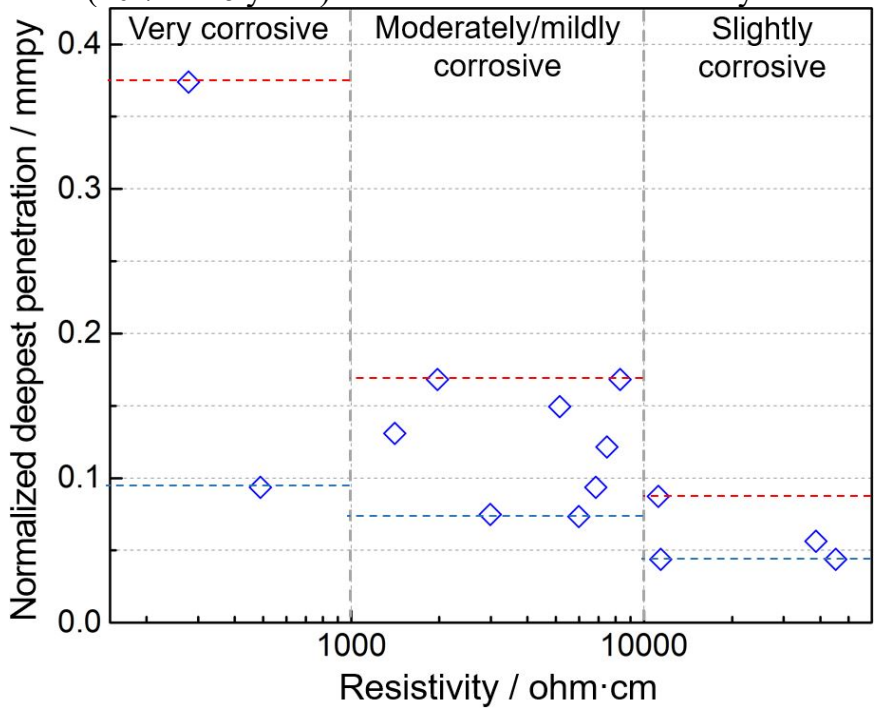

Figure 3.8. Normalized deepest penetration vs. soil resistivity plot from 14 data selected from the NBS corrosion dataset. Three corrosivity levels were determined by the USBR technical memorandum based on soil resistivity, and the normalized penetration data are the same as the data presented in Figure 3.7. 


\subsection{ANALYSIS OF CORROSION PROTECTION METHODS}

In this section, the corrosion penetration depths measured on DIP and cast iron pipe under different protection methods were compared using the corrosion data available from previous studies. The effect of different surface finishes on the normalized deepest penetration is compared in Figure 3.9 using the data from three references (Bonds 2005, Paris 1975, Horton 2014). The details of sample and test conditions for the reference data are summarized in the Appendix. The resistivity of soils for the presented data was lower than $1000 \mathrm{ohm} \cdot \mathrm{cm}$, indicating that soil corrosivity was not mild. In these soils, most non-Zn coated pipes exhibited penetration rates larger than $0.4 \mathrm{mmpy}$ (mm/year). Meanwhile, $75 \%$ of $\mathrm{Zn}$ coated pipes with a topcoat applied ( 6 out of 8 samples) had penetration rates smaller than $0.2 \mathrm{mmpy}$, and about $38 \%$ of the pipes ( 3 out of 8 samples) had no measurable penetration. This indicates that the application of a $\mathrm{Zn}$ coating with a topcoat effectively decreased corrosion damage on buried cast iron pipe and DIP.

A $\mathrm{Zn}$ coating with a topcoat is designed to provide both barrier and cathodic protections. The ISO 8179-1 standard specifies the formation of a topcoat with resin or bituminous paint on the $\mathrm{Zn}$ layer (ISO 2007). A damage-free topcoat and $\mathrm{Zn}$ layer can serve as a barrier for soil-derived solution, which could successfully block corrosion initiation and result in zero penetration as reported previously (Paris 1975, Horton 2014). It is, however, almost impossible to maintain a $\mathrm{Zn}$ coating and topcoat without any damage during industrial production and field installation. Damage to the $\mathrm{Zn}$ coating and topcoat may expose the iron pipe underneath to soil and soil-derived solution with no barrier protection for the exposed surface of the pipe. In this situation, cathodic protection of the $\mathrm{Zn}$ coating could slow the corrosion of iron pipe provided that the galvanic cell consisting of $\mathrm{Zn}$, iron pipe, and soil-derived solution is not interrupted. The formation of a protective layer consisting of a $\mathrm{Zn}$ corrosion product was previously confirmed on the exposed iron after a considerable amount of $\mathrm{Zn}$ was consumed by corrosion (Marchal 1981). This demonstrates the self-healing ability of a $\mathrm{Zn}$ coating, which could serve as a protective $\mathrm{Zn}$ corrosion product and mitigate corrosion at the damaged coating site.

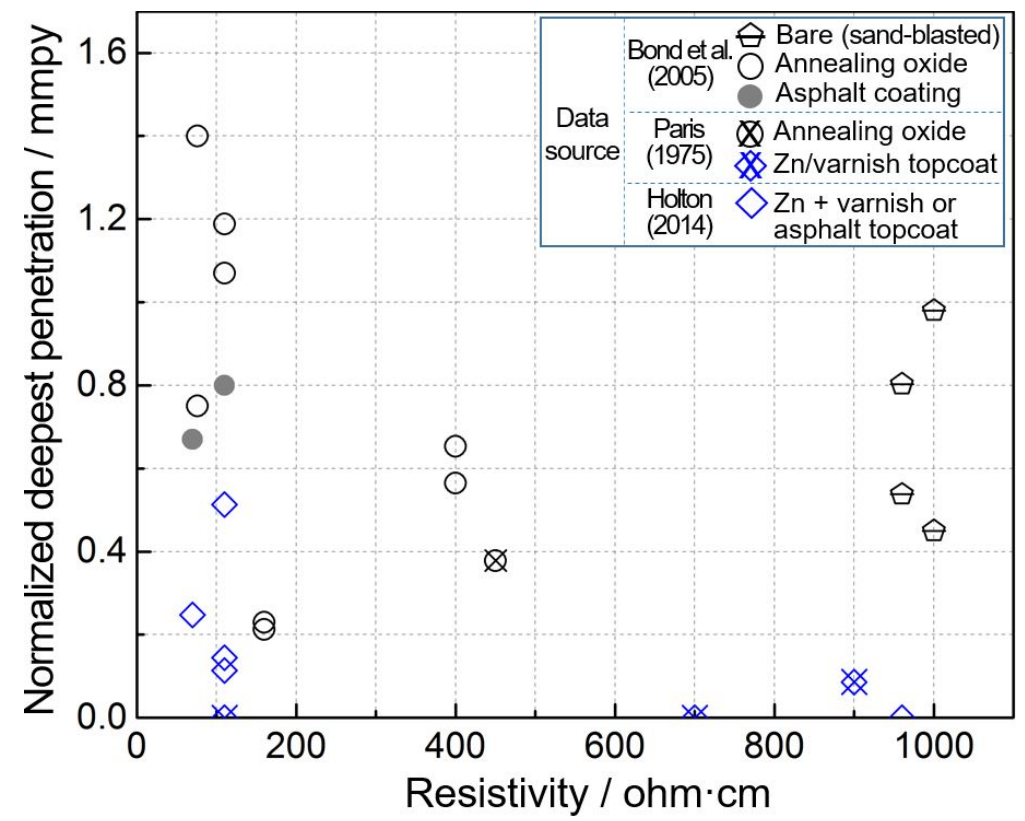

Figure 3.9. Normalized penetration of iron pipes (ductile and cast) measured for different surface conditions. The deepest penetration data collected from three sources (Bonds 2005, Paris 1975, Horton 2014) are normalized by the test duration ( 8 to 25 years), and the thickness of varnish or asphalt was $>1 \mathrm{~mm}$. 
The corrosion penetration of iron pipes with different corrosion protection strategies and surface conditions are compared in Figure 3.10. The measured resistivity of soils was lower than $1000 \mathrm{ohm} \cdot \mathrm{cm}$ in the referenced studies. Based on these results, it is demonstrated that the application of PE effectively decreased the corrosion penetration of as-annealed iron pipes. A combination of PE and $\mathrm{Zn}$ coating with a topcoat was even more successful, where no measurable penetration was detected after 9 years of burial. This implies that PE is compatible with $\mathrm{Zn}$ coating to strengthen the protection effect. The corrosion penetration under damaged PE was typically smaller than in non-PE conditions for both as-annealed and pipes with Zn coating and topcoat, which suggests that damaged PE does not worsen the corrosion of iron pipes. However, Szeliga and Simpson (2001) reached the opposite conclusion, that PE was not effective for corrosion mitigation for non-Zn coated (i.e., as-annealed or asphalt-coated) iron pipes. However, for pipes with $\mathrm{Zn}$ coating and topcoat, PE could provide a protection benefit as shown in Figure 3.10.

In highly corrosive soils, $\mathrm{PE}$ can be supplemented by cathodic protection $(\mathrm{CP})$ as recommended in the 2004 USBR technical memorandum (Calhoun 2004). The application of PE on an impressed-current CP system reduced the power to maintain a protective potential and decreased the DIP corrosion rate (Schiff and McCollom 1993). However, some concern about the compatibility of PE with CP was reported (Rajani and Kleiner 2003, Lindemuth and Kroon 2006, Marney and De Silva 2010), based on the idea that PE may, in some cases, impair the effectiveness of CP by shielding the path of protective current. This shieling effect of PE may apply for CP systems which have anodes outside of the PE. In Zn-coated pipes, however, $\mathrm{Zn}$ itself functions as a galvanic anode so that the current path forms inside the PE without any interruption. This suggests that the combination of $\mathrm{PE}$ and a $\mathrm{Zn}$ coating with topcoat could be an alternative method for PE alone with $\mathrm{CP}$ to provide comparable corrosion protection without the current shieling issue possible with $\mathrm{PE}$ combined with $\mathrm{CP}$.

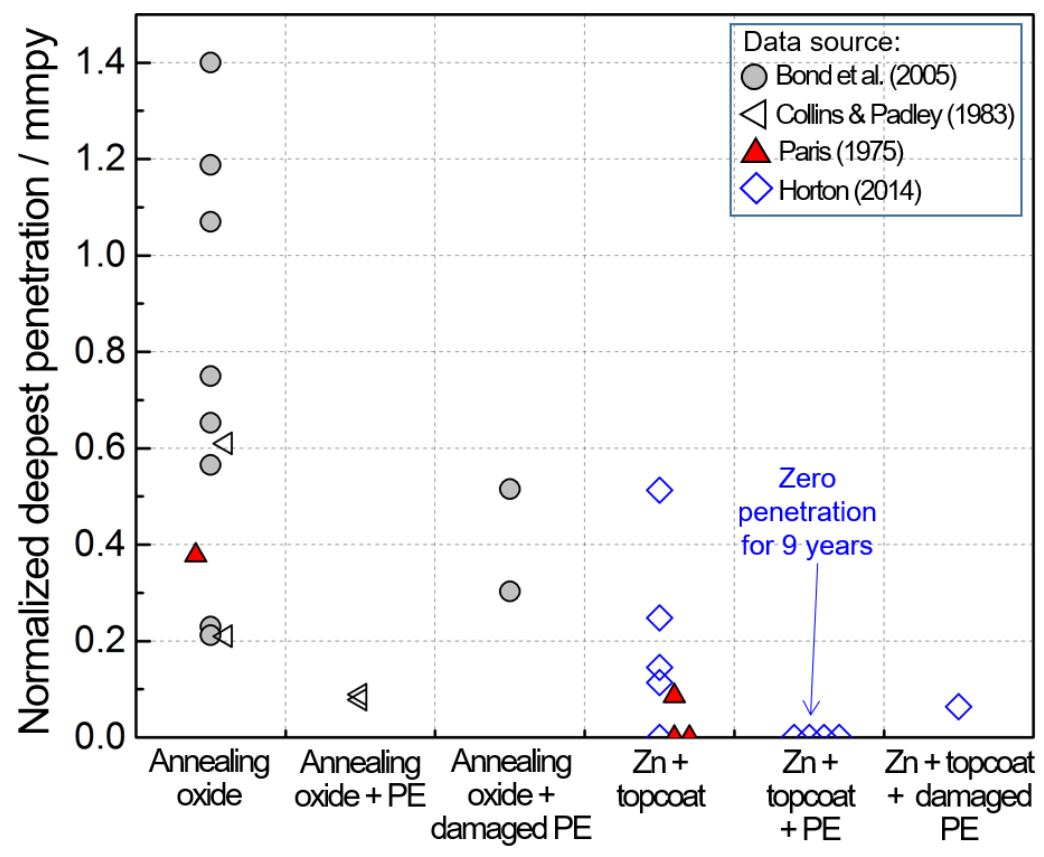

Figure 3.10. Normalized penetration of iron pipes (ductile and cast) measured under different protections (including PE and $\mathbf{Z n}+$ top coat). The deepest penetration data collected from four sources (Bond 2005, Collins and Padley 1983, Paris 1975, Horton 2014) are normalized by the test duration ( 8 to 25 years), and the thickness of varnish or asphalt was $>1 \mathrm{~mm}$. 


\subsection{SUMMARY OF TASK 2}

- The goal of this task was to establish a baseline for DIP corrosion based on prior work. The larger, older buried pipe studies did not contain DIP, as it was only introduced in $\sim 1970$, but can provide insight into the definition of corrosive soils.

- An initial machine learning analysis on the NBS buried pipe corrosion dataset estimated soil properties and weather condition to have a high influence on corrosion mass loss of soil-buried ferrous pipes.

- Further analysis on selected NBS corrosion data showed that both corrosion mass loss and penetration increased with decreasing soil resistivity. Larger deviations in corrosion mass loss and penetration were evident for the ferrous pipes in low resistivity $(>1000 \mathrm{ohm} \cdot \mathrm{cm})$ soils.

- A zinc coating with a topcoat (i.e., coal-tar varnish or asphalt) effectively decreased the corrosion penetration in corrosive soils. In one study, the combination of PE and $\mathrm{Zn}$ coating with a topcoat was extremely protective and did not allow corrosion penetration for 9 years. 


\section{TASK 3: DEVELOP A LONG-TERM TEST PLAN}

\subsection{OVERALL PLAN}

The goal of this task was to suggest a long-term test plan that will assist the USBR in developing more rigorous guidelines for protection of pipelines, particularly those buried in corrosive soils. It would be attractive to propose a short-term (1-2 year) plan to address this issue. However, with lifetime goals of 50-100 years, a more substantial demonstration of performance is needed to validate conclusions.

It is recommended that the USBR form an independent research team consisting of universities and independent laboratories not associated with any of the competing pipe manufacturers. The team would be advised by a committee of manufacturers, industry experts, and water utilities to conduct research to address relevant, fundamental questions such as (1) developing an improved definition of corrosive soils, not solely based on resistivity; (2) evaluating the relative effectiveness of various coating strategies to determine their effectiveness; (3) developing predictive corrosion modeling capabilities that would be available to the entire water utility industry; and (4) conducting long-term studies of pipeline corrosion to validate corrosion models in a variety of soils in the laboratory and in the field. Such a consortium would have the added benefits of educating the next generation of corrosion scientists for this industry and bringing scientific rigor to this important issue. An initial goal of the consortium would be to evaluate zinc-coated DIP, which has been used in Europe for $\sim 50$ years, and to explore its effectiveness relative to combinations of PE and CP. The consortium could also explore some new innovative concepts such as using a situational awareness data-driven webtool for monitoring pipeline corrosion in the US using open-source data such as social media and news feeds (see Section 4.4). An initial test of this concept was performed during this project with some degree of success.

\subsection{PROPOSED RESEARCH CONSORTIUM}

Soil type affects the composition, concentration, and volume of soil-derived solutions that are directly associated with corrosion damage on buried pipes. According to the US Department of Agriculture (USDA), more than 10 major soil types have been identified, as shown in Figure 4.1 from the USDA website. This indicates that the field corrosion tests for buried DIP should include at least one location for each major soil type. The NBS corrosion study on buried ferrous pipes (Romanoff 1957) was one of the first organized attempts to cover a wide variety of soils and understand the effect of different soils on pipe corrosion. As noted previously, DIP - as well as most of the current corrosion protection strategies, including PE and zinc coating - was not available at the time of the NBS studies. Thus, the previous work mainly studied pipes without corrosion protection, which would not be considered acceptable today. Therefore, a new generation of testing including state-of-the-art in situ corrosion monitoring is needed to evaluate the effectiveness of the proposed protection strategies and combinations of strategies. 


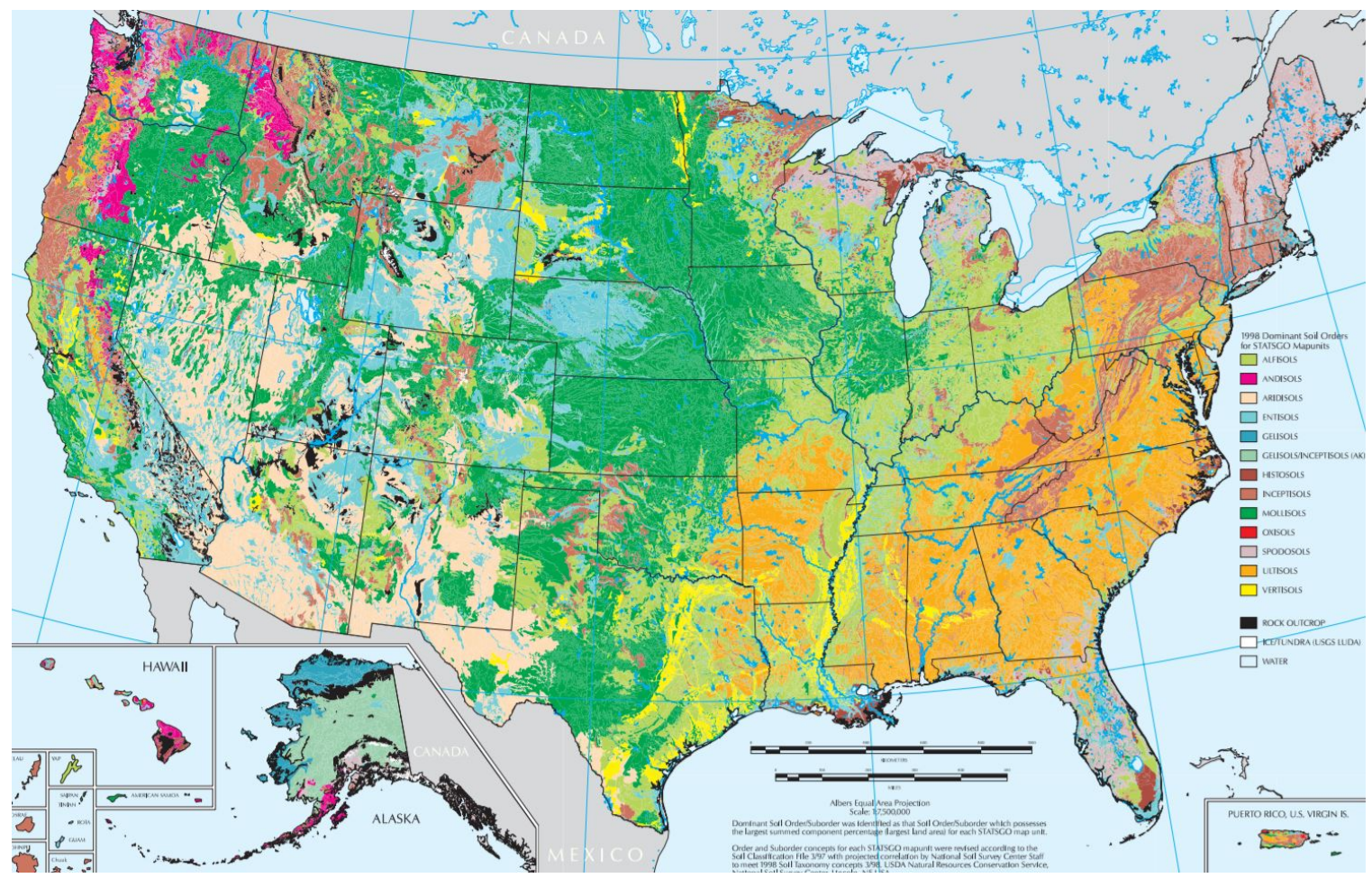

Figure 4.1. Dominant soil orders in the US including more than 10 major soil types. (https://www.nrcs.usda.gov/Internet/FSE_MEDIA/stelprdb1237749.pdf)

More recent publications on DIP corrosion have considered different surface conditions and protection strategies for buried pipes in different soils at multiple US locations (Bonds 2005, Horton 2014). The design of long-term field tests for buried DIP should be developed with input from experienced researchers from industry and corrosion consultants. Such interactions would also be advantageous to learn about recent developments in corrosion protection methods from industry. In order to collect and analyze an extensive amount of corrosion data from different US locations, a research consortium from across the US, including members from research laboratories and universities, could help to coordinate these studies. A major benefit of this approach would be standard measurements of, for example, soil corrosivity and corrosion damage, resulting in easily comparable data. The volume of corrosion data expected from this effort would be sufficiently high to have statistical significance and improve the results of the machine learning analysis discussed in Section 3.2.

\subsection{LABORATORY-BASED ACCELERATED TESTS}

In addition to field corrosion tests, laboratory-based corrosion tests would be conducted for pipe samples with different combinations of protection strategies using the in situ and ex situ test methods discussed in Section 1.2. In accelerated laboratory-based experiments, the testing soils could be maintained at an extremely aggressive condition, such that soil corrosivity would no longer be a variable, unlike field corrosion tests. Such a highly corrosive soil could shorten the time to produce measurable corrosion damage and also highlight the effect of different surface conditions and protection strategies more explicitly than in less-aggressive soils, which may produce minimal damage on both protected and unprotected specimens. Of course, the results of an accelerated tests must be benchmarked against field data in order to be useful in predicting performance. 
For a systematic analysis of corrosion, the measurable and controlled parameters can largely be divided into three categories: soil corrosivity, corrosion protection, and corrosion damage. Some example parameters for these categories are summarized in Table 4.1. In both field and laboratory experiments, corrosion damage can be used to evaluate the effect of soil corrosivity and corrosion protection. For example, a larger corrosion mass loss or penetration depth on pipe specimens could indicate a higher soil corrosivity for the same corrosion protection or less-efficient corrosion protection for the same soil corrosivity.

Table 4.1. Three categories of parameters associated with soil-buried corrosion

\begin{tabular}{ll}
\hline Category & Parameters \\
\hline Soil corrosivity & Resistivity, pH, moisture content, sulfide, chloride \\
Corrosion protection & PE, FBE, Zn coating, CP \\
Corrosion damage & Ex situ: corrosion mass loss, maximum penetration depth \\
& In situ: corrosion current \\
\hline
\end{tabular}

Using corrosion damage as the measure of soil corrosivity and protection strategy effectiveness would enable the correlation of soil corrosivity in laboratory and field conditions for different corrosion protection strategies. This concept is described in Figure 4.2. A successful correlation analysis between soil corrosivity, corrosion protection strategies, and measured corrosion damage would enable a prediction of corrosion damage in field conditions if soil corrosivity and corrosion protection have been quantified. However, soil corrosivity depends on multiple soil properties and environmental conditions, which would complicate the correlation analyses. Computer-based techniques can be used to evaluate such complicated correlations from the corrosion data generated and to develop predictive models for long-term behavior.

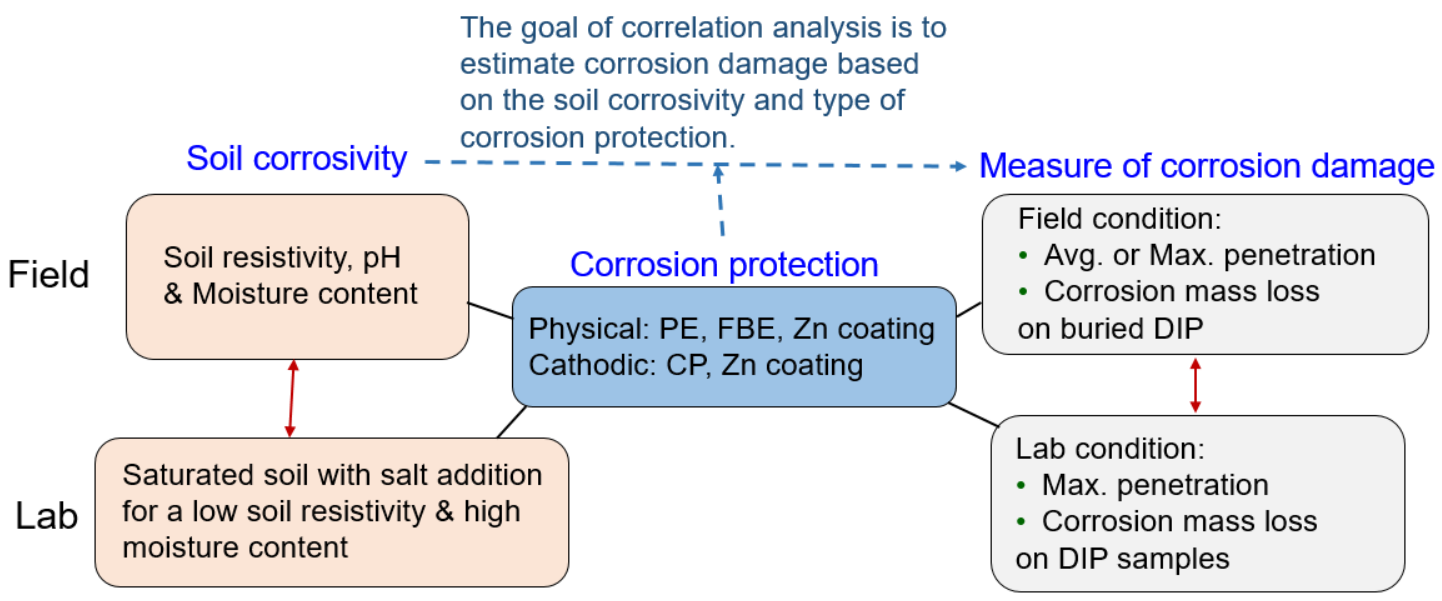

Figure 4.2. Measurable and controlled parameters in laboratory and field corrosion tests. For both laboratory and field tests, corrosion protection can be controlled. Correlation of soil corrosivity between laboratory and field tests is possible using corrosion damage as a metric. These correlations are marked with double end arrows. Arrow with broken line indicates the goal of correlation analysis.

\subsection{EXAMPLES OF SUGGESTED EXPERIMENTAL AND COMPUTER-BASED ANALYSES}

\section{Design of soil corrosion testing frame}

One example of a suggested laboratory experiment is described in Figure 4.3. The test frame is designed to conduct in situ (EIS and potentiodynamic polarization) and ex situ (mass loss and penetration) measurements simultaneously along with analysis of the soil-derived solution. The supply of water or salt 
solution can be controlled to achieve different levels of moisture and salt concentration in the soil. Realtime measurements of moisture content, $\mathrm{pH}$, and conductivity in the testing soil can be made to monitor time-dependent changes of the soil properties.

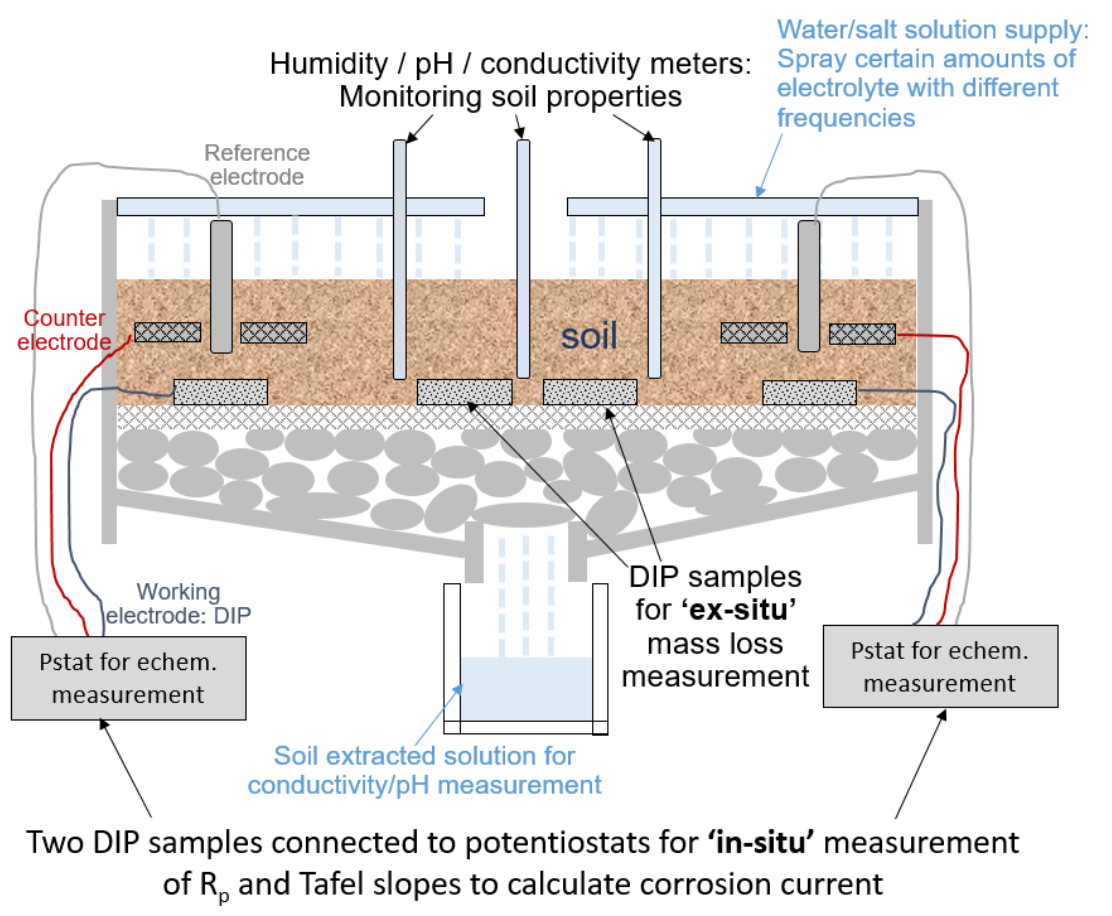

Figure 4.3. Suggested design of a soil corrosion testing frame.

\section{Situational awareness monitoring system}

Another example of a novel way to monitor the real-time occurrences of critical water main failures was initially attempted at ORNL's Computer Science Division using open-source information such as online mass media and social network services. As a proof of concept, a web-based dashboard was developed to explore and monitor social media mentions of keywords related to water pipe infrastructure. Not all information contains locations, but a sufficient number do to allow this type of analysis. The snapshots of these interfaces are shown in Figures 4.4 to 4.6. A monitoring result for key words associated with buried pipe line failure is shown in Figure 4.7. The frequency of key words appeared higher around Detroit, MI on the map, which is not surprising given the recent Flint water contamination from 2014 to 2015. Next steps in the infrastructure monitoring platform would be connecting to news outlets from across the US. This would facilitate advanced analytics such as topic modeling and sentiment analysis. 


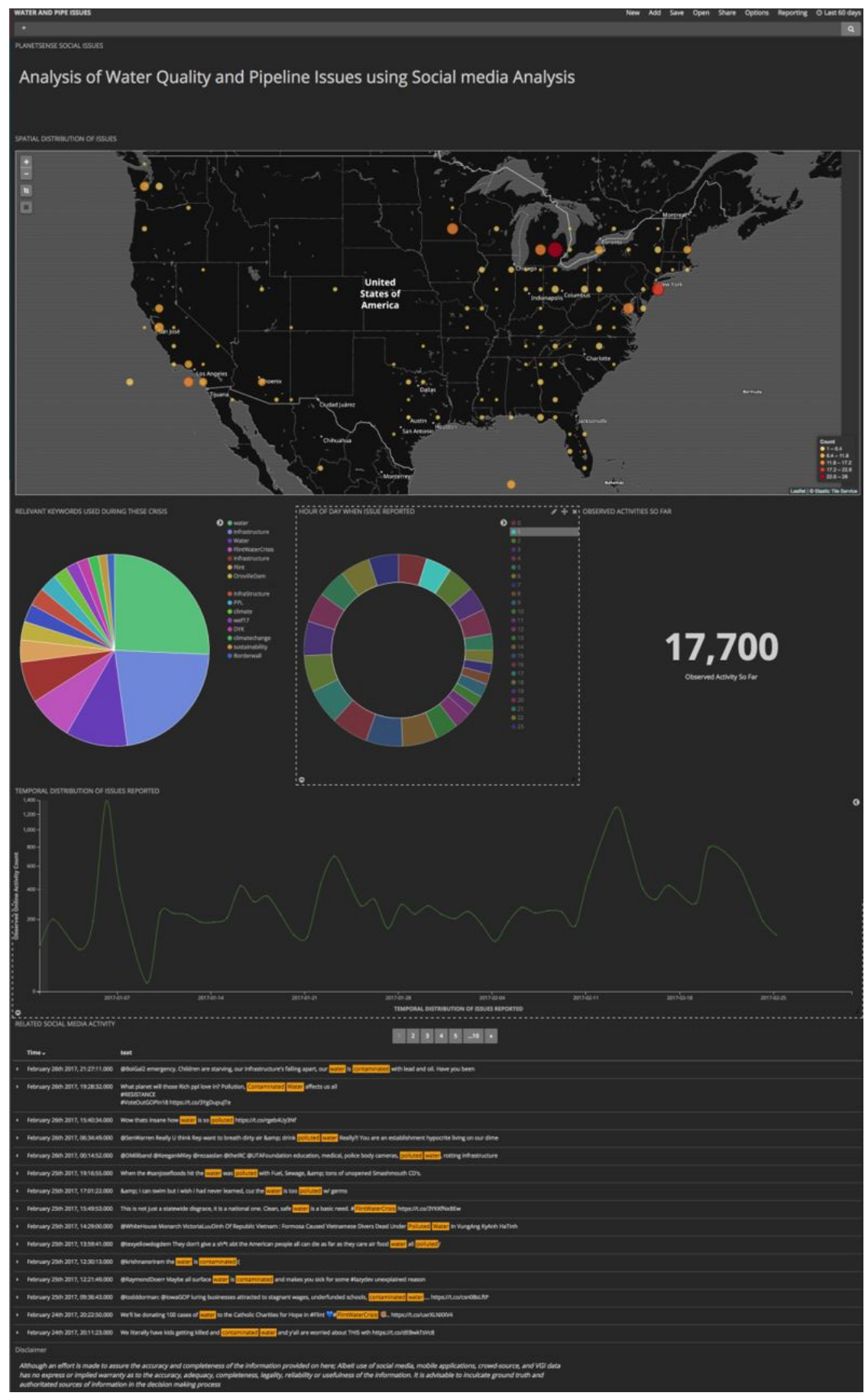

Figure 4.4. Screenshot of Infrastructure Monitoring Interface. 


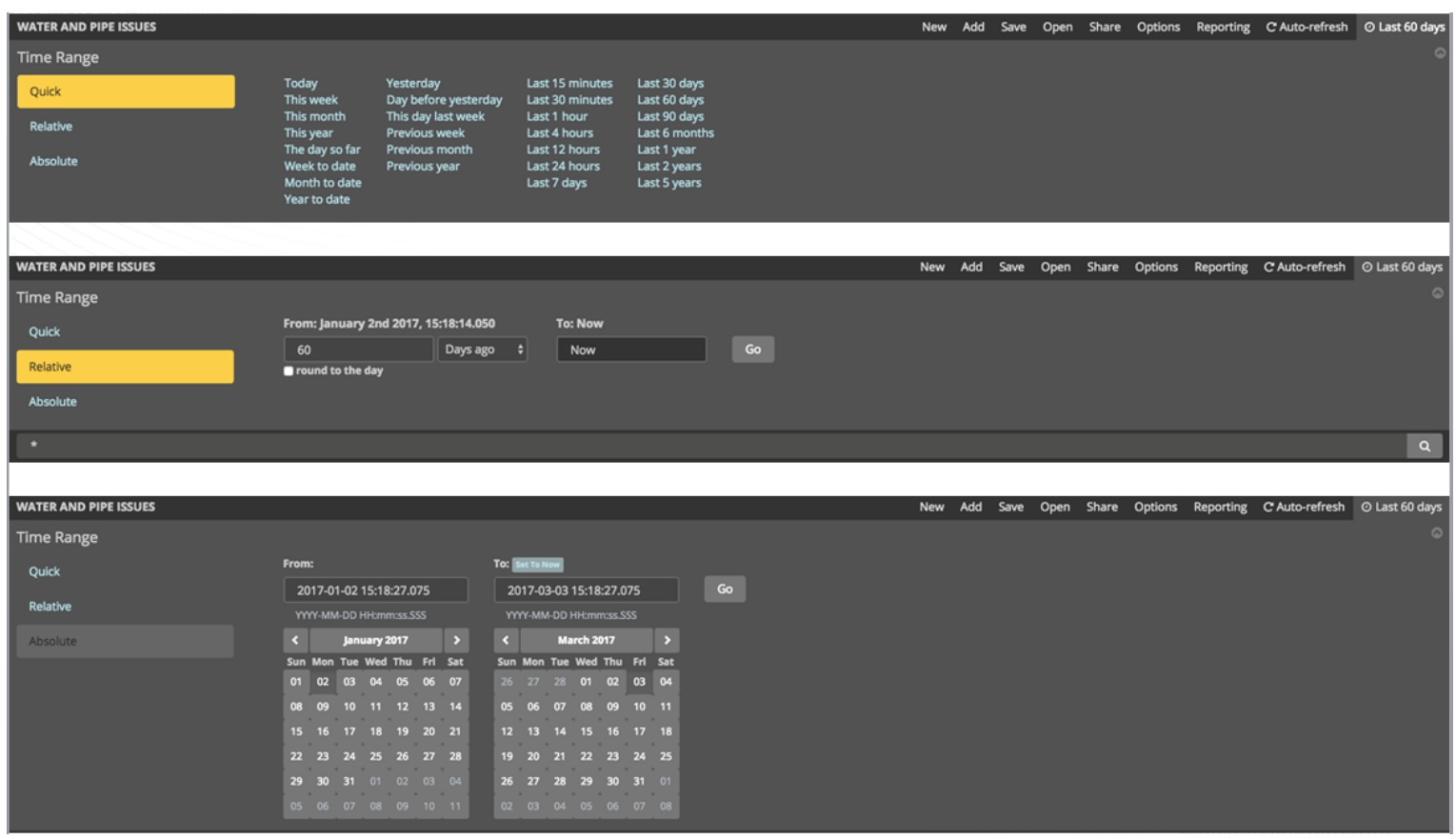

Figure 4.5. Temporal filtering capabilities.

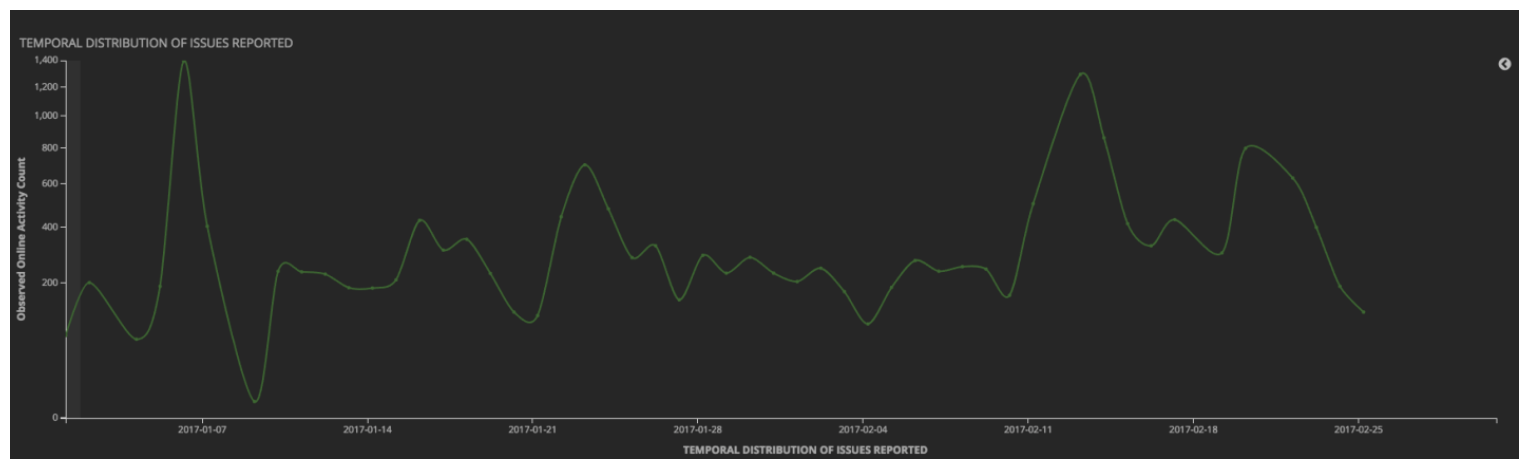

Figure 4.6. Temporal distribution of issues recorded for a 2 month period. 


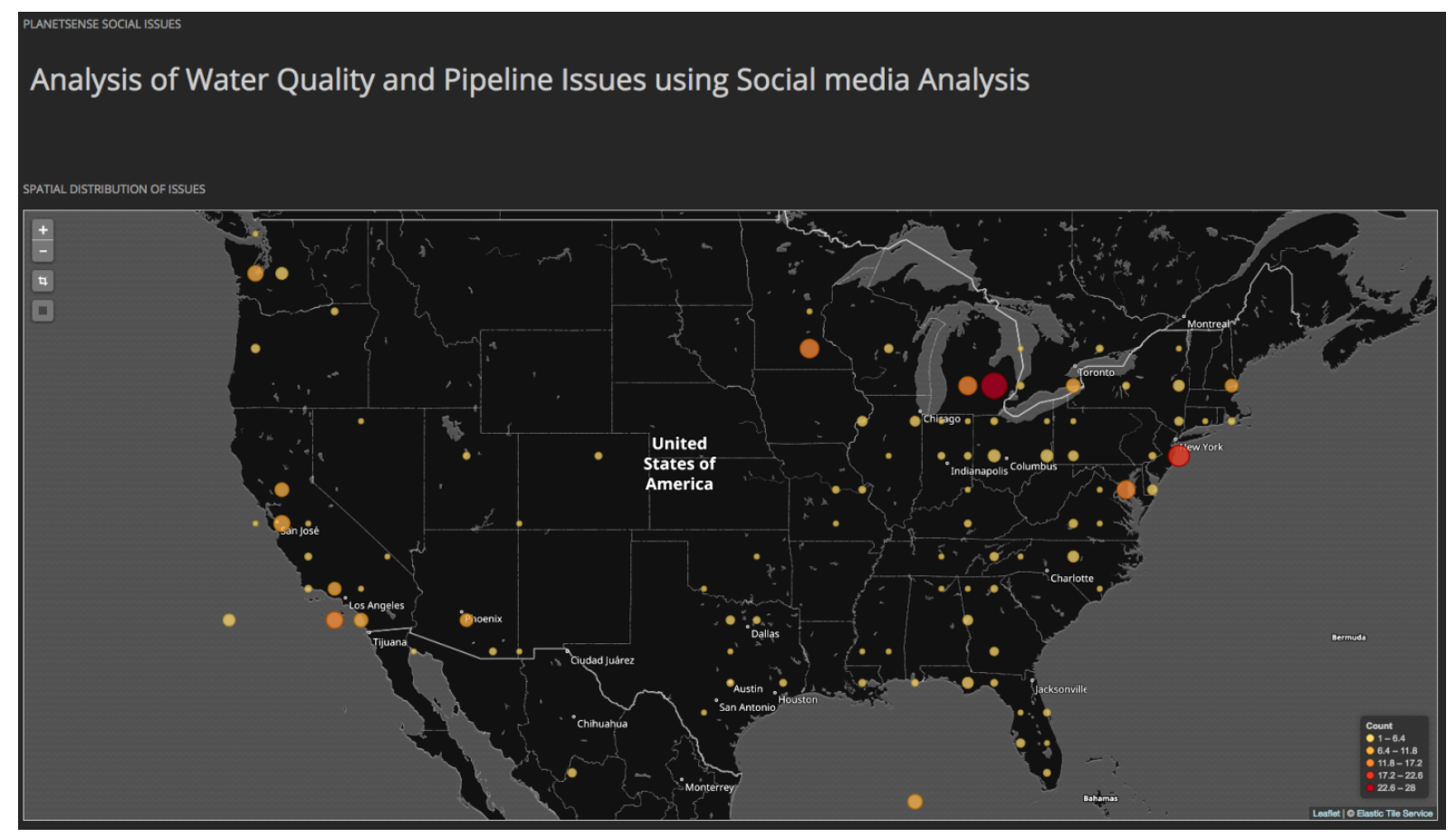

Figure 4.7. Spatial distribution of issues recorded for a 2 month period. As expected, water quality was mentioned frequently in Flint and Detroit, MI.

\subsection{SUMMARY OF TASK 3}

- The formation of a research consortium to manage and analyze a new generation of field and laboratory corrosion data in different US locations would be beneficial to support science-based recommendations for the USBR.

- An additional benefit of including universities in the consortium would be to educate a new generation of corrosion scientists familiar with these issues. These individuals would then assist US stakeholders in making informed decisions about pipeline corrosion issues.

- Correlation of field and laboratory corrosion data would lead to verified methods of accelerating testing of corrosion damage in the laboratory and ultimately lead to predictive models for the 50 100 year pipeline lifetime goals.

- Suggested experimental and computer-based strategies included developing accelerated laboratory testing strategies and using innovative data-mining techniques to help monitor and understand the impact of pipeline corrosion in the US. 


\section{TASK 4: EXPLORE ACCELERATED LABORATORY TESTING}

As it is not practical to wait decades to develop corrosion protection strategies and guidelines, this task focused on developing accelerated corrosion testing using laboratory-formulated soil and electrochemical measurements to estimate corrosion rates. DIP samples with a wide range of surface conditions, coatings, and PE were tested in laboratory-formulated soils. Standard linear polarization and electrochemical impedance spectroscopy (EIS) techniques were applied to evaluate initial and time-dependent corrosion rates of DIP and steel samples in soil-simulating solution and soil extract.

\subsection{CONSIDERATION OF ACCELERATING FACTORS IN SOIL CORROSION}

In soil-buried DIP, corrosion damage is expected to increase with increasing soil conductivity (e.g., inverse of soil resistivity), which is positively correlated with soil moisture (Calamita 2012). If the moisture level of two soils is the same, soil conductivity would increase as the concentration of soilderived solution increases. This means that both the moisture level and solution concentration of soils can be considered accelerating factors for soil corrosion. The moisture level of soil can be nearly $100 \%$ in a fully saturated soil and would remain at saturation if the evaporation of solution is effectively prevented. This fully saturated soil is capable of maintaining a constant and high soil conductivity to accelerate corrosion. A further increase of soil conductivity is possible by adding salt solutions. Accordingly, the laboratory-formulated soils used in this work were fully saturated with a salt solution to achieve a high soil conductivity (or low soil resistivity) for accelerated corrosion tests of DIP and steel pipeline samples. In brief, the accelerating factors adopted in this work were:

- $100 \%$ soil humidity: achieved by full saturation of soil

- Increased solution concentration in soil: a salt solution added for soil saturation

\subsection{PREPARATION OF DIP SAMPLES WITH OXIDE LAYER AND ZN COATING}

\section{Laboratory oxidation of DIP samples}

Specimens for testing were cut from 4" as-manufactured DIP (surface covered by oxide from manufacturer and asphalt topcoat) into rectangular pieces with each side 3 to $5.5 \mathrm{~cm}$ long. The mortar lining of as-manufactured DIP (shown in Figures 2.1 and 2.2) was removed mechanically prior to machining. To produce a "bare" surface, as-cut DIP samples were ground with an 80 grit grinder, to remove the asphalt and oxide layers and expose the metallic surface, followed by a 320 grit polish. To reform the oxide layer typically found on commercial DIP, the specimens were oxidized in laboratory air at $950^{\circ} \mathrm{C}$ for $2 \mathrm{~h}$ as described in Section 2.3. Unfortunately, in some cases this procedure led to spallation of the thermally grown iron oxide or "scale" as shown in Figure 5.1. The black oxide spalled, leaving a reddish surface on the specimens after the laboratory oxidation. Cross-sectional images of spalled and unspalled regions are shown in Figure 5.2.

The surfaces of DIP samples after the laboratory oxidation are presented in Figure 5.1, showing spallation of the black scale leaving a reddish oxide surface underneath. Two light microscopy cross-sectional images show regions with and without oxide spallation (Figure 5.2). The spalled section of oxidized DIP showed almost complete scale spallation, suggesting the remaining oxide may be only a few microns thick. The retained oxide layer was $\sim 50 \mu \mathrm{m}$ thick. 
a

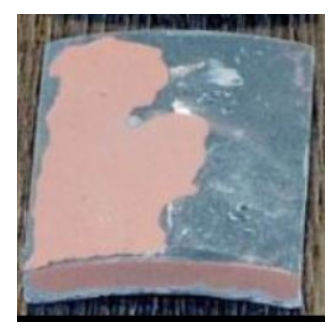

b

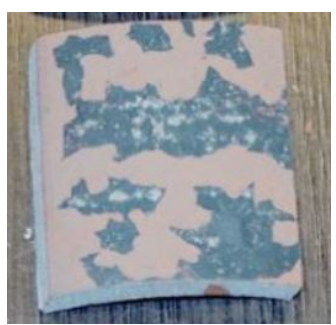

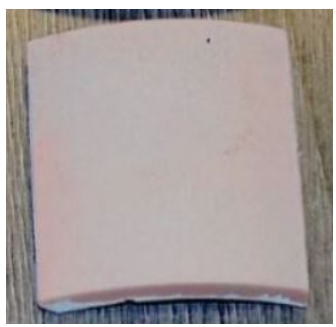

Figure 5.1. Appearance of laboratory-oxidized DIP samples: (a, b) partial spallation of black scale with reddish oxide surface underneath and (c) full spallation of black scale exposing reddish oxide surface. The specimens shown are $4-5 \mathrm{~cm}$ in width and length.

a

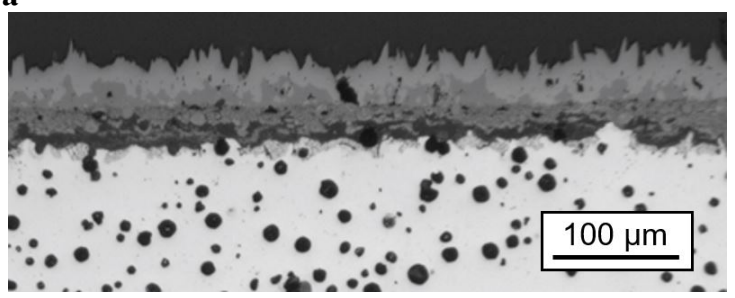

b

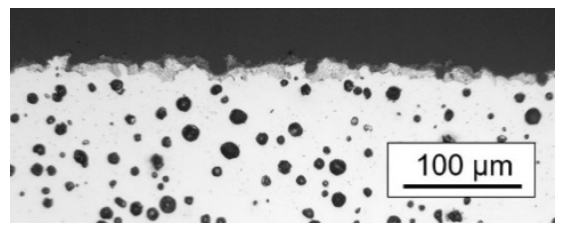

Figure 5.2. Light microscopy cross-section images of oxidized DIP samples (a) without oxide spallation and (b) with oxide spallation.

To minimize scale spallation, the bare DIP surface was sandblasted before the $50^{\circ} \mathrm{C}$ oxidation. An image of a sandblasted specimen after oxidation is shown in Figure 5.3a. Figure 5.3b shows a cross section of the oxide layer formed on the sandblasted specimen. The rougher metal-oxide interface likely inhibited scale spallation and appeared to result in a slightly thicker reaction product than the polished specimen shown in Figure 5.2a. Due to time constraints, some experiments were conducted with polished and oxidized specimens. The sandblasted and oxidized specimens were not used for laboratory testing.

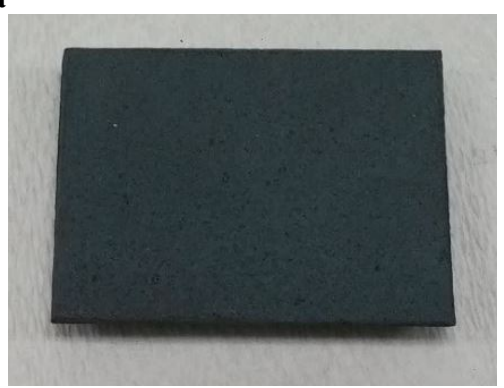

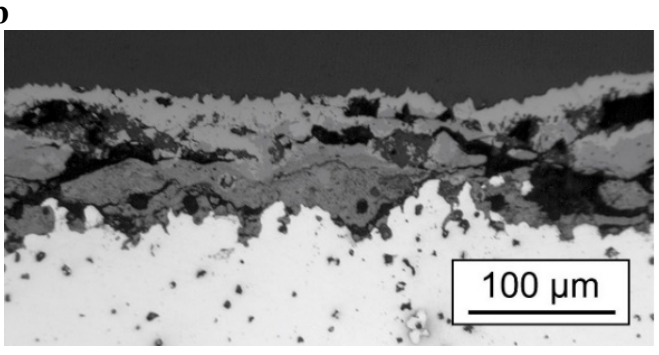

Figure 5.3. Laboratory-oxidized DIP with sandblast: (a) appearance of dark-gray oxide on a DIP sample measuring approximately $3.5 \times 4.5 \mathrm{~cm}^{2}$ and (b) cross-section light microscopy image of oxide layer formed on a sandblasted surface.

\section{Zn coating on laboratory-oxidized DIP samples}

To simulate zinc-coated DIP, DIP samples with different surface conditions were sent to Tennessee Metalizing Company in Oliver Springs, TN for application of zinc by air thermal spraying. This process is similar to the commercial zinc coating process (Section 2.3). Images of the $\mathrm{Zn}$-coated DIP samples are shown in Figure 5.4. The surface of the $\mathrm{Zn}$ coating was coarse and not reflective but appeared to be adherent with no spallation observed. A light microscopy cross-section image of the zinc coating on 
laboratory-oxidized (without sandblasting) DIP is shown in Figure 5.5. The non-uniform coating with porosity is similar to the commercial coating (Figure 2.17). The zinc coating appeared to be well-bonded to the oxide layer. Typically, a galvanic coating is applied directly to bare metal, so the galvanic protection of this coating will not be optimal. To test a more typical galvanic coating structure, a thermally sprayed zinc coating was applied to bare and sandblasted DIP without the oxide layer. Sandblasting was used to increase the surface roughness, a standard procedure for thermally-sprayed coatings. Cross-sectional light microscopy images of the zinc coating are shown in Figure 5.6. Based on these images, the coating appeared to have a similar microstructure as when sprayed on the oxide layer and there was no evidence of any reaction at the DI-zinc interface. Figure 5.6 also shows that the DIP microstructure was severely deformed by the sandblasting to a depth of $\sim 100 \mu \mathrm{m}$.
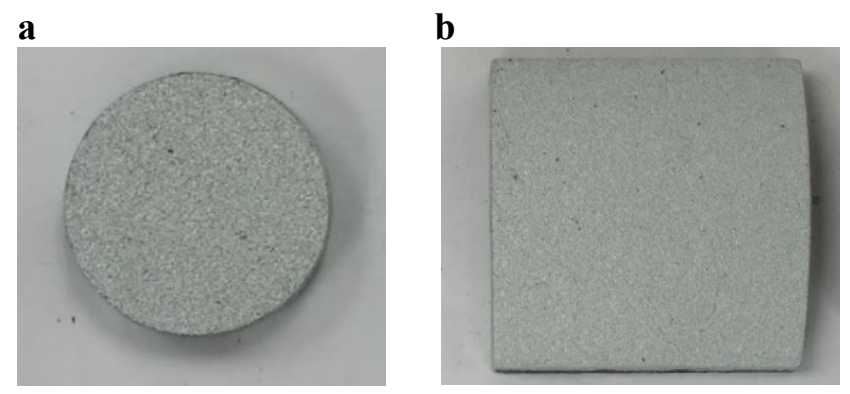

Figure 5.4. Zn coating formed by thermal spray on laboratory-oxidized DIP (substrate from Manufacturer C): (a) circular coupon (1" diameter), (b) DIP sample with each side measuring $\sim 4.5 \mathrm{~cm}$.

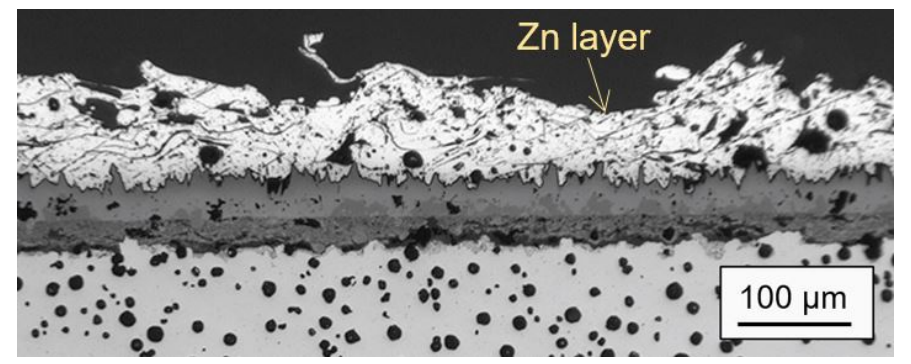

Figure 5.5. Cross-section light microscopy image of $\mathrm{Zn}$ /laboratory oxide layers formed on DIP.

a

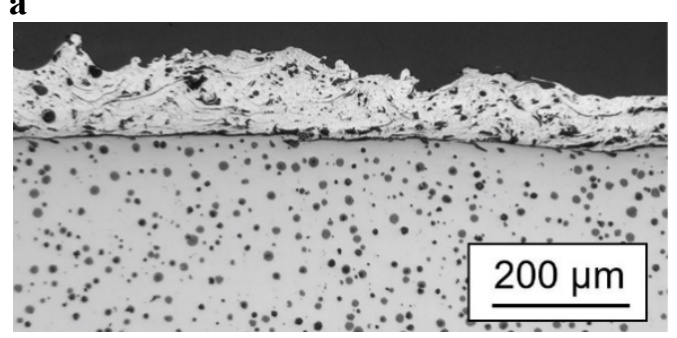

b

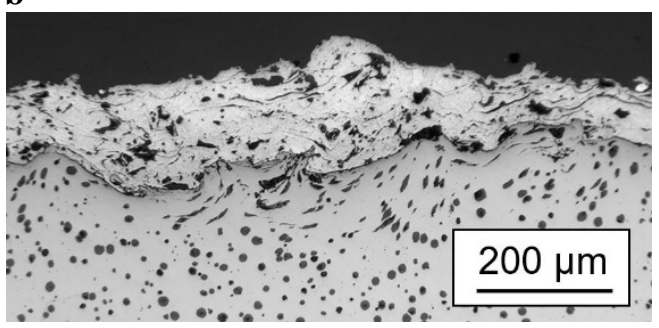

Figure 5.6. Cross-section light microscopy images of Zn layer coated on (a) bare DIP, (b) sandblasted DIP.

\section{Zn coating formed by DIP manufacturer}

Prior to the arrival of the zinc-coated DIP characterized in Section 2.3, ORNL was provided with a zinc coating sprayed on plastic substrates by a DIP manufacturer using the same commercial automated arcspray process. The commercial zinc-coated specimens and the thermally sprayed coating made for this project are shown in Figure 5.7. 


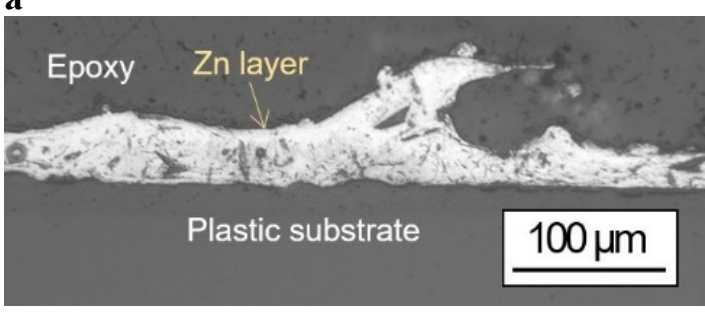

b

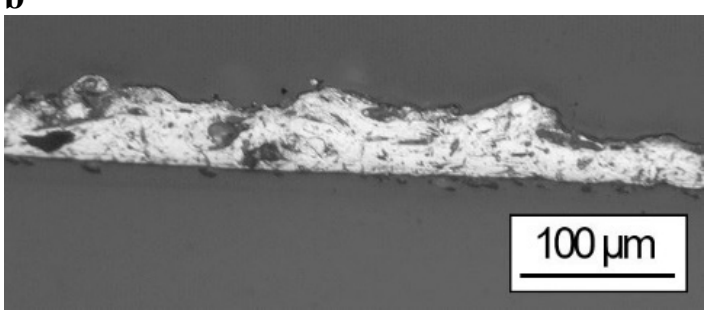

c

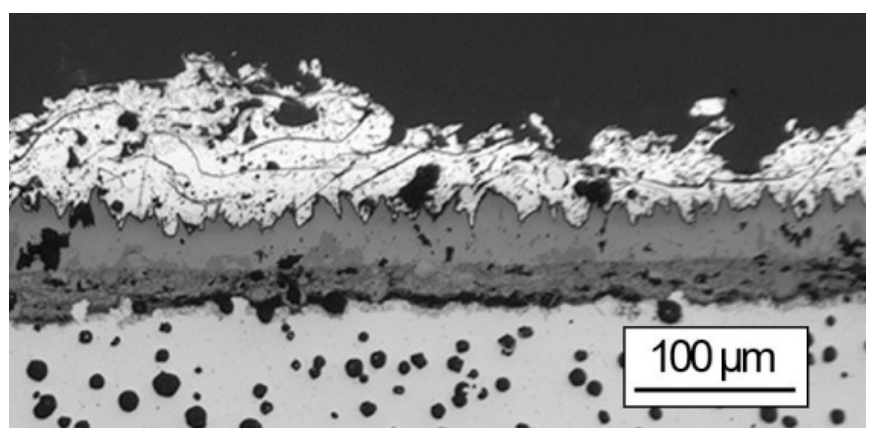

Figure 5.7. Cross-section light microscopy images of $\mathrm{Zn}$ coating formed by (a,b) a manufacturer and (c) this work.

\subsection{ACCELERATED CORROSION TEST IN AGGRESSIVE SOIL MIXTURE: EXPERIMENTAL AND CORROSIVE PROPERTIES}

\section{Materials}

Three photo images of bare, oxide-formed, and asphalt-coated DIP samples are shown in Figure 5.8. In addition, several different types of specimens were prepared, and these are summarized in Table 5.1. The test conditions also are summarized in Table 5.2. Specimens with a zinc coating on laboratory-formed oxide (no sandblast applied before laboratory oxidation) were exposed. Because the zinc coating was unlikely to fail during these relatively short, accelerated experiments, the coating was intentionally damaged to expose the underlying metal. Figure 5.9 shows how the coating was scribed. Some bare DIP samples were coated with liquid epoxy to simulate a fusion-bonded epoxy (FBE) coating such as that suggested by the 2004 USBR technical memorandum (Calhoun 2004). Examples of epoxy-coated specimens are shown in Figure 5.10. The $\sim 200 \mu \mathrm{m}$ epoxy coating was very uniform. A simulated PE also was tested by enclosing as-cut DIP samples with asphalt finish in 8 mil thick polyethylene bags (Figure 5.11).
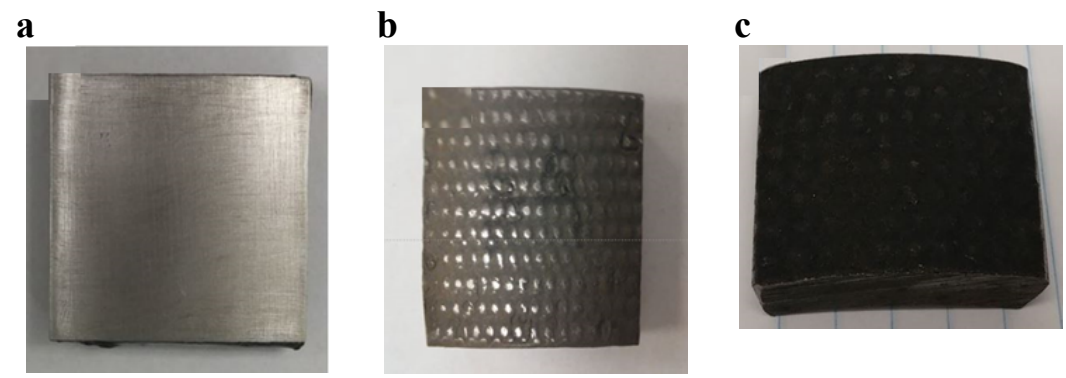

Figure 5.8. Images of DIP samples with each side $3.5-5 \mathrm{~cm}$ long: (a) bare surface, (b) manufacturer oxide, and (c) asphalt topcoat. 
Table 5.1. The surface conditions of DIP and steel samples

\begin{tabular}{|c|c|l|}
\hline \multirow{2}{*}{ DIP } & Manufacturer & \multicolumn{1}{c|}{ Surface or protection condition tested } \\
\cline { 2 - 3 } & $\mathrm{A}$ & Bare, manufacturer (annealing) oxide, fusion-bonded epoxy coating \\
\cline { 2 - 3 } & $\mathrm{B}$ & Bare, fusion-bonded epoxy coating \\
\hline Steel & $\mathrm{C}$ & $\begin{array}{l}\text { Bare, asphalt coating, Zn coating (most with a scribe), polyethylene } \\
\text { encasement }\end{array}$ \\
\hline
\end{tabular}

Table 5.2. Preparation details for six different test conditions

\begin{tabular}{ll}
\hline \multicolumn{1}{c}{ Test condition } & \multicolumn{1}{c}{ Preparation details } \\
\hline Bare & $\begin{array}{l}\text { Mechanical grinding (80 grit) to remove asphalt/oxide layer of as-manufactured DIP } \\
\text { then finished with } 240 \sim 320 \text { grit paper (Figure 5.8a) }\end{array}$ \\
Manufacturer oxide & $\begin{array}{l}\text { As-manufactured DIP samples with annealing oxide but no asphalt coating (Figure } \\
5.8 \mathrm{~b})\end{array}$ \\
Asphalt coating & As-manufactured DIP samples with asphalt coating + annealing oxide (Figure 5.8c) \\
Zn coating & $\begin{array}{l}\text { Thermal spray Zn coating on laboratory-oxidized DIP (Figure 5.4), most samples with } \\
\text { intended scribes exposing bare surface underneath (Figure 5.9) }\end{array}$ \\
Liquid epoxy coating & $\begin{array}{l}\text { A commercial epoxy coating (product name: Protal 7200, brand: Denso) on } \\
\text { sandblasted bare DIP to simulate fusion-bonded epoxy coating (Figure 5.10) }\end{array}$ \\
Polyethylene & $\begin{array}{l}\text { 8 mil thick polyethylene bags used to enclose as-manufactured DIP sample with } \\
\text { asphalt coating (Figure 5.11) }\end{array}$ \\
\hline
\end{tabular}

a

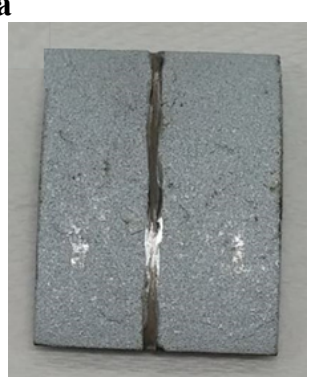

$\mathbf{b}$

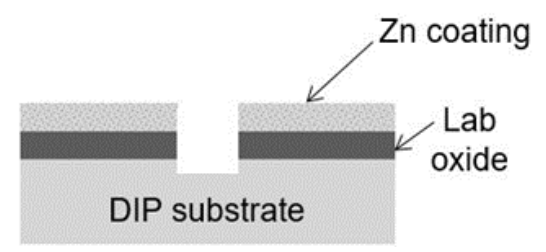

Figure 5.9. Zinc-coated DIP with a linear scribe ( $\sim 5 \mathrm{~mm}$ wide) exposing DI substrate: (a) appearance of a sample with sides 3.5 and $5.5 \mathrm{~cm}$ long and (b) schematic of scribe cross section. 
$\mathbf{a}$

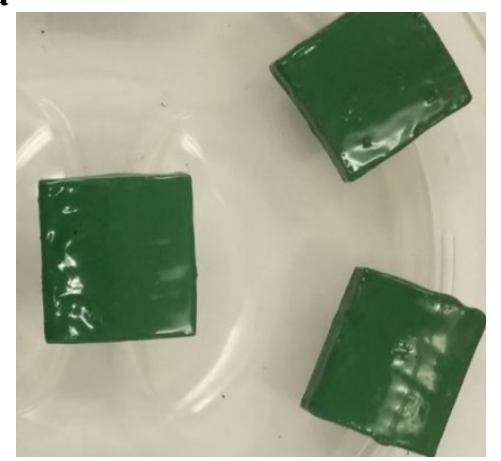

b

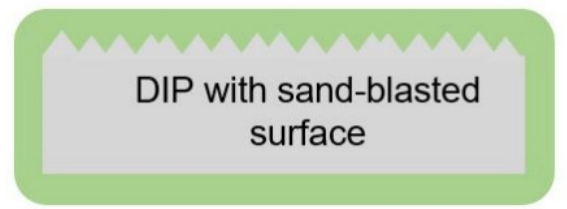

c

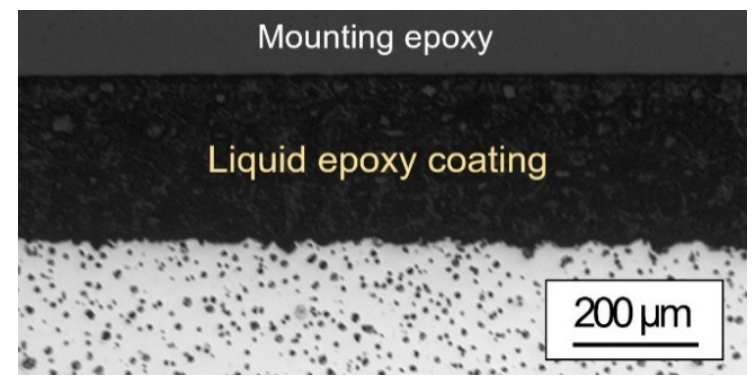

Figure 5.10. Liquid epoxy coated DIP samples: (a) appearance of epoxy (green) coated DIP samples, (b) schematic of cross section, and (c) light microscopy image of cross-sectioned sample. The pictured DIP samples are $3.5-4.5 \mathrm{~cm}$ long.

$\mathbf{a}$

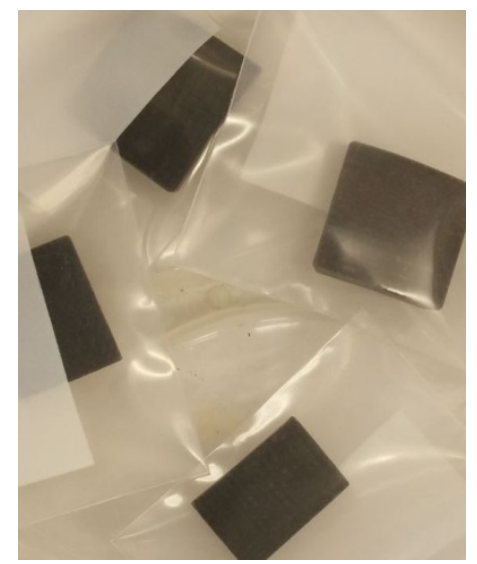

b

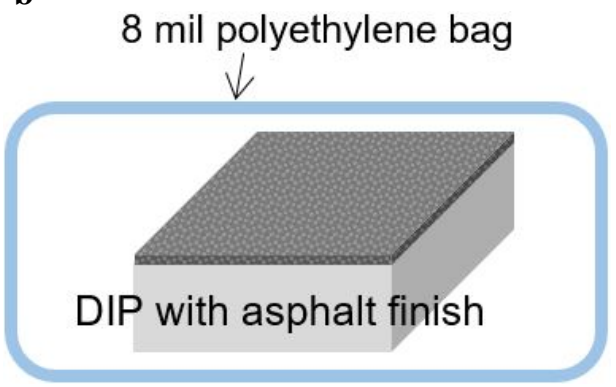

Figure 5.11. Simulated polyethylene encasement of DIP samples: (a) appearance of DIP samples in sealed polybag and (b) schematic of encased DIP sample. The pictured DIP samples are $3.5-4.5 \mathrm{~cm}$ long.

\section{Laboratory-formulated soil mixtures}

Details of the laboratory-formulated soil, the solutions added, and the testing conditions are summarized in Table 5.3. The testing duration was varied from 10 to 60 days, and one soil test was conducted outdoors for 30 days. The inner surface and cut sides of DIP and steel specimens were masked with black wax to prevent corrosion other than on the outer surface. After black wax masking, the samples were placed in polymer dishes that had drainage holes on the bottom. Each dish held three to seven specimens with the exposed (non-masked outer) surface facing upward. DIP samples placed on the polymer dishes were buried in base soil at different depths in an $18.9 \mathrm{~L}$ ( 5 gal) plastic bucket as shown schematically in 
Figure 5.12. After the burial of samples, $\mathrm{MgSO}_{4}+\mathrm{MgCl}_{2}$ solution (the concentration denoted in Table 5.3) was added until the solution level was at least $2 \mathrm{~cm}$ above the soil level. A plastic bucket with the soil and solution inside is shown in Figure 5.13.

Table 5.3. Preparation details of laboratory-formulated soils and accelerated testing conditions

\begin{tabular}{|l|c|l|}
\hline & $\begin{array}{c}\text { Number of } \\
\text { variable }\end{array}$ & \multicolumn{1}{c|}{ Details } \\
\hline Base soil & 1 & $\begin{array}{l}\text { Top soil (brand: Organic Valley) + peat moss (brand: Miracle Gro). } \\
\text { The weight ratio of top soil and peat moss was } \sim: 1 . \\
\text { The total amount of soil satisfied ASTM G162 (ASTM 2010), which specified } \\
40 \mathrm{~cm}^{3} \text { soil per } 1 \mathrm{~cm}^{2} \text { sample area }\end{array}$ \\
\hline Added solution & 2 & $\begin{array}{l}\text { Salt solution: } 0.028 \sim 0.046 \mathrm{M} \mathrm{MgSO} 4+0.014 \sim 0.023 \mathrm{M} \mathrm{MgCl}_{2} . \\
\text { Laboratory DI water }(\sim 0.7 \mathrm{Mohm} \cdot \mathrm{cm}) \text { for one soil test. } \\
\text { The volume of solution added per } 1 \mathrm{~kg} \text { of top soil: } 0.71 \sim 1.15 \mathrm{~L} / \mathrm{kg}\end{array}$ \\
\hline Test duration & 5 & Min. and max. duration: 10 and 60 days \\
\hline $\begin{array}{l}\text { Exposure } \\
\text { condition }\end{array}$ & 2 & $\begin{array}{l}\text { Indoors: laboratory area maintained at } 21 \sim 22^{\circ} \mathrm{C} . \\
\text { Outdoors for one soil test: ORNL campus, temperature varied during the } 30 \text { day } \\
\text { exposure }\end{array}$ \\
\hline
\end{tabular}

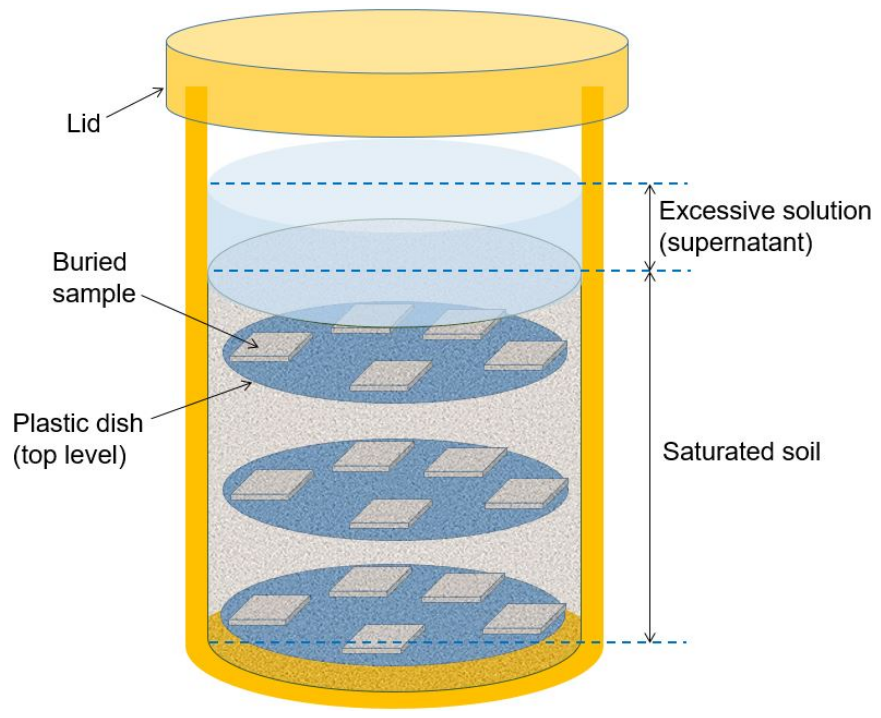

Figure 5.12. Schematic of DIP samples buried in a saturated soil mixture. The bin capacity is $\sim 18,930 \mathrm{~cm}^{3}$ ( 5 gal). 
a

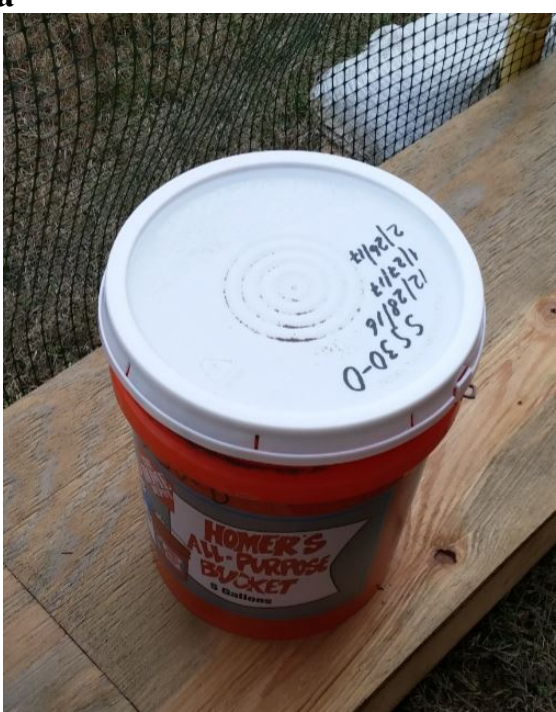

b

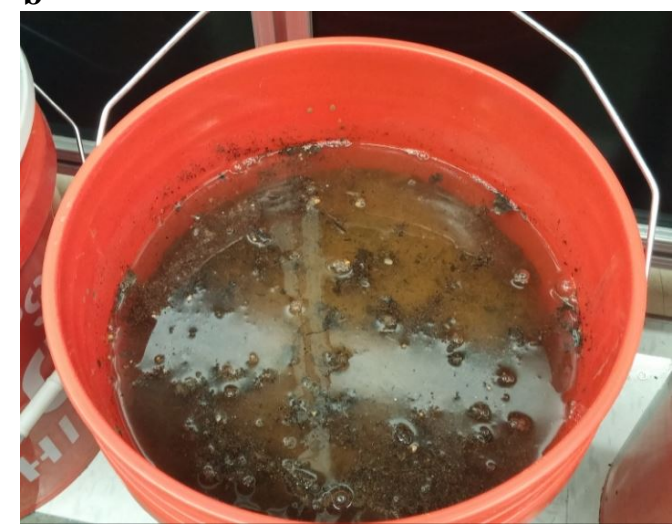

Figure 5.13. Accelerated corrosion testing in saturated soil: (a) soil bucket placed outdoors and (b) saturated soil with excessive solution layer.

During the soil tests, resistivity and $\mathrm{pH}$ of the laboratory-formulated soil mixtures were periodically measured in excessive solution and saturated soil using portable $\mathrm{pH}$ and conductivity probes (Hanna instruments). The measured resistivity and $\mathrm{pH}$ from seven soil tests are plotted in Figure 5.14. The resistivity of saturated soils for accelerated tests ranged from 150 to $250 \mathrm{ohm} \cdot \mathrm{cm}$, which was much lower than the reported resistivity for the most corrosive soil $(<1000 \mathrm{ohm} \cdot \mathrm{cm})$ (Calhoun 2004). The highest and lowest soil pH's during accelerated testing were 7.3 and 4.6 in excessive solution and 6.9 and 5.3 in saturated soil, respectively. These $\mathrm{pH}$ values were within the soil $\mathrm{pH}$ range reported in most of the NBS data (36 of 47 presented in Figure 3.5), indicating that the $\mathrm{pH}$ of the laboratory-formulated (saturated) soil accurately reproduced the soil $\mathrm{pH}$ found in field conditions. 


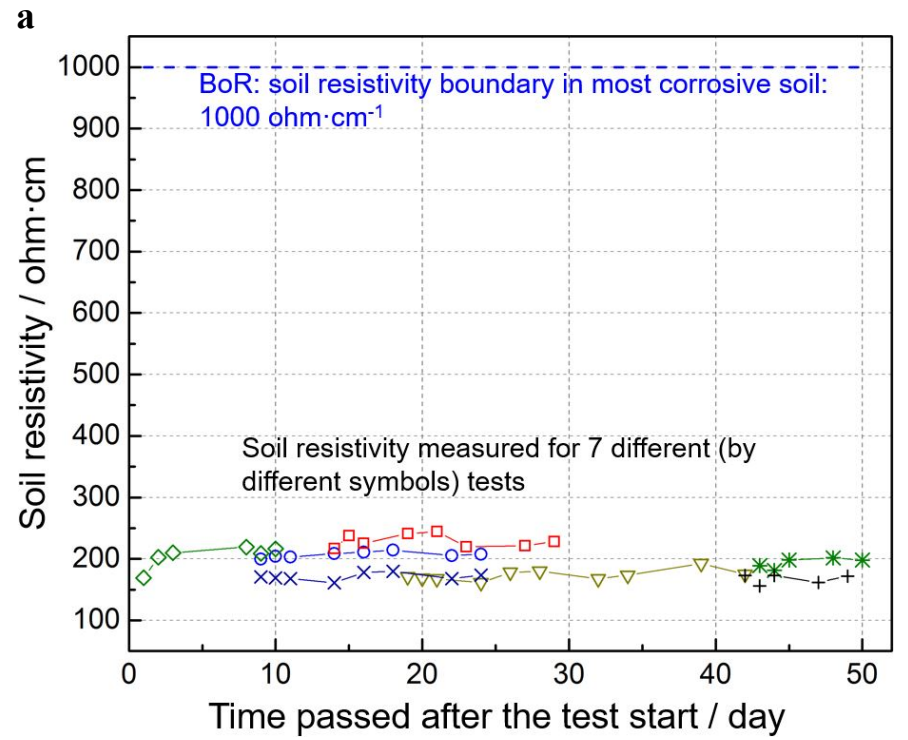

b

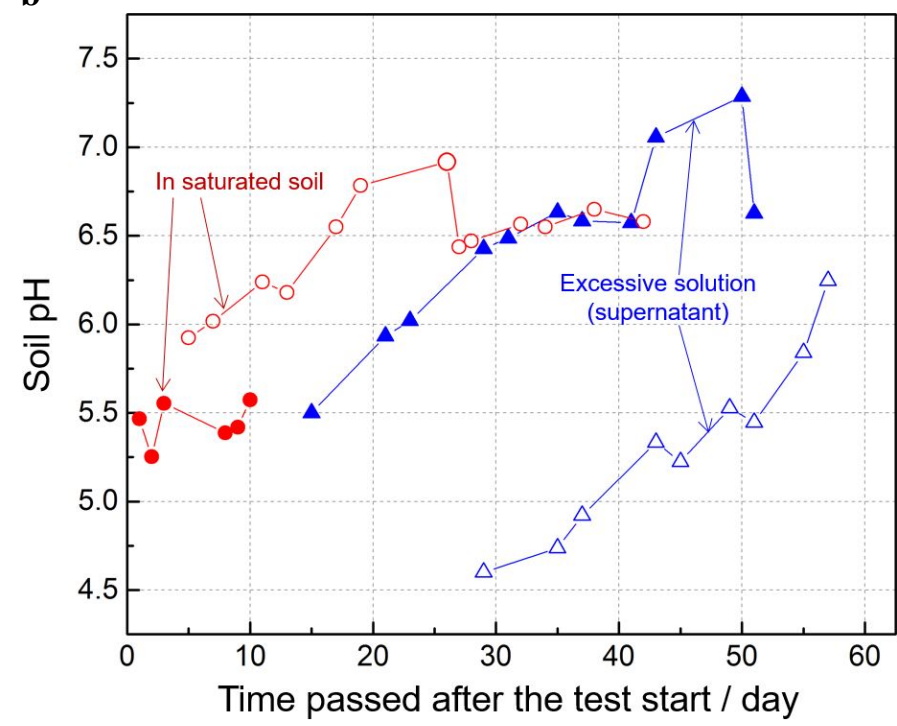

Figure 5.14. Monitoring of measured (a) resistivity and (b) pH in saturated soil and excessive solution with increasing testing time.

\section{Extraction of soil-derived solution and immersion test}

The saturated soils after 30 day tests were filtered to collect soil extract. The soil extract contained soluble salts that originated from the soils as well as initially added salt to create a slightly different corrosive solution. Inductively coupled plasma-optical emission spectroscopy (ICP-OES) was conducted to reveal the concentration of $\mathrm{Mg}^{2+}, \mathrm{Ca}^{2+}, \mathrm{Cl}^{-}$, and $\mathrm{SO}_{4}{ }^{2-}$ in the soil extract. The analyzed ionic concentrations are compared with the concentration of salt solution initially added to soils in Table 5.4. The concentrations of $\mathrm{Mg}^{2+}, \mathrm{Cl}^{-}$and $\mathrm{SO}_{4}{ }^{2-}$ were similar in both solutions with $\mathrm{Ca}^{2+}$ detected in the soil extract. 
Table 5.4. The composition of soil extract and added salt solution

\begin{tabular}{lcccc}
\hline Concentration, $\mathrm{mM}$ & $\mathrm{Mg}^{2+}$ & $\mathrm{Ca}^{2+}$ & $\mathrm{Cl}^{-}$ & $\mathrm{SO}_{4}^{2-}$ \\
Soil extract (ICP-OES analyzed) & 38 & 8 & 47 & 49 \\
Added salt solution & $40 \sim 60$ & - & $28 \sim 46$ & $28 \sim 46$ \\
\hline
\end{tabular}

The corrosion of DIP and steel samples without solid soil particles was examined by immersing the samples in the soil extract for 30 days. The comparison of saturated soil and immersion tests could reveal the tortuosity effect of the solid soil particles which could limit the transport of dissolved gases and aqueous ions associated with corrosion. Bare Manufacturer A DIP and steel samples were placed separately in glass containers and immersed with $200 \mathrm{~mL}$ of soil extract. The mouth of the testing containers was covered by a polymer film with $\sim 6$ small pores to minimize evaporation but still expose the soil extract to air. A schematic of the immersion test using soil extract is shown in Figure 5.15.

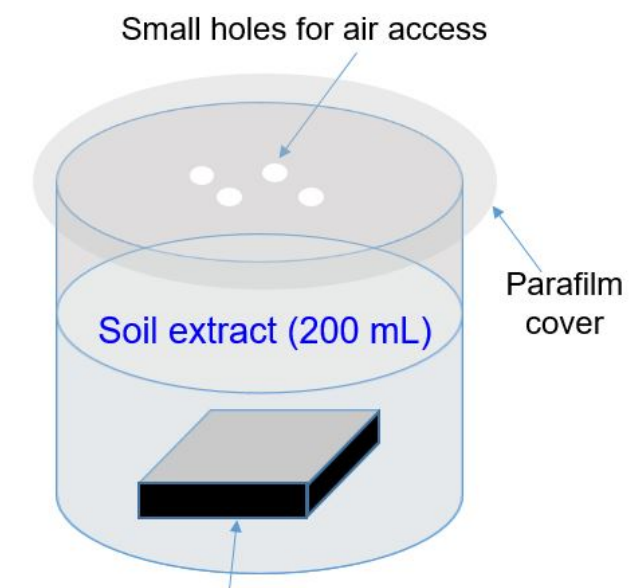

Bare DIP or Steel samples masked with black wax to expose only one surface

Figure 5.15. Schematic of immersion test for DIP and steel samples; the samples were immersed for 30 days.

\section{Measurement of corrosion mass loss}

After soil burial and immersion tests, the DIP and steel samples underwent a post-cleaning process to remove corrosion products and pre-existing surface layers (oxide layer, asphalt and $\mathrm{Zn}$ coating). The postcleaning process included non-acid and acid treatments, and the details of the treatments are summarized in Table. 5.5. In most cases, the acid treatment was conducted first, followed by a non-acid treatment, and this sequence was repeated at least twice. For the first batch of specimens, the non-acid treatment was implemented first, followed by acid cleaning, but this was less effective. The appearance of DIP samples after non-acid cleaning is shown in Figure 5.16. For bare DIP samples, multiple black spots were observed on the surface (Figure 5.16a). Meanwhile, DIP samples with asphalt finish had red-tinted corrosion products on the surface (Figure 5.16b). The black spots on corroded DIP samples were mostly removed after acid cleaning as shown in Figure 5.17.

To estimate the corrosion mass loss of liquid-epoxy-coated DIP samples, the sample mass before epoxy coating was measured first for the initial mass. After the soil tests, the epoxy coating was removed by methylene chloride (also called dichloromethane), and the sample mass without the epoxy layer was measured for the final mass. The difference between the initial and final masses was considered as the corrosion mass of DIP under simulated FBE protection. Similarly, the sample mass was measured without polyethylene bags before and after the soil tests to estimate the corrosion mass loss of DIP under simulated PE condition. The mass change was measured on a Mettler Toledo model MS403S balance. 


\begin{tabular}{ll}
\hline & Procedure \\
\hline Non-acid & 1. Rinse in water for at least 2 min \\
cleaning & 2. Immerse in commercial rust remover (Evaporust) with ultrasonication for at least 3 min \\
& 3. Lightly rub with brush (avoid scratching the DIP substrate) \\
\hline Acid cleaning & 1. Immerse in $50 \%$ diluted stock HCl solution with $3.5 \mathrm{~g} / \mathrm{L}$ hexamethylene tetraamine for at \\
& \begin{tabular}{l} 
2. Rinse with running water for at least 5 min \\
\hline
\end{tabular}
\end{tabular}

a

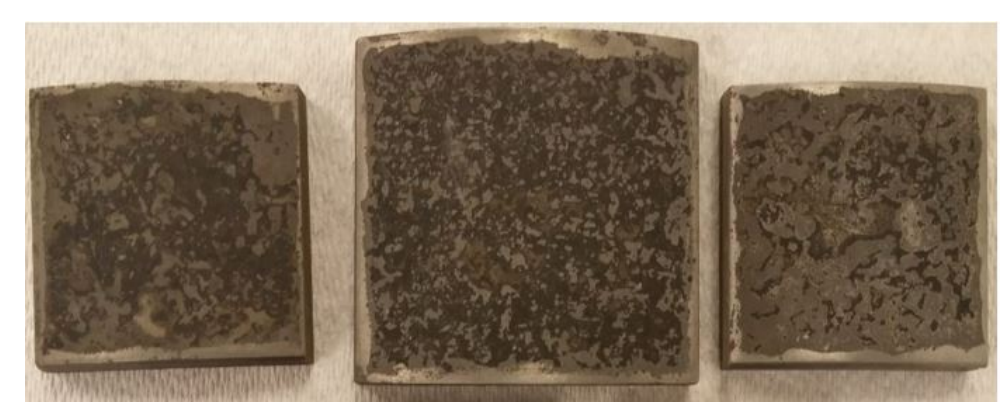

b

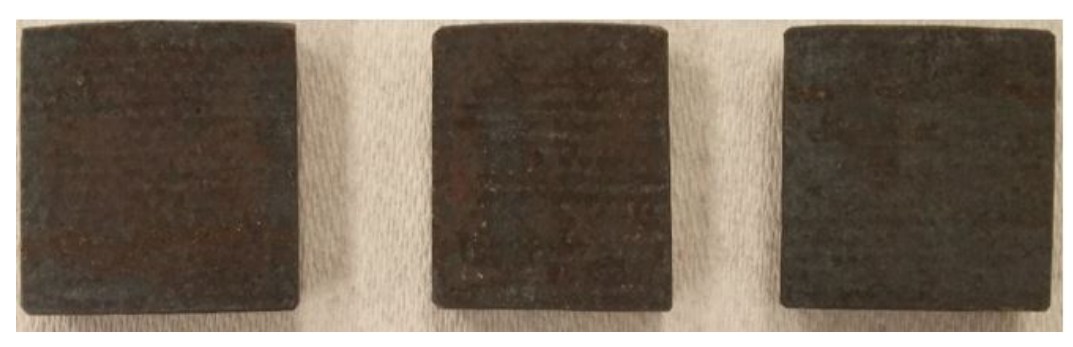

Figure 5.16. DIP samples after non-acid cleaning: (a) bare and (b) asphalt-coated; the sides of DIP samples are 3.5 to $5 \mathrm{~cm}$ long.

a

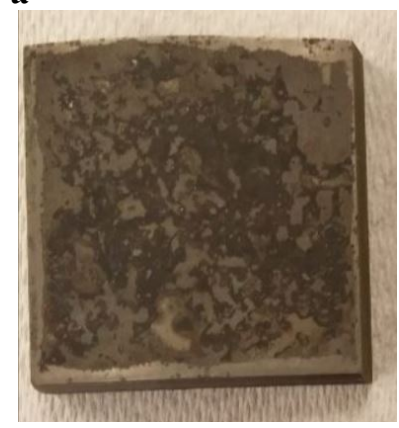

b

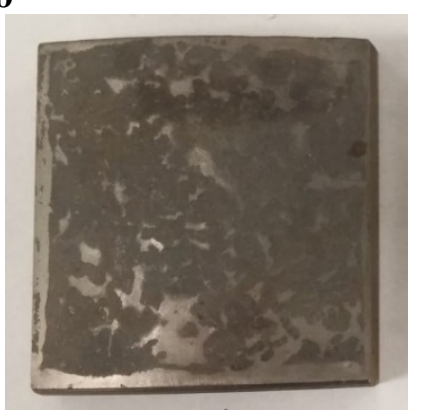

Figure 5.17. Manufacturer A DIP samples (pre-test condition: bare) cleaned by (a) non-acid cleaning and (b) non-acid + acid cleaning. The sides of DIP samples are $\sim 4.8 \mathrm{~cm}$ long. The mass loss resulting from the removal of the pre-existing surface layers was corrected by different methods, which are summarized in Table 5.6. The mass loss of the manufacturer oxide was difficult to estimate because the sample surface was not uniform, making the correct measurement of surface area very difficult. A conservative assumption that the mass loss resulted solely from DI loss was adopted for DIP samples with original annealing oxide, which did not need any correction. In asphalt-coated DIP specimens, the mass loss of the surface layer 
was measured by treating six non-exposed (not corroded) samples with acid cleaning. This practice resulted in approximately $0.4 \%$ of mass loss in the samples. The correction of asphalt-coated DIP samples, therefore, was made by deducting $0.4 \%$ of the original mass from the measured mass loss. The Zn-coated sample with laboratory oxide underneath also was corrected by deducting the mass of a 100 $\mu \mathrm{m}$ thick $\mathrm{Zn}$ layer and a $5 \mu \mathrm{m}$ thick oxide layer from the measured mass loss. The thickness of the laboratory-fabricated oxide was much less $(5 \mu \mathrm{m})$ than the average thickness measured in Section 2.4

$(60 \sim 100 \mu \mathrm{m})$ because of oxide spallation (Figure 5.1).

Table 5.6. Correction of mass loss for different sample conditions.

\begin{tabular}{ll}
\hline Pre-existing surface layer & Correction \\
\hline Manufacturer oxide & No correction was made \\
\hline Asphalt + manufacturer oxide & $\begin{array}{l}0.4 \% \text { of original mass was deducted from measured mass loss. } \\
\text { Correction equation: } \\
\text { (Original sample mass } \times 0.996)- \text { sample mass measured after test }= \\
\text { corrected corrosion loss }\end{array}$ \\
\hline Zn coating + lab. oxide & $\begin{array}{l}\text { Assumed } 100 \mu \mathrm{m} \text { thick } \mathrm{Zn} \text { layer and } \sim 5 \mu \mathrm{m} \text { lab oxide was removed: } \\
\text { Zn layer removal }=0.01 \mathrm{~cm} \times \mathrm{Zn} \text {-covered surface area } \times 7.3 \mathrm{~g} \mathrm{~cm}^{-3} \\
\\
\text { Lab oxide removal }=5 \times 10^{-4} \mathrm{~cm} \times \text { sample surface area } \times 5.4 \mathrm{~g} \mathrm{~cm}^{-3} \\
\\
\text { Correction equation: } \\
\text { Original sample mass }-(\mathrm{Zn} \text { layer removal }+ \text { laboratory oxide removal } \\
+ \text { sample mass measured after test })=\text { corrected corrosion loss }\end{array}$ \\
\hline
\end{tabular}

\subsection{ACCELERATED CORROSION TEST IN AGGRESSIVE SOIL MIXTURE: MASS LOSS}

\section{Bare DIP and steel samples}

Corrosion mass loss of bare DIP and steel samples is compared in Figure 5.18. The mass loss of bare Manufacturer B DIP did not significantly change with exposure time, suggesting that the corrosion attack on the sample was concentrated in the initial 10 days but then significantly reduced during further exposure. The reason for the severe initial corrosion could be due to the highly corrosive saturated soil (characterized by low resistivity in Figure 5.14). After this initial intensive corrosion, DIP samples could form thick corrosion products that limit the progress of corrosion. Further investigation is needed to prove this hypothesis. The mass loss of the steel specimens only increased slightly with time, similar to the Manufacturer B DIP. For the 30 day soil tests, the mass loss of the DIP specimens was larger than for the steel samples in most cases, with wider scatter for the Manufacturer A and B DIP specimens. The mass loss data of bare DIP samples can be compared to results from different protection strategies to assess their effectiveness in mitigating corrosion. 


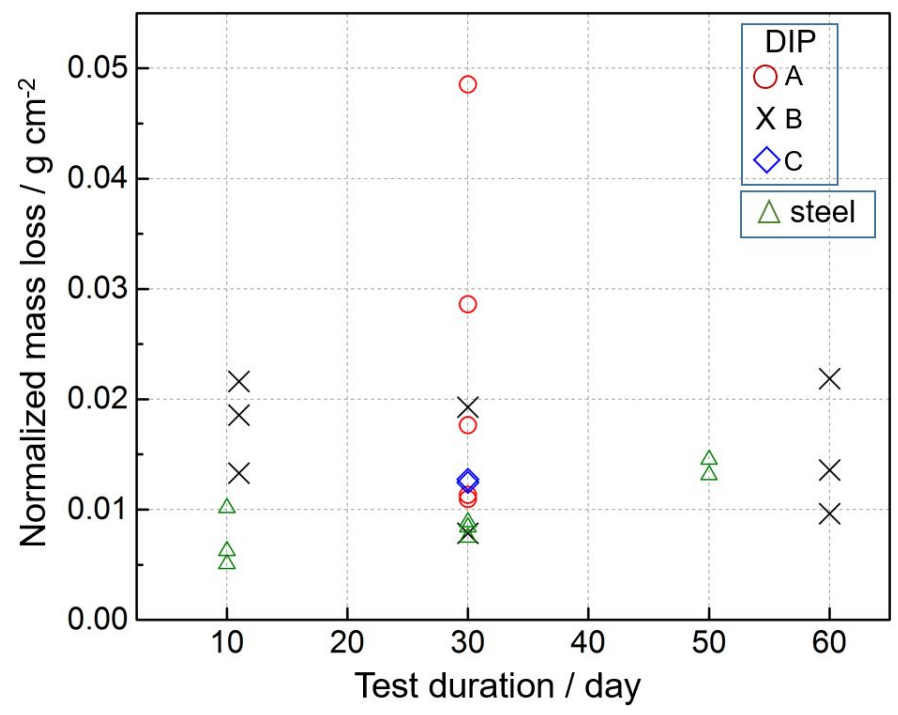

Figure 5.18. Normalized mass loss of bare DIP and steel samples with increasing test duration.

The mass loss of bare DIP and steel samples in different corrosive conditions are compared in Figure 5.19. A large scatter in mass loss after 30 days was observed for the DIP specimens in saturated soil and immersion tests, which makes it difficult to evaluate the effect of concentration (vs. deionized [DI] water), temperature variation (from outdoor exposure), and soil tortuosity (vs. immersion). Steel samples showed a much smaller data scatter. The mass loss of steel was not significantly different in salt solutionsaturated and DI water-saturated soils but was somewhat larger in immersion tests. Overall, the effects of environmental factors associated with the salt concentration, temperature, and soil tortuosity did not seem to influence corrosion damage significantly in these accelerated tests.

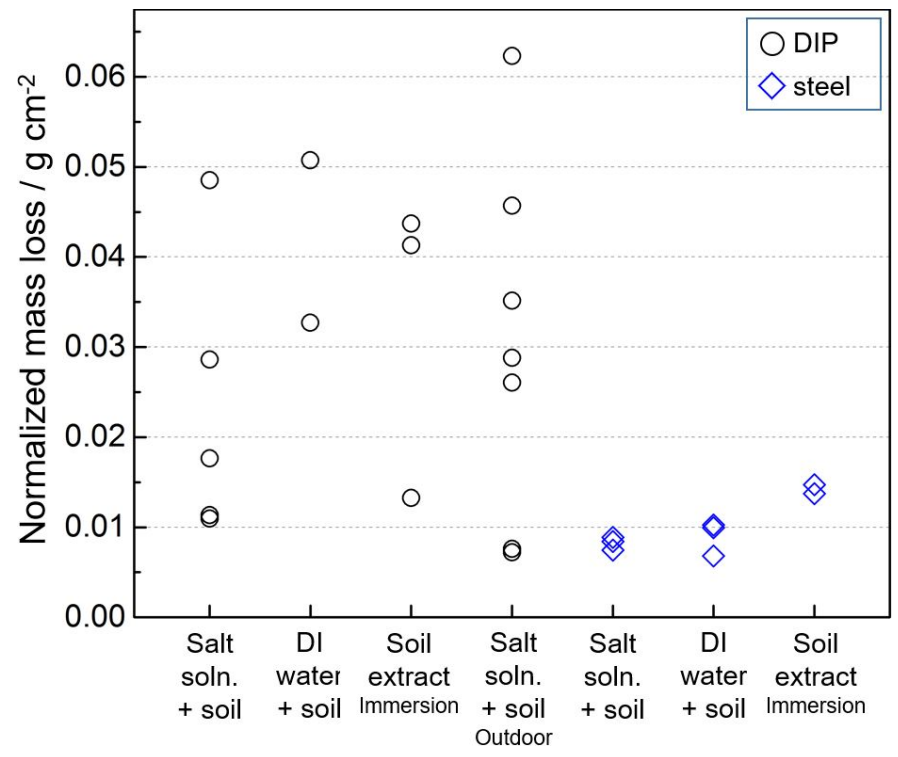

Figure 5.19. Normalized mass loss of bare DIP and steel samples after 30 day tests in different conditions.

\section{DIP with manufacturer (annealing) oxide, asphalt finish and Zn coating}

The mass loss of DIP samples with manufacturer (annealing) oxide are plotted in Figure 5.20, showing no distinctive change in mass loss with increasing time. DIP samples with oxides exhibited mass loss comparable to the lowest mass loss measured in bare DIP (shaded region). This could suggest that the 
oxide layer slowed the progress of corrosion and prevented severe mass loss. A previous study that utilized an electric resistance (ER) probe to estimate mass loss by corrosion showed that the increase of mass loss with time was considerably smaller in oxide-covered DIP than in bare samples (Bell 2007). The mechanism of how the surface oxide reduces corrosion is not yet clear. Further collection of data from well designed and controlled experiments is needed to further study the role of this surface oxide in retarding corrosion.

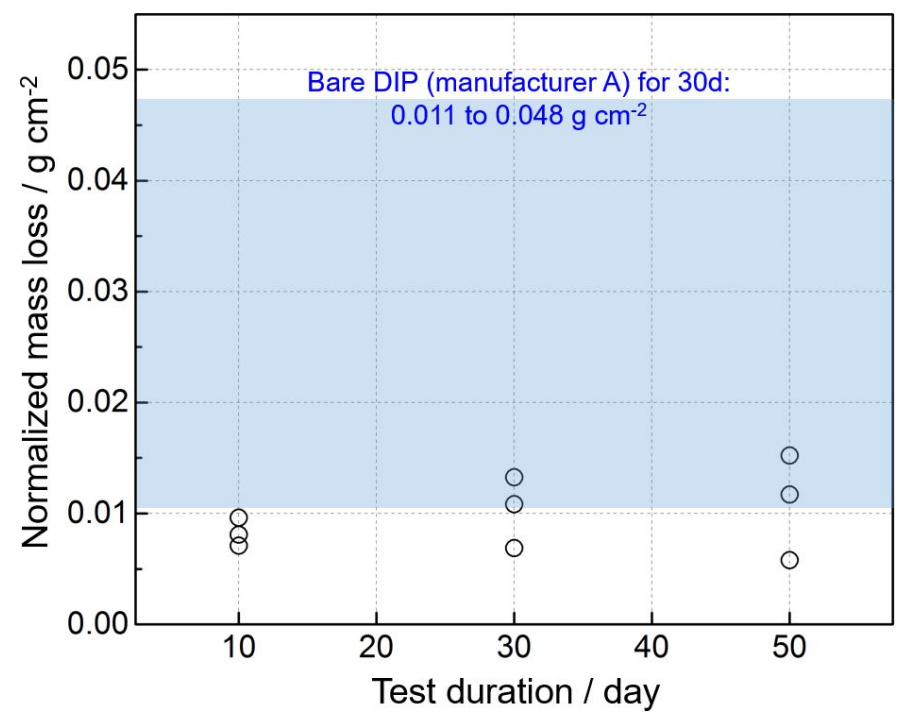

Figure 5.20. Normalized mass loss of Manufacturer A DIP with manufacturer (annealing) oxide. Shaded region indicates the distribution of mass loss measured in bare DIP.

The mass loss of DIP with an asphalt finish and underlying oxide is compared with bare samples in Figure 5.21. The mass loss of DIP with asphalt and oxide was not time-dependent but was greater than that for bare DIP, which was not expected. This suggests that the correction made to estimate the mass loss may not be accurate or that the scatter in the data is larger than expected. Additional work is needed to study this issue.

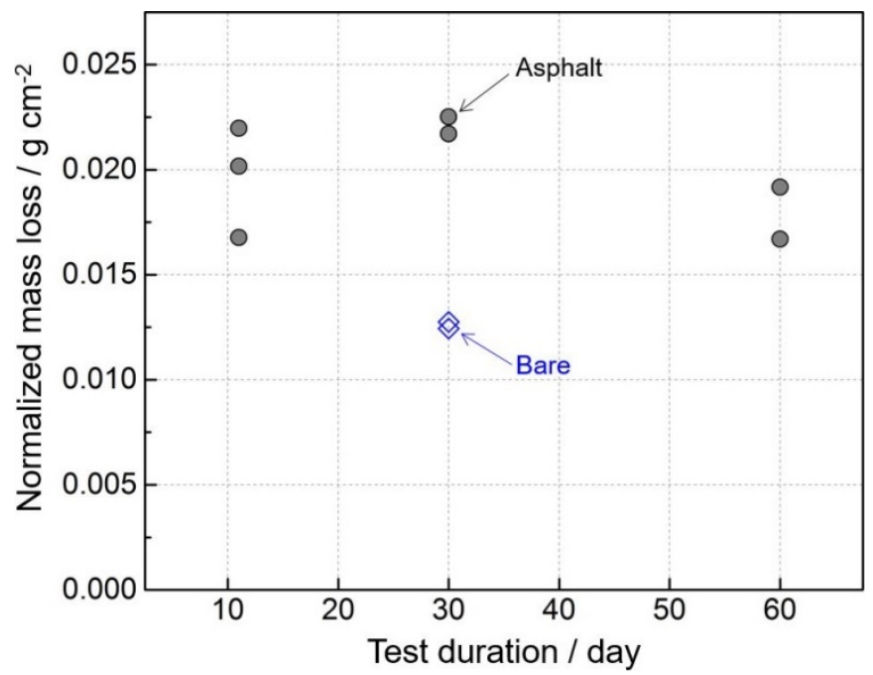

Figure 5.21. Normalized mass loss of DIP (Manufacturer C) in bare and as-manufactured (asphalt + oxide) conditions. 
The mass losses of DIP with pristine and damaged zinc coatings are compared with the average mass loss of bare samples in Figure 5.22. Recall that these samples had a zinc layer formed on laboratory-fabricated oxide. The DIP specimens with a damaged zinc layer (described in Figure 5.9) exhibited greater mass losses than bare samples. In contrast, the mass loss of the DIP specimen with a pristine Zn coating was only slightly smaller than the average mass loss of bare samples, implying that the protective behavior was not ideal. These results suggest that the zinc layer was limited to physical protection. Additional testing is needed with and without a fully adherent oxide layer to better understand the performance of the zinc layer in both cases.

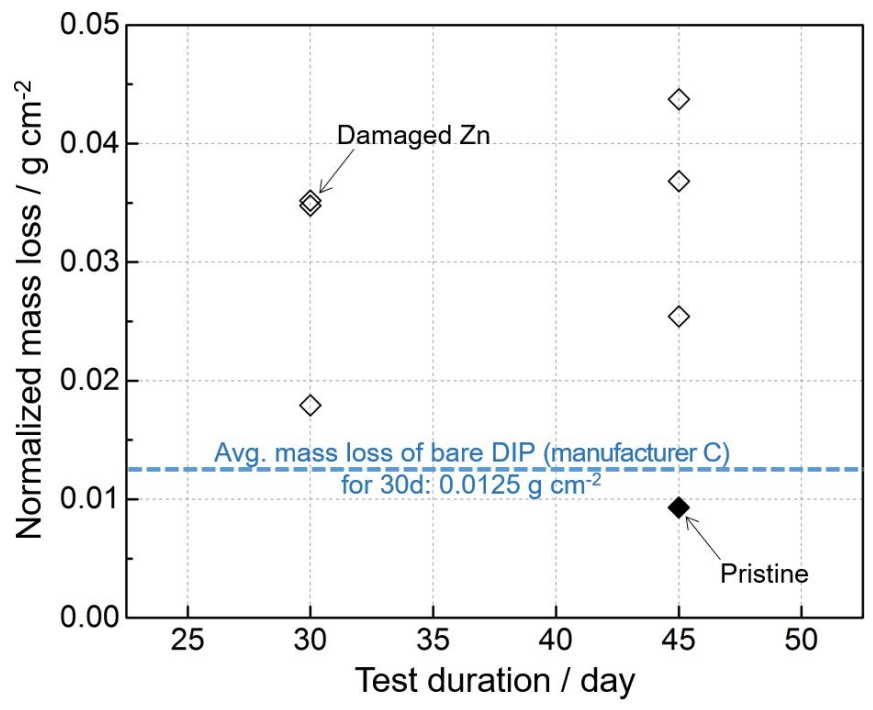

Figure 5.22. Normalized mass loss of DIP with pristine and damaged Zn coatings. The thick broken line indicates the average mass loss measured from bare DIP.DIP with simulated FBE coating and polyethylene encasement

The mass loss of DIP samples protected by polyethylene bags and liquid epoxy coating (which simulated PE and FBE coatings, respectively) are shown with the mass loss data from bare and Zn-coated DIP in Figure 5.23. The negative values of mass loss in liquid epoxy coated samples were due to remnants of the coating ( $>200 \mu \mathrm{m}$ found in Figure 5.10c) that were not completely removed. Inspection of DIP samples with simulated PE and FBE found no corrosion damage. There was no evidence of moisture permeation into the PE bag after the soil tests. Based on the results of mass loss and visual inspections, it can be concluded that these physical protections can significantly inhibit DIP corrosion by blocking the access of corrosive electrolytes to the underlying DIP specimens, at least for the relatively short time (10 days) of this experiment. It is possible that these physical barriers may eventually allow some permeation of corrosive electrolytes to the underlying DIP specimens. Further experiments with different PE scenarios (perfectly sealed, loosely sealed, and damaged) could be conducted in combination with other protective coatings ( $\mathrm{Zn}, \mathrm{FBE}$, etc.) to assess these various combinations. 


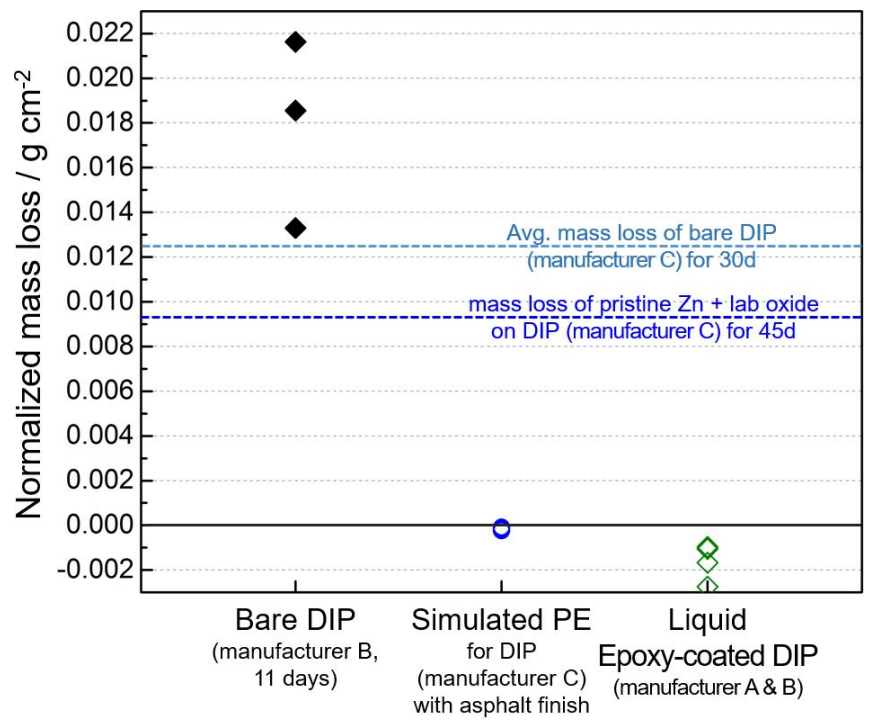

Figure 5.23. Normalized mass loss of DIP protected by simulated polyethylene encasement (PE) and liquid epoxy coating after the 10 day test. Mass losses of DIP in bare and pristine $\mathrm{Zn}$-coating conditions are also plotted/designated for comparison.

\subsection{ELECTROCHEMICAL TESTS: EXPERIMENTAL}

A schematic of the DIP and steel working electrodes used in this work are shown in Figure 5.24. Both DIP and steel samples were cut into circular coupons of 1.9 or $2.5 \mathrm{~cm}$ diameter (surface area of 2.9 or 5.1 $\mathrm{cm}^{2}$ ), and the coupons were welded with lead wires and mounted with epoxy. The electrode surfaces were polished to a 600 grit finish and thoroughly rinsed with DI water immediately before the experiment. Platinized (Pt-coated) metal wire and saturated calomel electrode (SCE) were used as counter and reference electrodes, respectively. A soil-simulating solution introduced previously (Zenati 2015) was chosen as a testing electrolyte, and its composition and measured conductivity are summarized in Table 5.7. The compositions of other soil-simulating solutions are found in the Appendix. Soil extract collected from saturated laboratory soil (described in Section 5.3) was also used for electrochemical measurement, and its composition and conductivity are also summarized in Table 5.7.

A schematic of the electrochemical cell used in this work is shown in Figure 5.25. The glass beaker containing $250 \mathrm{~mL}$ of soil-simulating solution or soil extract was open to air at room temperature. The working electrode surface faced upward, and the tip of the SCE was located $\sim 1 \mathrm{~cm}$ above the surface of the working electrode. The corrosion susceptibility of the samples was tested by using potentiodynamic and electrochemical impedance spectroscopy (EIS) techniques. For the EIS measurements, a box covered with aluminum foil was used to minimize measurement noise in the high frequency regime. Open circuit potential (OCP) was recorded for 30-60 min prior to all potentiodynamic and EIS measurements. This OCP delay allowed the DI or steel in testing solutions to reach electrochemical equilibrium. Details of the experimental parameters used for potentiodynamic polarization and EIS are described in the next section with the results. 


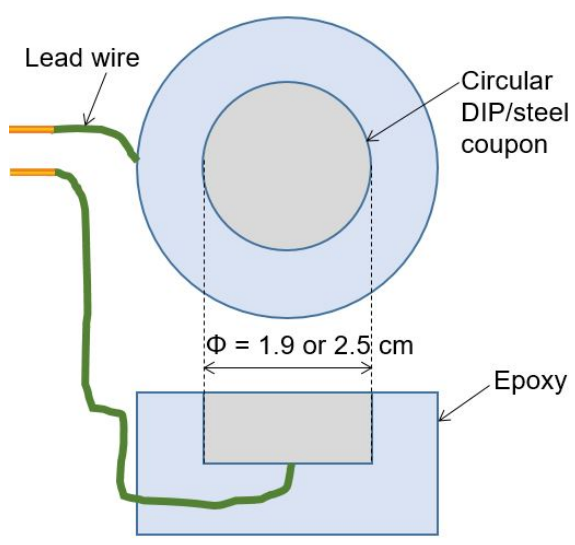

Figure 5.24. Schematic of epoxy-mounted ductile iron/steel electrode.

Table 5.7. Ionic concentrations of soil-simulating solution and soil extract

\begin{tabular}{ccc}
\hline \multirow{2}{*}{ Constituent } & \multicolumn{2}{c}{ Concentration (mM) } \\
\cline { 2 - 3 } & Soil-simulating solution & Soil extract (from Table 5.4) \\
\hline $\mathrm{Mg}^{2+}$ & 240 & 38 \\
$\mathrm{Ca}^{2+}$ & 15 & 8 \\
$\mathrm{Na}^{+}$ & 918 & Unknown \\
$\mathrm{K}^{+}$ & 21 & Unknown \\
$\mathrm{Cl}^{-}$ & 388 & 47 \\
$\mathrm{SO}_{4}^{2-}$ & 530 & 49 \\
Measured conductivity $\left(\mathrm{mS} \cdot \mathrm{cm}^{-1}\right)$ & 11.75 & 7.94 \\
\hline
\end{tabular}

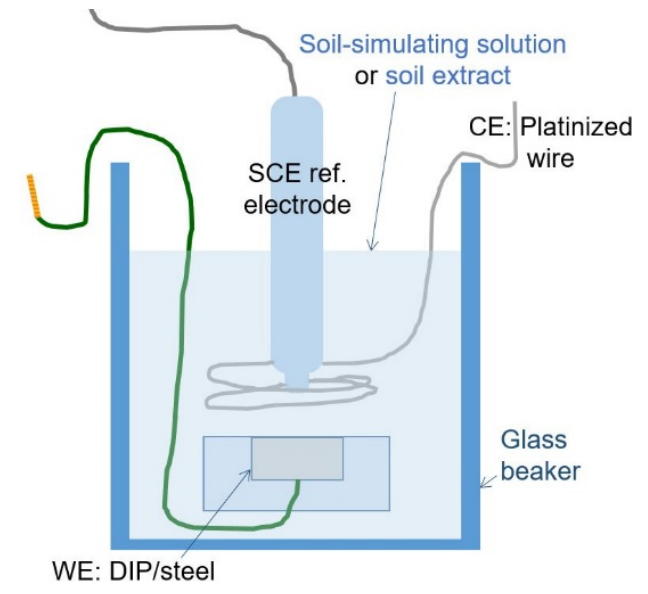

Figure 5.25. Configuration of electrochemical cell.

\subsection{ELECTROCHEMICAL TESTS: RESULTS}

The focus of this section is to compare corrosion susceptibility of bare DIP and steel samples in soilsimulating solution and soil extract. Linear polarization (LP) and EIS techniques were utilized to determine Tafel slopes, corrosion current and polarization resistances, which are associated with the corrosion rate of bare DIP and steel. The time dependency of polarization resistance in DIP and steel is also discussed. 


\section{Tafel and polarization resistance analyses on potentiodynamic curves}

Three potentiodynamic curves of different DIP samples were compared in soil-simulating solution as shown in Figure 5.26. Prior to these scans, DIP samples were polarized to $50 \mathrm{mV}$ below OCP with a scan rate of $0.167 \mathrm{mV} / \mathrm{s}$. Zero current potentials (ZCPs), at which the measured currents approached zero during the scan, are also designated in the figure. The ZCP of DIP samples varied within $40 \mathrm{mV}$, which is not significantly different. Anodic Tafel slopes estimated from two potential and current coordinates of each curve (also designated in Figure 5.26) were quite close to each other, indicating the anodic behavior of polarized DIP samples is similar for the three samples. Therefore, only one DIP sample (Manufacturer A) was chosen for further electrochemical tests.

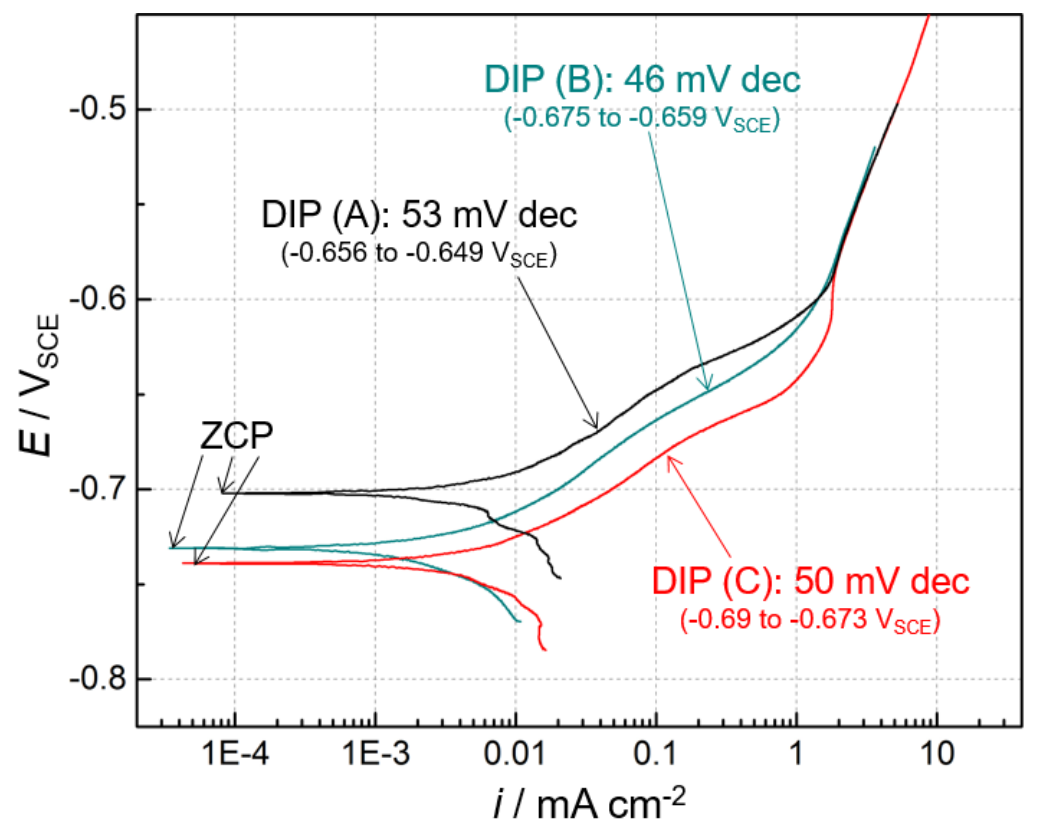

Figure 5.26. Linear polarization curves of DIP samples from all three manufacturers in soil-simulating solution; zero current potential and anodic slopes of each curve are denoted.

The anodic and cathodic behavior of metals can be sensitive to their polarization history and may not be reversible, leading to incorrect estimation of Tafel slopes. To check the reversibility of polarization, cyclic polarizations with anodic and cathodic peak potentials were conducted for DIP and steel samples with two different performance sequences as described in Figure 5.27. In the anodic first method, a cyclic scan with anodic peak potential was first conducted, which applied a net anodic charge before a cathodic cyclic scan (Figure 5.27a). The opposite was applied for the cathodic first method (Figure 5.27b).

The resulting potentiodynamic curves for DIP and steel samples are plotted in Figures 5.28a,b for the anodic- and cathodic-first methods, respectively. The same soil-simulating solution was used for these measurements. In the anodic-first method, the OCP values of DIP and steel decreased after the anodic cyclic scan, which deviated from the initial potentials of anodic and cathodic scans. This indicates that the corrosion reaction after the anodic scan was not reversible. In contrast, the initial potentials of anodic and cathodic cyclic scans had small deviation in the cathodic-first method, implying that the corrosion reaction was fairly reversible. Also notice that the anodic curves in the cathodic- and anodic-first methods are similar, which implies that the anodic kinetics of DIP and steel were not influenced by the cathodic scan. These reversible anodic and cathodic polarization curves allow more accurate estimation of corrosion current in the Tafel analysis. 
a

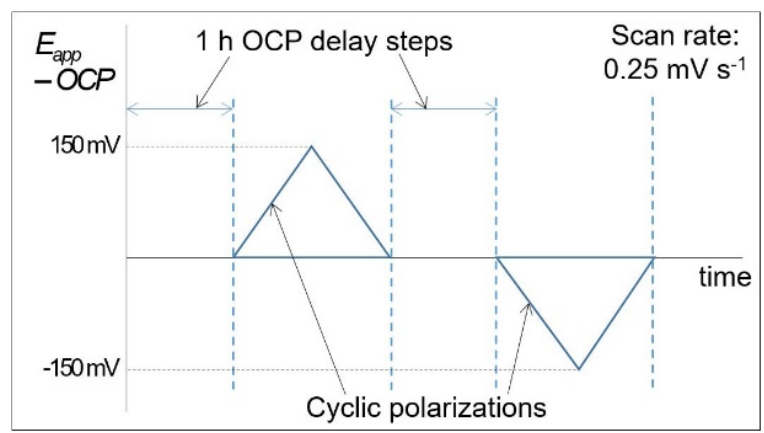

b

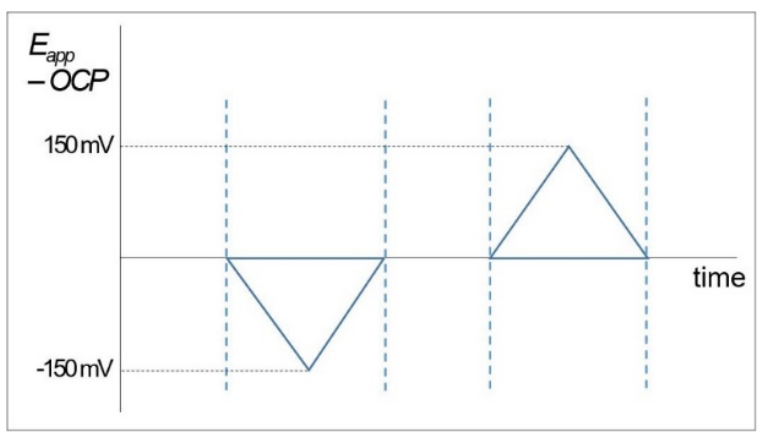

Figure 5.27. Two-step cyclic polarization with different sequence of performance: (a) anodic cyclic scan first and (b) cathodic cyclic scan first with peak potentials $150 \mathrm{mV}$ above and below OCP.

a

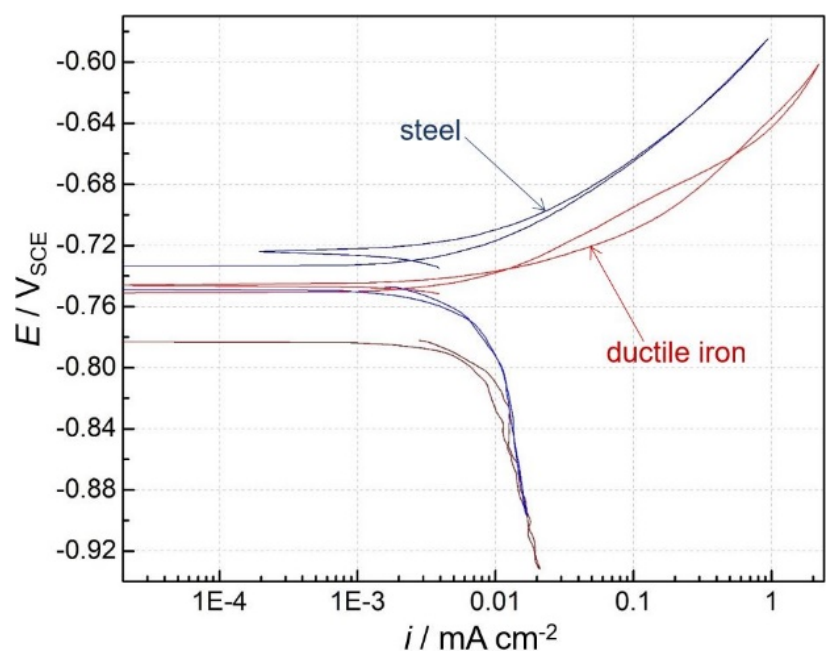

b

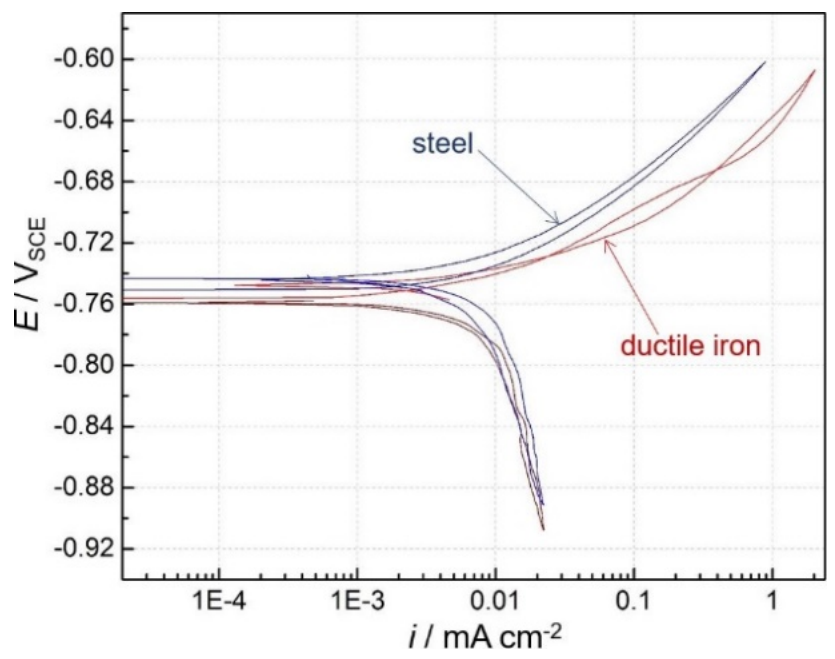

Figure 5.28. Comparison of cyclic polarization curves of DIP and steel in soil-simulating solution from performing the (a) anodic cyclic scan first and (b) cathodic cyclic scan first. 
To record highly reversible anodic and cathodic kinetics, DIP and steel electrodes were initially polarized downward to $150 \mathrm{mV}$ below OCP (cathodic scan) and subsequently polarized upward to $150 \mathrm{mV}$ above OCP, which gave full polarization curves including anodic and cathodic branches. This pre-cathodic polarization was adopted based on the result of the cyclic scans in Figure 5.28, which showed that the initial cathodic scan barely affected OCP and subsequent anodic kinetics. Applied potential versus time for this polarization technique is described in Figure 5.29a. Full polarization curves of DIP and steel after the initial cathodic scan are also shown in Figure 5.29b. These curves were collected using soil-simulating solution. The full polarization curves were analyzed using EC-Lab software to determine anodic and cathodic Tafel slopes as well as corrosion currents. A screenshot of software-assisted Tafel analysis is shown in Figure 5.29c. All data points selected for Tafel analysis were at least $40 \mathrm{mV}$ away from ZCP to minimize the interference of counter kinetics. In general, anodic interference offsetting some portion of the cathodic reaction is higher as the potential approaches ZCP in the cathodic branch.
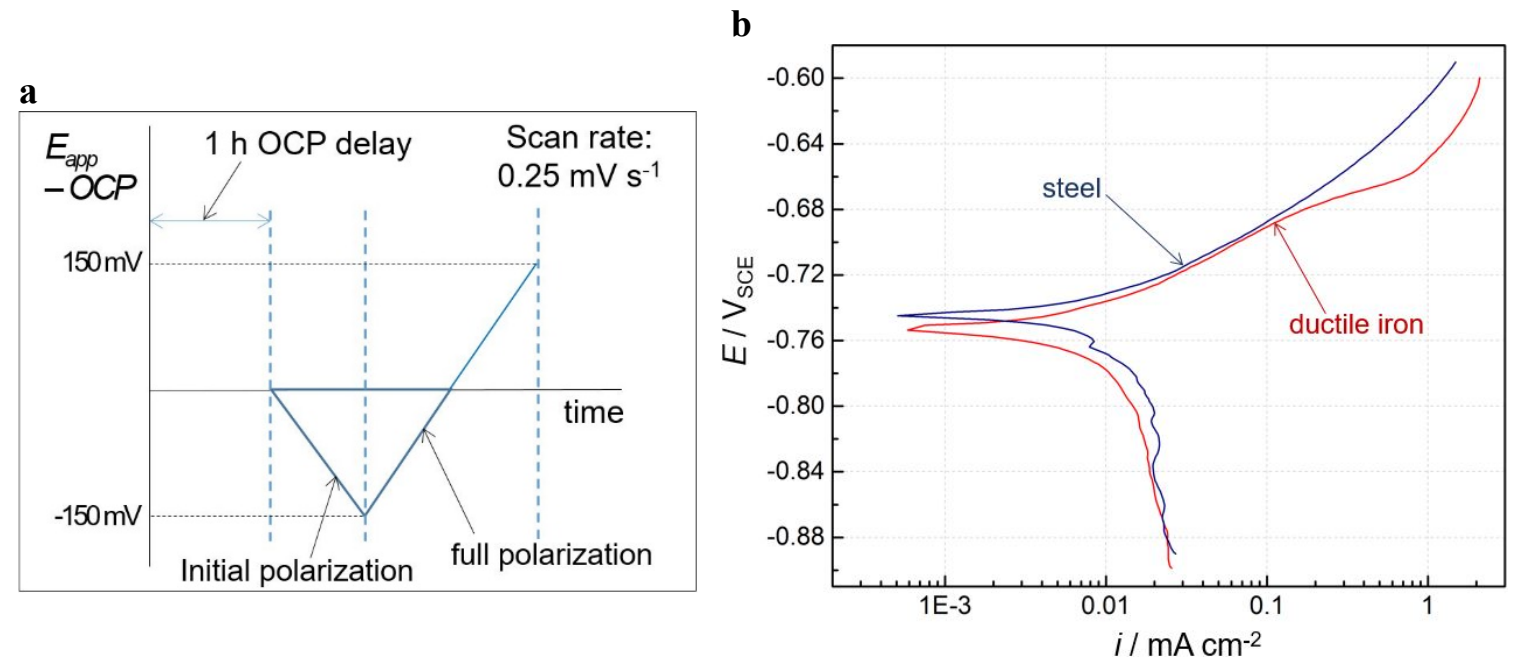

c

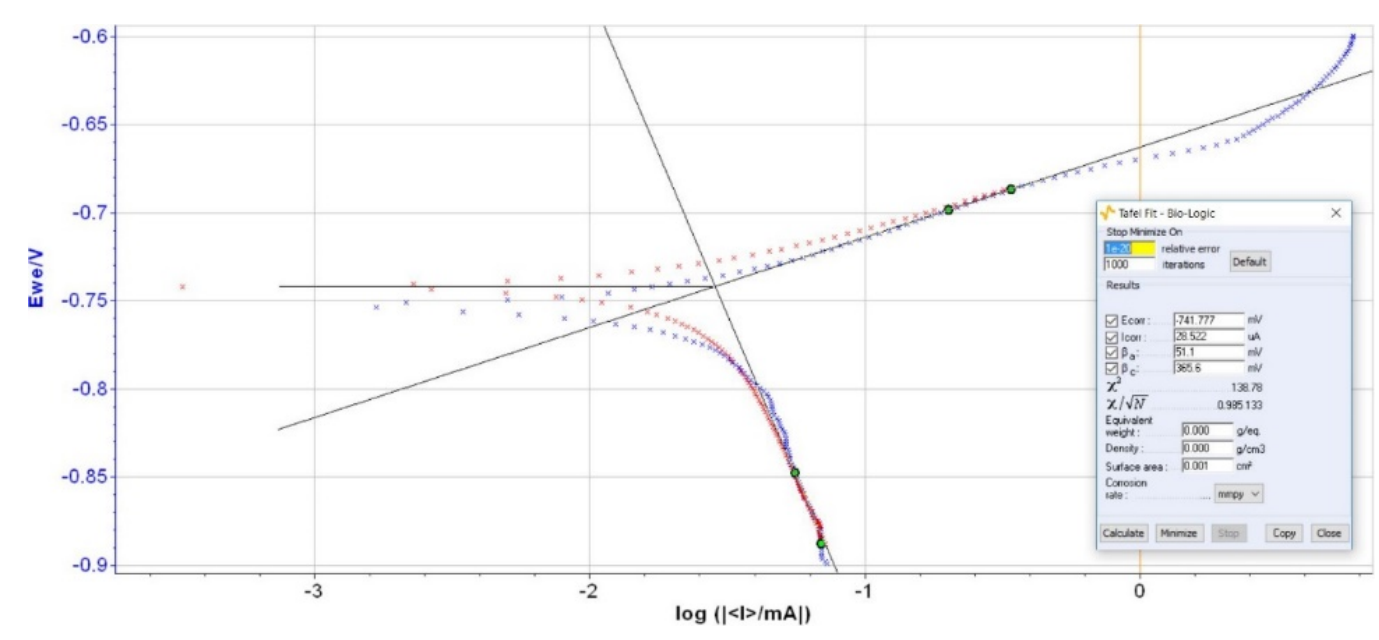

Figure 5.29. Full polarization curve with after cathodic polarization for Tafel analysis: (a) applied potential vs time plot showing initial and full polarizations, (b) full polarization curves of DIP and steel in soilsimulating solution, and (c) snapshot of Tafel analysis assisted by EC-Lab software.

Anodic and cathodic Tafel slopes in soil-simulating solution are plotted for DIP and steel samples in Figure 5.30. A common unit of Tafel slopes is millivolts per decade $(\mathrm{mV} / \mathrm{dec})$, which indicates the potential required to increase current by 10 times. The deviation of anodic slopes $\left(b_{a}\right)$ in DIP and steel is 
less than $10 \mathrm{mV} / \mathrm{dec}$, but the values of $\mathrm{b}_{\mathrm{a}}$ in steel are slightly larger than in DIP (steel $\sim 70 \mathrm{mV} / \mathrm{dec}$, and DIP $\sim 45 \mathrm{mV} / \mathrm{dec}$ ). This difference of anodic slope, however, is not significant enough to cause a noticeable change in corrosion rates. Cathodic slopes $\left(b_{c}\right)$, on the other hand, showed wide deviation (up to $380 \mathrm{mV}$ in steel) with a steeper slope (larger than $280 \mathrm{mV} / \mathrm{dec}$ ) in both DIP and steel samples. These large slopes imply that the cathodic reaction, which would be mostly $\mathrm{O}_{2}$ reduction, is mostly limited by diffusion. In this case, the type of material (DIP or steel) has little effect on the cathodic slopes. To summarize, the anodic and cathodic kinetics associated with corrosion are not significantly different between DIP and steel in soil-simulating solution.

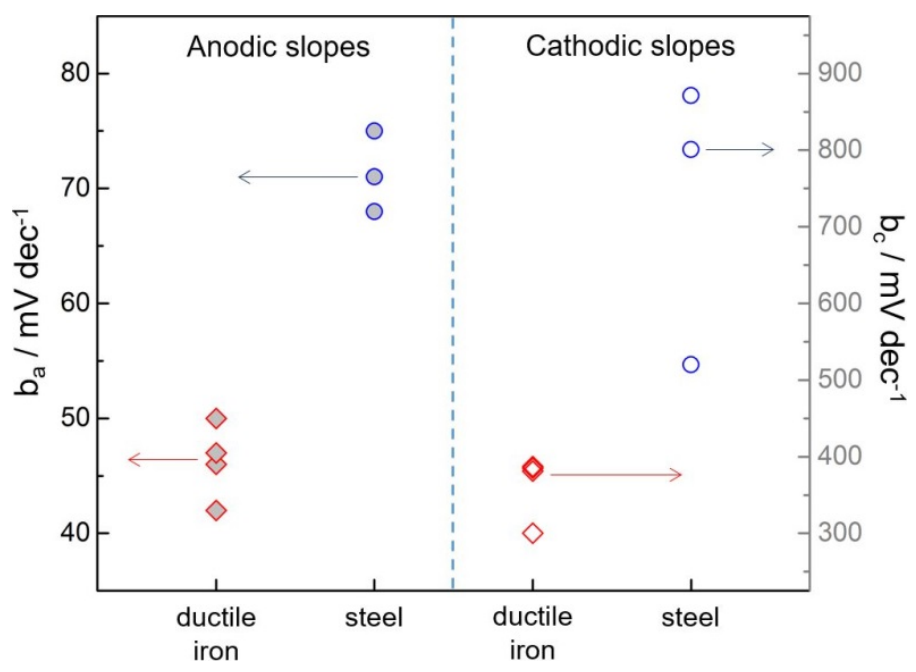

Figure 5.30. Anodic and cathodic Tafel slopes for DIP and steel in soil-simulating solution.

The effect of solution type on Tafel slopes of DIP is shown in Figure 5.31. In this case, the full polarization curves used for Tafel analysis were initiated from $200 \mathrm{mV}$ below OCP without an initial downward scan, meaning $200 \mathrm{mV}$ was stepped down at once. The upper limit of the scan was $200 \mathrm{mV}$ above OCP, and the scan rate was $0.25 \mathrm{mV} / \mathrm{s}$. The anodic slopes in soil extract were slightly larger than in the soil-simulating solution but they were not significantly different. The DIP cathodic slopes were above $240 \mathrm{mV} / \mathrm{dec}$ in both soil-simulating solution and soil extract, again indicating that the cathodic reaction is mostly controlled by diffusion. Thus, no effective difference in anodic and cathodic kinetics was estimated on DI in soil-simulating solution and soil extract. 


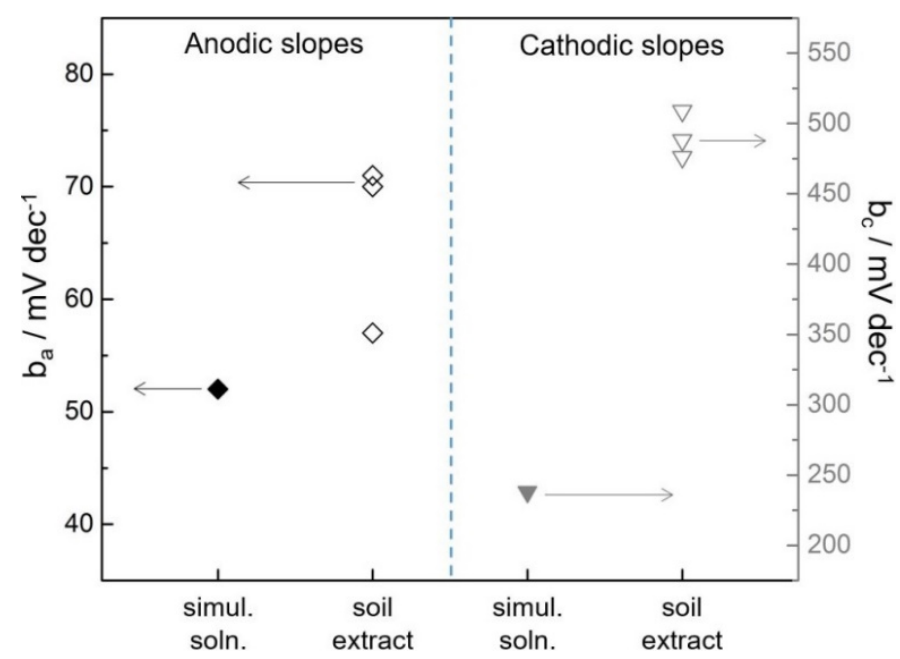

Figure 5.31. Anodic and cathodic slopes of DI in soil-simulating solution and soil extract. The full polarization curves for Tafel analysis were collected without initial cathodic polarization, and the scan range was $200 \mathrm{mV}$ below/above OCP.Software-assisted Tafel analysis also provided estimated corrosion currents, which are compared for different conditions in Figure 5.32. In soil-simulating solution, DI exhibited a lower corrosion rate than steel. The corrosion rate of DI was higher in soil extract than in soil-simulating solutions. This was unexpected because soil-simulating solution had a higher ionic concentration and conductivity as shown in Table 5.7. This may suggest a saturation in the corrosion rate, where the increasing ionic concentration and conductivity no longer contribute to corrosion kinetics. Instead, other organic and inorganic species that were not detected in the soil extract may have influenced the higher DI corrosion current. Further investigation is needed to specify the aqueous species in soil extract that may be causing a higher corrosion rate.

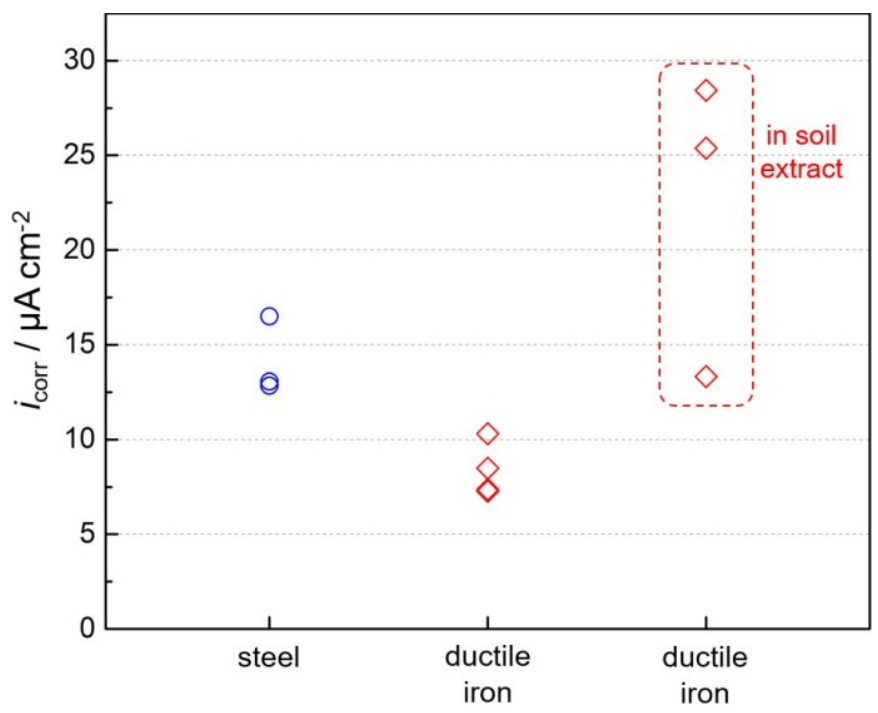

Figure 5.32. Corrosion currents of DIP and steel estimated by Tafel analysis in soil-simulating solution and soil extract. The data in the broken box are corrosion currents of DI in soil extract. Polarization resistances of DIP and steel were also estimated by EC-Lab software for the full polarization curves used for Tafel analysis. An example software-assisted estimation of polarization resistance is shown in Figure 5.33. Polarization resistance $\left(\mathrm{R}_{\mathrm{p}}\right)$ and corrosion current $\left(I_{\text {corr }}\right)$ are inversely proportional and correlated by the equation: 


$$
I_{\text {corr }}=\frac{1}{2.303 \cdot \mathrm{R}_{\mathrm{p}}} \times \frac{\left(\mathrm{b}_{\mathrm{a}} \cdot \mathrm{b}_{\mathrm{c}}\right)}{\left(\mathrm{b}_{\mathrm{a}}+\mathrm{b}_{\mathrm{c}}\right)}
$$

where $b_{a}$ and $b_{c}$ are the anodic and cathodic slopes as denoted previously. If the anodic and cathodic slopes are given, it is possible to calculate the corrosion current from the polarization resistance. Using Tafel slopes estimated for DIP and steel in different solutions (Figures 5.30 and 5.31), the corrosion currents based on polarization resistance are plotted in Figure 5.34. In the soil-simulating solution, the estimated corrosion currents are higher in steel than in DI. Also of note is that the corrosion current of DI is higher in soil extract than in soil-simulating solution. These are analogous to the trend of corrosion currents estimated by the Tafel analysis. The estimated corrosion currents by Tafel analysis and polarization resistance are directly compared in Figure 5.35. The corrosion rates are very close between the two methods, cross-validating each other.

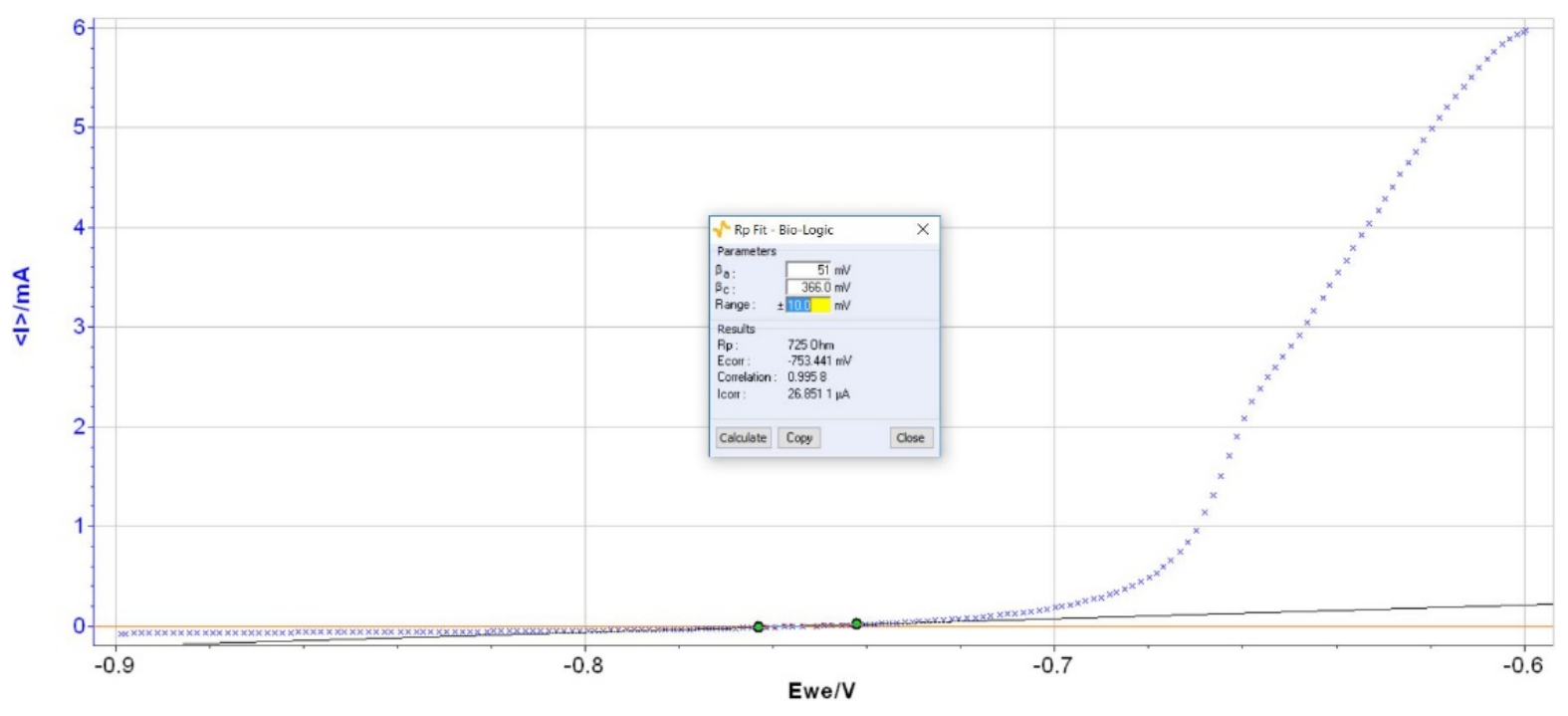

Figure 5.33. A snapshot of software-assisted estimation of polarization resistance in a full polarization curve of DI in soil-simulating solution. Note that the current scale is linear.

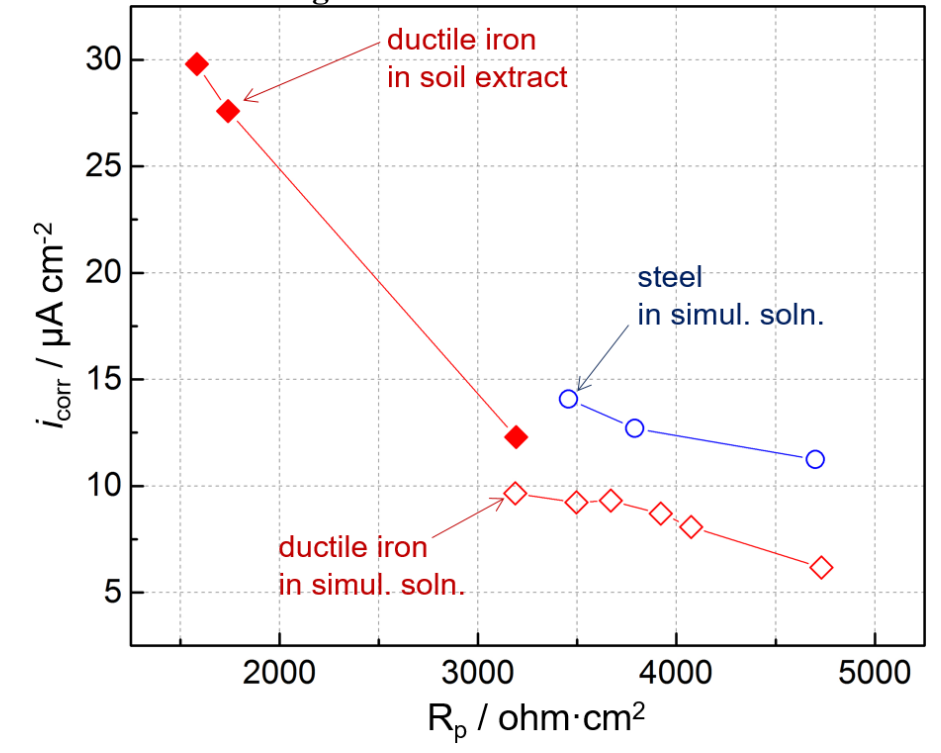

Figure 5.34. Estimated polarization resistance and corrosion current of DIP and steel in soil-simulating solution and soil extract. 


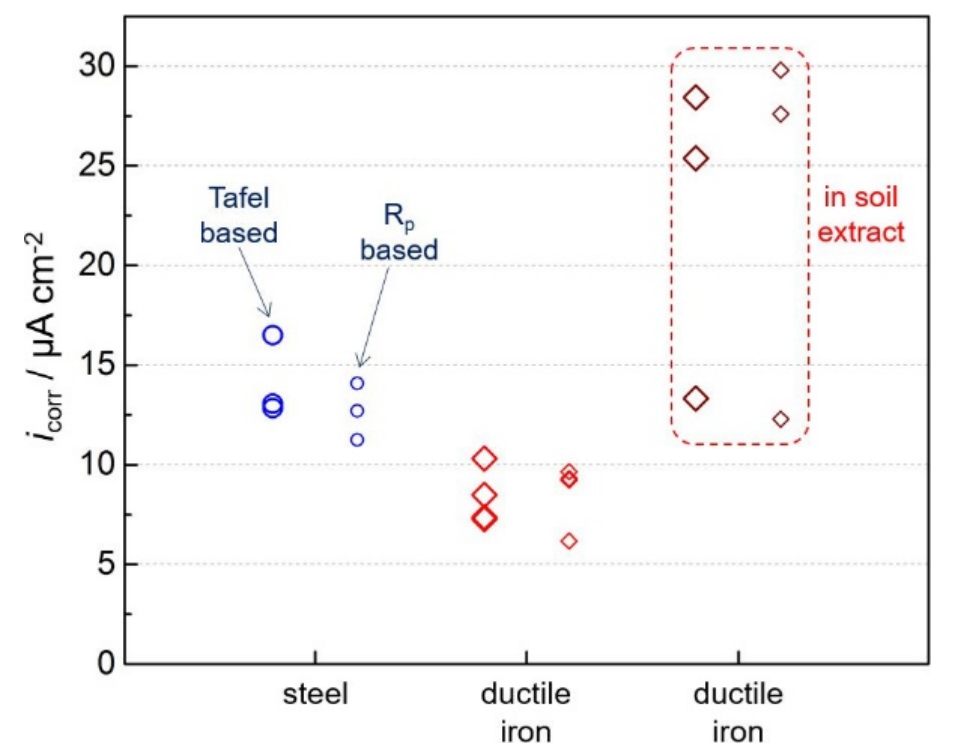

Figure 5.35. Comparison of corrosion currents estimated by Tafel- and polarization resistance-based analyses in soil-simulating solution and soil extract (data in the broken box).

\section{EIS measurement}

EIS measurements use a small perturbation of potential which minimizes the electrochemical disturbance on corroding metals. This allows long-term monitoring of naturally progressing (i.e., undisturbed) corrosion of metals. EIS data contain frequency-dependent impedance and phase shift which can be fitted to estimate the value of polarization resistance associated with anodic and cathodic reactions for corrosion. In this work, EIS measurements were conducted on DIP and steel samples to assess the timedependent change of polarization resistance in soil-simulating solution and soil extract. The ranges of high and low frequency limits for EIS were $1 \mathrm{MHz}$ to $800 \mathrm{kHz}$ and 10 to $1 \mathrm{mHz}$, respectively. The potential amplitude was $\pm 10 \mathrm{mV}$ against OCP, which was established after a $1 \mathrm{~h}$ delay.

Nyquist plots of DIP and steel samples measured after a $1 \mathrm{~h} \mathrm{OCP}$ delay are shown in Figure 5.36. These EIS measurements were conducted in the soil-simulating solution. In the plot, "day 0" indicates the data were collected on the date of test initiation. In this way, "day 1" denotes the data that were collected a day after the test initiation. The plots were characterized by a single depressed semicircle for both DIP and steel samples, implying that the corrosion interface can be described by a simple Randle circuit with a constant phase element (CPE). An equivalent circuit model of a Randle circuit with CPE is shown in Figure 5.37. $R_{s}$ and $R_{p}$ indicate solution and polarization resistances, and CPE $E_{d l}$ describes non-ideal capacitance of the double layer at the corroding metal and solution interface. Z-View software was used to fit Nyquist plots into Randle circuits with $\mathrm{CPE}_{\mathrm{dl}}$, which gave numerical values of solution and polarization resistances. Snapshots of Z-View fitting on a Nyquist plot of DI are shown in Figure 5.38. 


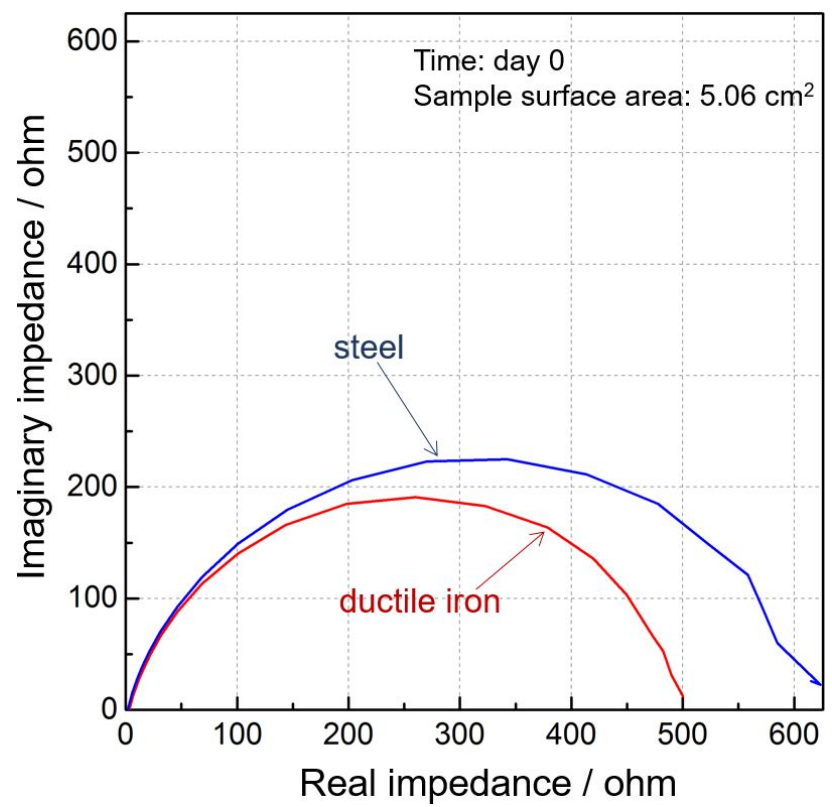

Figure 5.36. Nyquist plots of DIP and steel in soil-simulating solution.

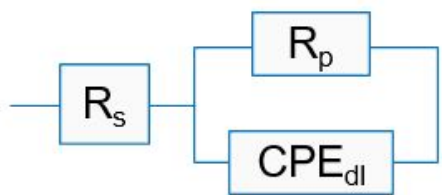

Figure 5.37. Randle circuit with constant phase element of double layer. 


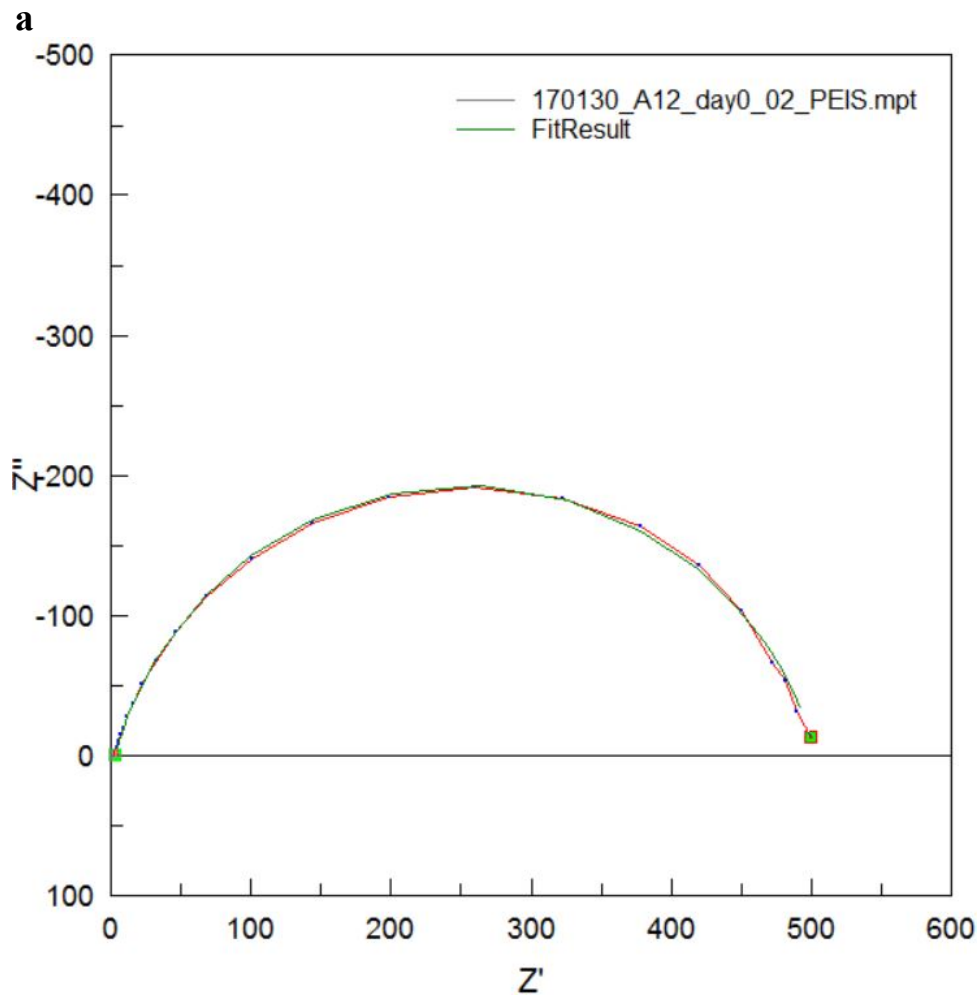

b
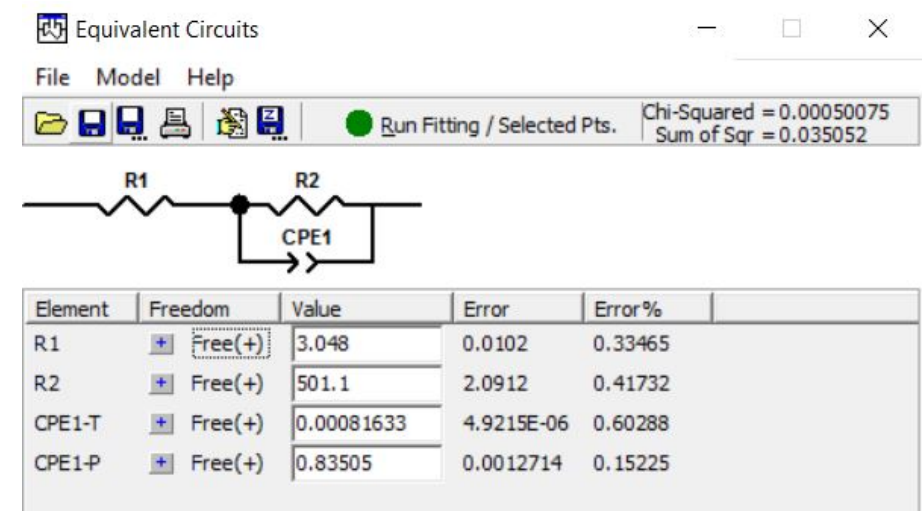

Figure 5.38. Software-assisted fitting of Nyquist plot: (a) a snapshot of fitted plot and (b) fitted values of circuit element.

Values of polarization resistance, determined by fitting day 0 EIS data or potentiodynamic curves, are plotted for DIP and steel in Figure 5.39. These polarization resistances are associated with the corrosion rate (or corrosion current) in the early stage of corrosion. As noted in Eq. (5.1), polarization resistance is inversely proportional to corrosion current. If the anodic and cathodic slopes are similar to each other in the testing conditions, lower polarization resistance indicates higher corrosion current. In soil-simulating solution, the polarization resistances of DIP and steel were not significantly different in most cases regardless of the fitting method, although the EIS-based estimation gave smaller values than potentiodynamic curves. 


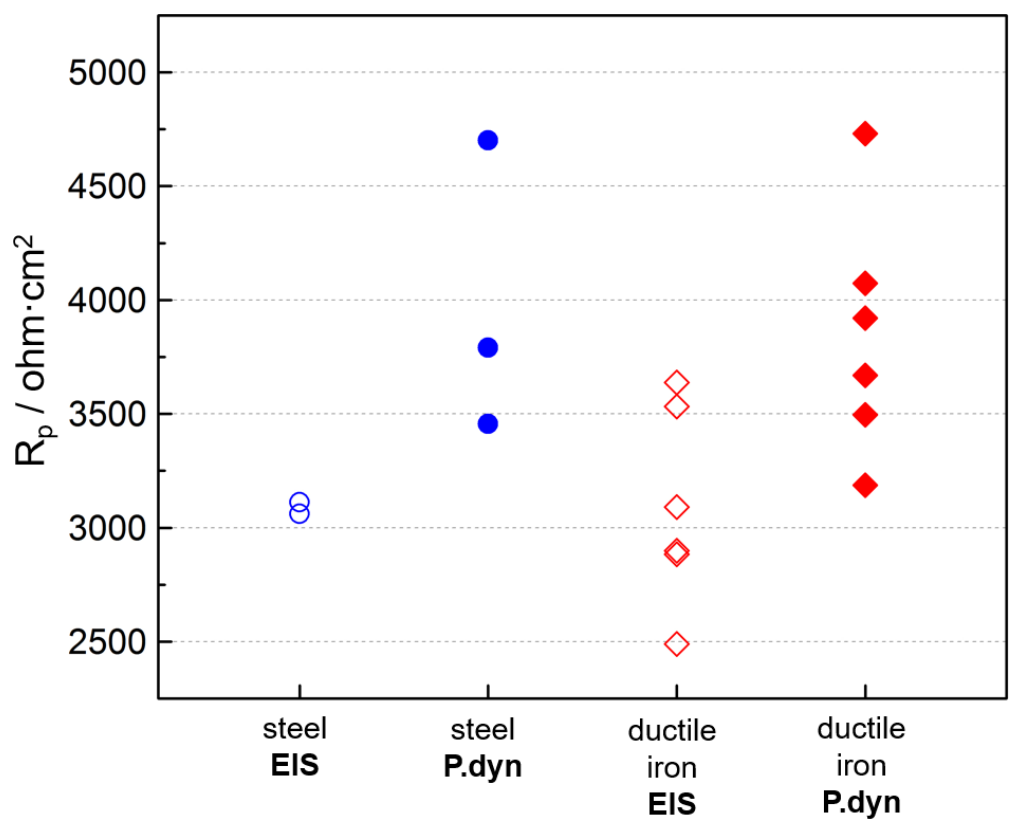

Figure 5.39. Polarization resistance of DIP and steel in soil-simulating solution determined by fitting: (a) Nyquist plots and (b) polarization curves from EIS and potentiodynamic (P.dyn) techniques.

Values of solution and polarization resistances with increasing time are plotted in Figure 5.40 for DIP and steel in the soil-simulating solution and soil extract. The solution resistance was higher in the soil extract than in the soil-simulating solution as shown in Figure 5.40a. This agrees with the results that the conductivity of soil extract was lower than that of the soil-simulating solution (Table. 5.7). The polarization resistance was lower in soil extract than in the soil-simulating solution, which implies that the corrosion current would be higher in soil extract if the anodic and cathodic slopes are similar in both solutions. This agrees with the higher corrosion current estimated from Tafel and polarization resistance analyses in Figure 5.35.

In the soil-simulating solution, values of polarization resistance increased with time, but they were within the distribution range of the initial polarization resistance until day 10, as shown in Figure 5.40b. This indicates that the corrosion rate of DI would not change much for the first 10 days in the soil-simulating solution. On day 15 , the polarization resistance was higher than the maximum value of day 0 , which could be associated with a decrease in corrosion current. A decrease in corrosion rate is generally related to the formation of a corrosion product layer, which could limit the transportation of ionic and gas species essential to the corrosion reaction. In soil extract, the polarization resistance of steel increased with time, which could lower the corrosion rate. On the other hand, the polarization resistance of DI in soil extract did not change significantly within 6 days. 


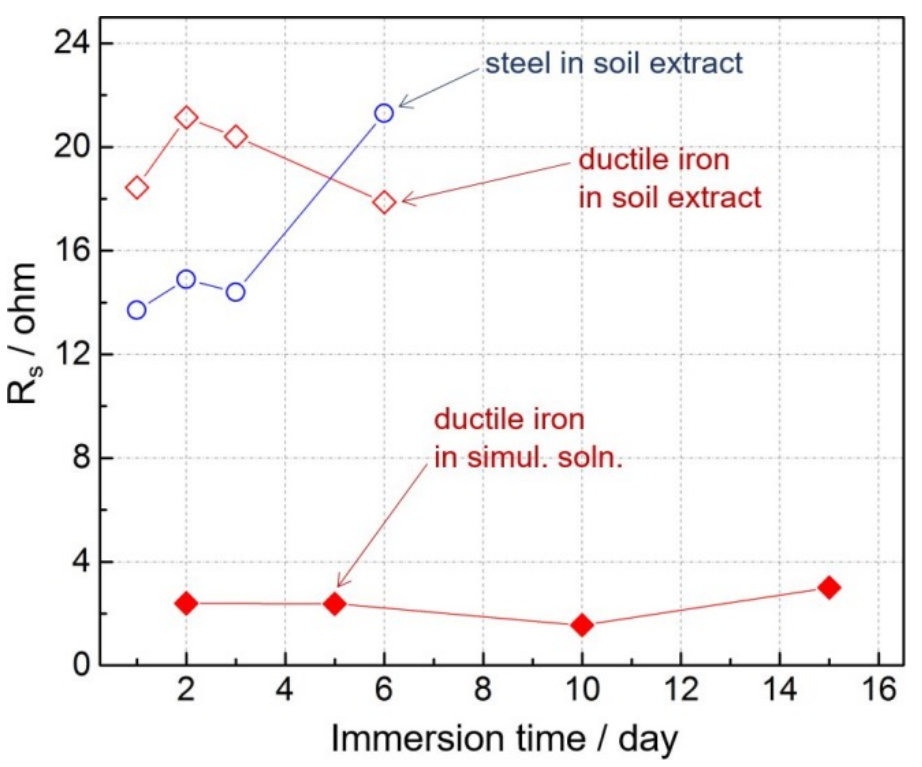

b

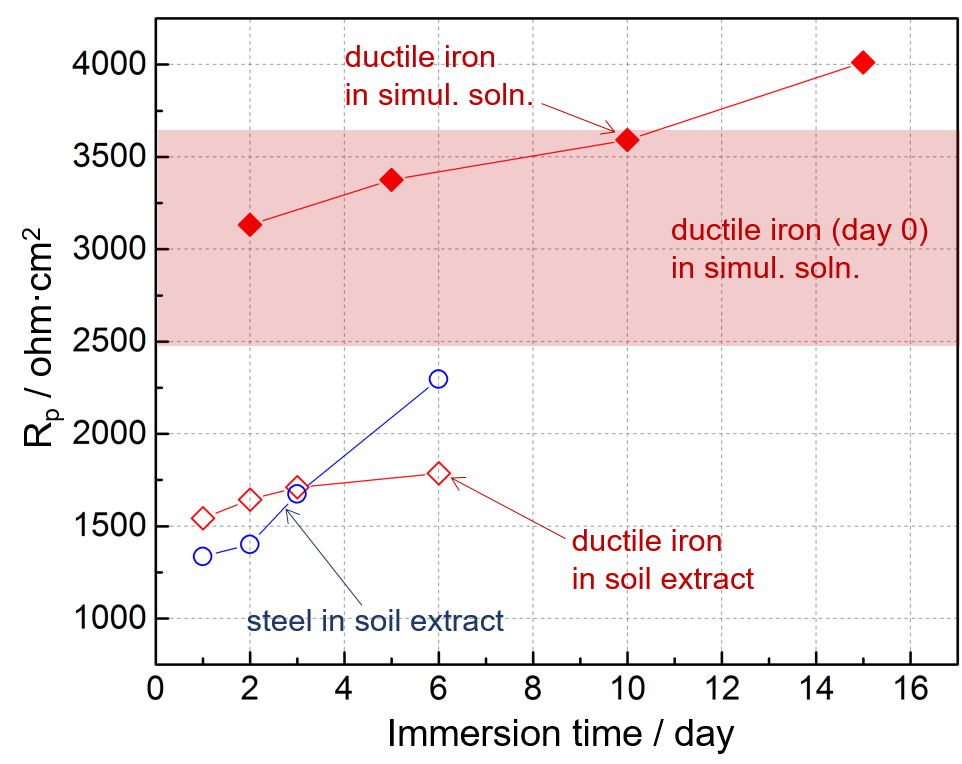

Figure 5.40. Fitted values of (a) solution and (b) polarization resistances with increasing immersion time. The shaded region in (b) indicates the distribution range of polarization resistance fitted for day 0 data.

\subsection{COMPARISON OF FIELD AND LABORATORY-SIMULATED SOIL CORROSION}

\section{Mass loss in field condition and accelerated laboratory tests}

The testing period for the mass loss data of 36 sites selected from the NBS study (in Figures 3.5 and 3.6) varied from 10 to 33 years. To narrow the variation in test period, a group of mass loss data with burial time of 20 to 22 years was chosen from the NBS data, which provided a total of 17 data points. The 17 selected NBS data points were linearly interpolated to estimate mass loss for 30 days, which is simply calculated by: 


$$
\text { Mass loss in } 30 \text { days }=\frac{\text { NBS mass loss data }(\text { from } 17 \text { sites })}{\text { NBS test period }(20 \text { to } 22 \text { years })} \times \frac{30}{365}
$$

The 30 day mass loss vs soil resistivity for the 17 NBS data points is plotted in Figure 5.41. These NBS data were considered as the estimated mass loss of buried ferrous pipes in corrosive field conditions. The average mass loss of DI samples after 30 days of saturated soil test (in this work) is compared with the average of the 17 NBS mass loss data (representing field conditions) in Figure 5.42. The comparison of the mass loss data shows that the accelerated tests designed in this study resulted in a 14 to 30 times increase in corrosion damage compared to the average of the selected field data. This result validates the approach taken in this work for an accelerated test method that would be maximized in fully saturated soils with salt solutions.

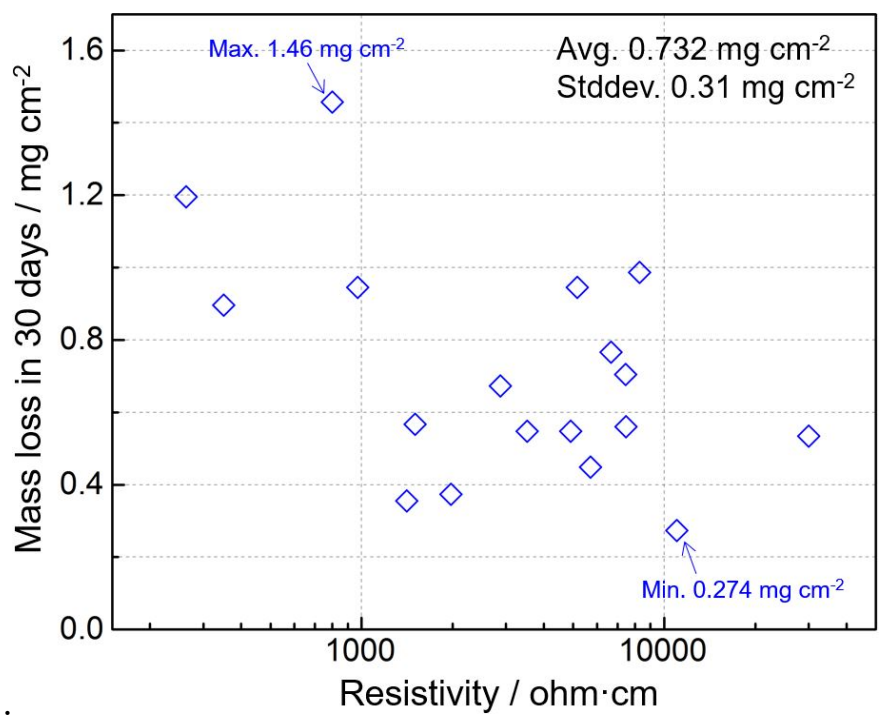

Figure 5.41. Mass loss vs soil resistivity plot of 17 data selected from the NBS corrosion dataset. The maximum value is more than 4 times larger than the minimum value. The average and standard deviation of all mass loss data are also noted on the plot. 


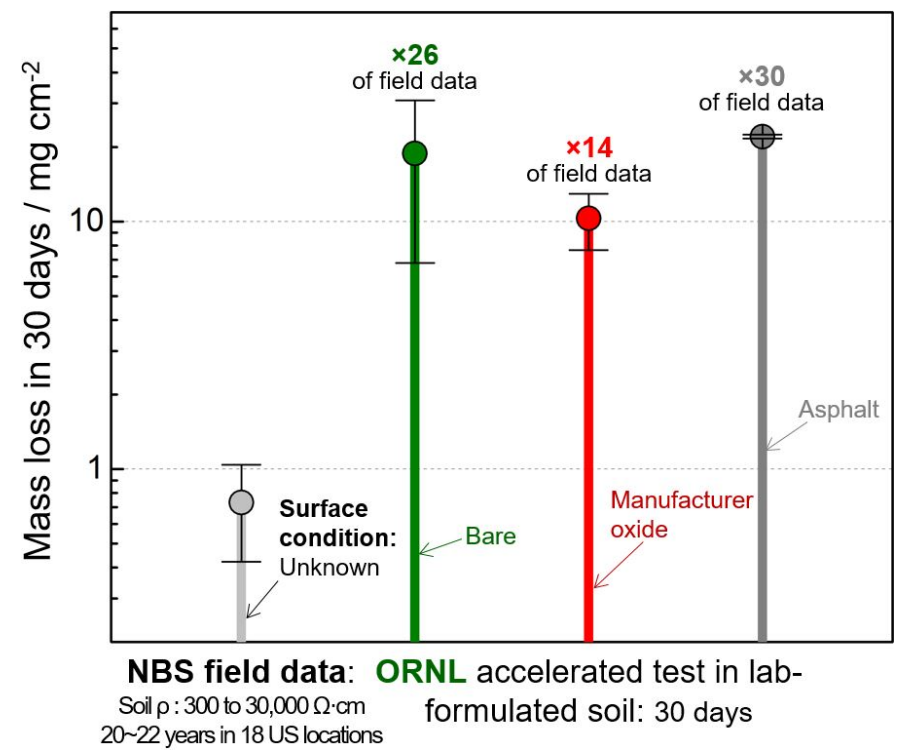

Figure 5.42. Comparison of 30 day mass loss values measured in this work (ORNL accelerated test) and estimated from NBS corrosion database.

The rate of mass loss in field soil and in a solution-based corrosion test are compared in Figure 5.43. The mass loss rate of bare DIP in soil extract and soil-simulating solutions was calcuated by converting the corrosion current presented in Figure 5.35. Meanwhile, the mass loss rate in field soil conditions was calculated using the average NBS data used in Figures 5.41 and 5.42 for ferrous pipes. Bare DIP samples in soil extrect and in soil-simulating solution exhibited 23 and 9 times higher corrosion rates than the average in field soil, respectively. In the solution-based tests, the entire surface of the DIP sample formed the corrosion interface at all times, which may not be possible in soil-buried pipes in field conditions. The presence of a corrosion interface in soil-buried pipes would not be continuous in field soils due to the fluctuation of soil humidity. This descrepancy could explain the higher corrosion rates measured in solution-based tests where DI samples corroded constantly via a fully established corrosion interface.

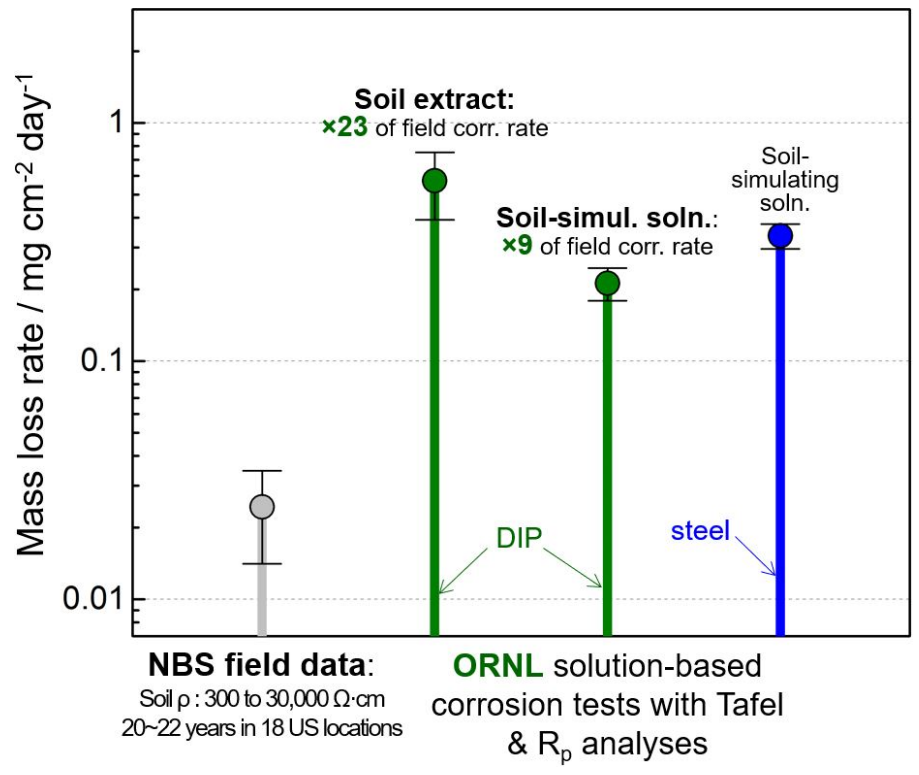

Figure 5.43. Comparison of mass loss rates measured in this work (ORNL solution-based test) and estimated from the NBS corrosion database. 


\subsection{SUMMARY OF TASK 4}

- Commercially prepared zinc coated DIP was not readily available during the course of this project. Therefore, to replicate commercial DIP, a laboratory oxidation process was developed, followed by thermally spraying zinc, which produced a microstructure similar to that of the commercial process.

- Two types of accelerated laboratory testing were explored. One used saturated soil and the other used electrochemical techniques.

- Accelerated corrosion tests using a saturated soil mixture were conducted for DIP samples with different surface conditions (bare, manufacturer-annealed oxide, and asphalt finish) and protection methods (Zn coating, simulated PE, and liquid epoxy coating). PE and liquid epoxy coating effectively prevented corrosion for 10 day exposures in soil tests. The laboratory-prepared zinc coatings were more effective when they remained intact (i.e., not intentionally damaged).

- Electrochemical techniques, including potentiodynamic scans and electrochemical impedance spectroscopy, were used to compare the corrosion rate of bare ductile iron and steel samples. The results of electrochemical measurements suggest that the corrosion rates of ductile iron and steel are not effectively different in bare conditions.

- For DIP samples, accelerated corrosion tests using saturated soils in this work resulted in corrosion mass loss over 16 times greater than the damage estimated from the NBS dataset in field conditions in buried soil. The corrosion rate of DIP samples in soil-simulating solution and soil extract was 9 and 23 times higher than the rates calculated from the NBS dataset.

- The results generated suggested several areas that require further investigation: (1) the relevancy of the corrosion kinetics in the accelerated experiments, (2) the role of the surface oxide in the corrosion process, (3) the effect of different polyethylene encasement scenarios on its effectiveness (e.g., with and without damage), and (4) the specific aqueous species in soil extract that may be causing a higher corrosion rate. 


\section{SUMMARY AND CONCLUSIONS}

The goal of this project was to evaluate zinc-coated ductile iron pipe (DIP) in highly or severely corrosive soils. This information was then to be used to evaluate whether zinc-coated DIP met the requirements of the 2004 USBR technical memorandum 8140-CC-2004-1 (Calhoun 2004). The project was complicated by the limited availability of commercial zinc-coated DIP.

Within the short ( $<1$ year) timeframe of the project, four tasks were planned and executed:

1. Characterize commercial ductile iron pipe. Commercial DIP material with no zinc coating was obtained via third parties from each of the three US DIP manufacturers. However, zinc-coated DIP is a special-order product and was not readily available. Each of the manufacturers' DIP products were evaluated, including examining the microstructure, chemistry, and mechanical properties. All manufacturers had a similar surface protection with a thermally grown oxide that is formed during high temperature air annealing and an outer top coating, which was typically asphalt. In the last month of the project, zinc-coated DIP was obtained from one manufacturer and characterized for microstructural features. Rather than a typical galvanic coating applied to the metal substrate, the zinc was applied on the thermally grown oxide on the pipe and then coated with an asphalt topcoat. Because commercial zinc-coated DIP was not readily available for this project, a process was developed to simulate the surface finish of DIP in the laboratory by growing a similar oxide and thermally spraying a zinc coating layer. While there was no time to perform accelerated corrosion testing (Task 4), microstructure comparisons were performed to provide a link to the laboratory-fabricated zinc coatings.

2. Consolidate available corrosion data. Considerable pipeline corrosion data were generated by the National Bureau of Standards (now NIST) in the first half of the $20^{\text {th }}$ century with ferrous pipes buried in different soils for decades. However, these studies were conducted before DIP was commercialized, and these studies did not consider surface protection strategies, which are considered mandatory today. These datasets might be useful in developing a better definition of corrosive soil, rather than using a single parameter such as resistivity. An initial attempt was made to use machine learning to more precisely identify the characteristics of corrosive soils. This strategy should be continued in order to develop an improved understanding of soil corrosivity. A limited amount of more recent published data was found that examined DIP with various corrosion protection strategies, including zinc coating, polyethylene encasement, and cathodic protection. There are indications that combinations of these strategies could be very effective in protecting DIP in corrosive soils; however, the dataset is limited and more work is needed to study the various concepts.

3. Develop a long-term test plan. Based on the information gathered during this project, it appears that more scientific rigor should be employed in studying the corrosion of buried pipeline and in selecting corrosion mitigation strategies for 50-100 year service lifetimes. Given the monetary and societal value of this issue in the US, it is recommended that the USBR form an independent research team consisting of universities and independent laboratories not associated with any of the competing pipe manufacturers to examine key issues and the use of this standard for zinccoated DIP. To focus the research of the consortium on relevant issues, an advisory committee should be selected, including manufacturers, industry experts, and water utilities, to recommend pertinent research topics. An initial goal of the consortium would be to evaluate zinc-coated DIP and the recommendations of the 2004 memo. A long-term goal would be to develop and validate predictive models to assist in the selection of the most economical pipeline solutions. 
4. Explore accelerated laboratory testing. Rather than wait decades for field data, an initial attempt was made to identify accelerated laboratory experiments to simulate buried pipeline corrosion. Several strategies were explored, including saturated soil and electrochemical techniques to accelerate degradation in soil on various coating strategies. In 10-60 day experiments, the corrosion rates were accelerated by 1-2 orders of magnitude. Polyethylene encasement, favored by the DIP industry, and a bonded dielectric coating, recommended by the 2004 technical memorandum, both showed excellent performance in short-term testing. Undamaged zinc-coated specimens made in the laboratory also showed excellent behavior in these accelerated experiments. Significant further work would be needed to validate an accelerated testing approach and relate it to much longer experiments in corrosive soils. Furthermore, accelerated testing should be developed to provide inputs for predictive models for pipeline corrosion.

As noted above, the project was unfortunately complicated by the lack of availability of commercial zinccoated DIP. Considerable effort was invested in developing a procedure for fabricating specimens of zinc-coated DIP in the laboratory, including laboratory forming of the thick iron oxide layer that normally forms on DIP during annealing following pipe casting. After considerable study of this complex issue, it appears that studying the performance of zinc-coated DIP with and without polyethylene encasement and with and without cathodic protection is an important goal, as these combinations may be an effective strategy to protect DIP in corrosive soils that was considered neither in the 2004 technical memorandum nor in the 2009 National Academy study about the 2004 memo. This is despite the fact that zinc coatings have been used in Europe for $\sim 50$ years. However, the available relevant performance data for combinations of these solutions in corrosive soils appears to be limited. Therefore, a test program is needed to evaluate these potential corrosion mitigation strategies beyond this initial $<1$ year project. 


\section{ACKNOWLEDGMENTS}

The project was funded by the US Bureau of Reclamation, an agency of the US Department of the Interior. At ORNL, the authors are grateful for the technical support of E. Hess, R. Simpson, M. Howell, M. Stephens, T. Lowe, D. Coffey and T. Jordan. J. R. Keiser and S. S. Raiman provided useful comments on the manuscript. The microscopy at ORNL was supported by the US Department of Energy, Office of Nuclear Energy, Fuel Cycle R\&D Program and the Nuclear Science User Facilities. 


\section{REFERENCES}

American Pipe. 2017. "Zinc-Coated Ductile Iron Pipe."

AS. 2008. "Australian Standard 3680, Polyethylene Sleeving for Ductile Iron Piping." Standards Australia.

AS. 2008. "Australian Standard 3681, Application of Polyethylene Sleeving for Ductile Iron Piping." Standards Australia.

ASTM. 2010. "Standard G162-99, Standard Practice for Conducting and Evaluating Laboratory Corrosion Tests in Soils." American Society for Testing and Materials.

ASTM. 2011. "Standard G1-3, Standard Practice for Preparing, Cleaning, and Evaluating Corrosion Test Specimens." American Society for Testing and Materials.

ASTM. 2012. "Standard G187-12a, Standard Test Method for Measurement of Soil Resistivity Using the Two-Electrode Soil Box Method." American Society for Testing and Materials.

ASTM. 2014a. "Standard A874/A874M-98, Standard Specification for Ferritic Ductile Iron Castings Suitable for Low-Temperature Service." American Society for Testing and Materials.

ASTM. 2014b. "Standard A536-84, Standard Specification for Ductile Iron Castings." American Society for Testing and Materials.

AWWA. 2004. Manual M11, Steel Pipe: A Guide for Design and Installation, $4^{\text {th }}$ ed. American Water Works Association.

AWWA. 2009. Manual M41, Ductile-Iron Pipe and Fittings. American Water Works Association.

AWWA. 2010. "Standard C105-10, Polyethylene Encasement for Ductile-Iron Pipe Systems.” American Water Works Association.

Bell, G. E. C., and A. E. Romer. 2004. "Making 'Baggies' Work for Ductile Iron Pipe.” In Pipeline Engineering and Construction (John J. Galleher, Jr., and Michael T. Stift, Eds.). Proc. ASCE Pipeline Division Specialty Congress, San Diego, Aug. 1-4, 2004. American Society of Civil Engineers.

Bell, G. E. C., C. G. Moore, and S. Williams. 2007. "Development and Application of Ductile Iron Pipe Electrical Resistance Probes for Monitoring Underground External Pipeline Corrosion.” Paper 07335 in CORROSION 2007. NACE-07335. NACE International.

Bell, J., C. G. Moore, L. Solis, and G. E. C. Bell. 2012. "Investigation of Corrosion Mechanisms and Control for Encased Ductile Iron Pipe." Materials Performance 51(6): 34-38.

Bonds, R., L. Barnard, M. Horton, and G. Oliver. 2005. "Corrosion and Corrosion Control of Iron Pipe: 75 Years of Research.” Journal of American Water Works Association 97(6): 88-98.

BS. 1996. "Standard 6076, Specification for Polymeric Film for Use as a Protective Sleeving for Buried Iron Pipes and Fittings (for Site and Factory Application)." British Standard.

Calamita, G., L. Brocca, A. Perrone, S. Piscitelli, V. Lapenna, F. Melone, and T. Moramarco. 2012. "Electrical Resistivity and TDR Methods for Soil Moisture Estimation in Central Italy Test-Sites." Journal of Hydrology 454-455: 101-112.

Calhoun, T. R., D. W. Harris, and J. Keith. 2004. Corrosion Considerations for Buried Metallic Water Pipe. Technical Memorandum 8140-CC-2004-1, July. US Bureau of Reclamation.

Caproco. 1985. Underground Corrosion of Water Pipes in Canadian Cities: Case, the City of Calgary, Final Report. ENG-83/240. CANMET contract report. 
Cole, I. S., and D. Marney. 2012. "The Science of Pipe Corrosion: A Review of the Literature on the Corrosion of Ferrous Metals in Soils." Corrosion Science 56: 5-16.

Collins, H. H., and T. J. Padley. 1983. "Protection of Spun Ductile-iron Pipes Against Corrosion by Soils." $5^{\text {th }}$ International Conference on the Internal and External Protection of Pipes, October 1983, Innsbruck, Austria.

Dillon, C. P. 1994. "Table 20.1, Assessment of Overall Soil Corrosivity to Steel." In Corrosion Control in the Chemical Process Industries. Materials Technology Institute of the Chemical Process Industries.

DIN. 1985. "Standard 50929 Part 3, Corrosion of Metals; Probability of Corrosion of Metallic Materials When Subject to Corrosion from the Outside; Buried and Underwater Pipelines and Structural Components." German Institute for Standardization.

DIPRA. 1985. “A Technical Review of Caproco's Report Entitled Underground Corrosion of Water Pipes in Canadian Cities, Case: The City of Calgary." Ductile Iron Pipe Research Association.

DoD (US Department of Defense). 2003. "Unified Facilities Criteria (UFC) 3-570-06, Cathodic Protection Systems."

Drew, J. E. 1995. Pipe Materials Selection Manual. Swindon, UK: WRc, p. 128.

Ellis, D. G., G. Moore, and P. Ferguson. 1998. "Environmental Corrosion Testing of Ductile Iron Water Pipes.” Paper 010. Corrosion and Prevention-98, November, Hobart, Australia.

Gulec, A., O. Cevher, A. Turk, F. Ustel, and F. Yilmaz. 2011. "Accelerated Corrosion Behaviors of Zn, $\mathrm{Al}$ and Zn/15Al Coatings on a Steel Surface." Materials and Technology 45(5): 477-482.

Horton, A. M. 2014. “Zinc Metallizing for External Corrosion Control of Ductile Iron Pipe.” Proceedings of Pipelines 2014, pp. 1307-1318, Portland, OR, ASCE.

ISO. 2006. "Standard 8180, Ductile Iron Pipelines - Polyethylene Sleeving for Site Application." Geneva: International Organization for Standardization.

ISO. 2007. "Standard 8179-1, Ductile Iron Pipe - External Zinc Coating." Geneva: International Organization for Standardization.

Jack, T. R., and N. J. Wilmott. 2011. "Corrosion by Soils.” Uhlig's Corrosion Handbook, $3^{\text {rd }}$ ed., R. W. Revie (Ed.), pp. 333-349. New York: John Wiley.

Jyrkama, M., M. Pandey, P. Angell, and D. Munson. 2017. "Estimating External Corrosion Rates for Buried Carbon Steel Piping in Different Soil Conditions." CNL Nuclear Review, in press. DOI: http://dx.doi.org/10.12943/CNR.2016.00020.

Lindemuth, D., and D. Kroon. 2006. "Ductile Iron Pipe: Proven Synergistic Corrosion Protection.” ASCE Pipelines Conference. American Society of Civil Engineers.

Logan, K. H., S. P. Ewing, and C. D. Yeomans. 1928. Soils, Materials, and Results of Early Observations. Technical paper 328, Soil Corrosion Studies. Washington, DC: National Bureau of Standards.

Logan, K. H. 1945. Underground Corrosion. Washington, DC: National Bureau of Standards.

Marchal, R. 1981. "Protection of Buried Ductile Iron Pipelines with a Zinc Based Coating - Healing Power of Coating Damages." $4^{\text {th }}$ International Conference on the Internal and External Protection of Pipes, September, Noordwijkerhout, Netherland.

Marney D., and D. De Silva. 2010. Performance and Life-Span of Polyethylene Wrap Materials for Ductile Iron Pipes: Literature Review. Water for a Healthy Country Flagship Report.

McWane Ductile. 2017. "Zinc Coated Ductile Iron Pipe." 
Munson, D., M. Pandey, M. Jyrkama, and P. Angell. 2016. "Historical Rates of Soil Side Corrosion for Use in Fitness-for-Service Evaluations of Buried Metallic Pipe.” PVP2016-63923. ASME 2016 Pressure Vessels and Piping Conference. New York: ASME.

NACE. 2013. "Standard 10A292, Corrosion and Corrosion Control for Buried Cast- and Ductile-Iron Pipe." National Association of Corrosion Engineers.

NCEI online database. https://www.ncdc.noaa.gov/cdo-web/search.

Newman, R. C., K. Rumash, and B. J. Webster. 1992. "The Effect of Pre-Corrosion on the Corrosion Rate of Steel in Neutral Solutions Containing Sulphide: Relevance to Microbially Influenced Corrosion." Corrosion Science 33(12): 1877-1884.

Paris, M. 1975. "Zinc Based Coating for Protecting Buried Gray and Ductile Iron Pipes against Corrosion." $1{ }^{\text {st }}$ International Conference on the Internal and External Protection of Pipes, September, University of Durham, Durham, England.

Rajani, B., and Y. Kleiner. 2003. "Protecting Ductile-Iron Water Mains: What Protection Method Works Best for What Soil Condition?” Journal of American Water Works Association 95(11): 110-125.

Ricker, R. E. 2010. “Analysis of Pipeline Steel Corrosion Data from NBS (NIST) Studies Conducted Between 1922-1940 and Relevance to Pipeline Management." Journal of Research of the National Institute of Standards and Technology 115: 373-392.

Romanoff, M. 1957. Underground Corrosion. NBS Circular 579. Gaithersburg, MD: National Bureau of Standards.

Rossum, J. R. 1969. "Predicting of Pitting Rates in Ferrous Metals from Soil Parameters." Journal of American Water Works Association 69(6): 305-310.

Schiff, M. J., and B. McCollom. 1993. "Impressed Current Cathodic Protection of Poly-ethylene-Encased Ductile Iron Pipe." Materials Performance 32(8): 23-30.

Sherar, B.W., I. M. Power, P. G. Keech, S. Mitlin, G. Southam, and D. W. Shoesmith. 2011. "Characterizing the Effect of Carbon Steel Exposure in Sulfide Containing Solutions in Microbially Induced Corrosion," Corrosion Science 53(3): 955-960.

Sherar, B., P. Keech, and D. Shoesmith. 2013. "Effect of Sulfide on Carbon Steel Corrosion in Anaerobic Near-Neutral pH Saline Solutions." Corrosion 69(1): 67-76.

Spickelmire, W. 2002. “Corrosion Considerations for Ductile Iron Pipe.” Materials Performance 41(7): $16-23$.

Szeliga. M. J., and D. Simpson. 2001. “Corrosion of Ductile Iron Pipe: Case Histories.” Material Performance 40(7): 22-27.

U.S. Pipe. 2017. "Metallic Zinc Coated Pipe: Active Corrosion Protection for Ductile Iron Pipe."

Zenati, A. A., A. Benmoussat, and A. Bourdim. 2015. "Localized Corrosion Study of X60 Pipeline Steel in Soil Solution and Inhibitive Effect by Disodic Hydrogeno-Phosphate." Journal of Materials and Environmental Science 6(7): 1896-1901. 



\section{APPENDIX}

\begin{tabular}{|c|c|}
\hline \\
\hline \multicolumn{2}{|c|}{ 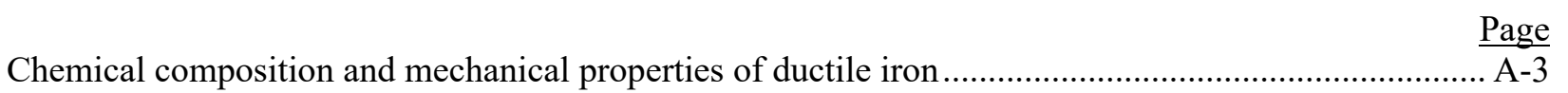 } \\
\hline 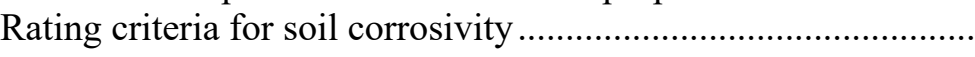 & $\ldots \mathrm{A}-4$ \\
\hline dditional analyses of soil corrosivity based on NBS dataset... & A-10 \\
\hline Compositions of different soil-simulating solutions ..................... & A-11 \\
\hline 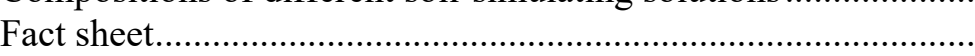 & A-12 \\
\hline
\end{tabular}





\section{APPENDIX}

\section{Chemical composition and mechanical properties of ductile iron}

Table A.1. Chemical composition of ductile iron ASTM A874 / A874M-98 (ASTM 2014a)

\begin{tabular}{lcc}
\hline \multicolumn{1}{c}{ Element } & Minimum, \% & Maximum, \% \\
\hline Total carbon & 3.0 & 3.7 \\
Carbon equivalent (carbon $+1 / 3$ silicon) & $\ldots$ & 4.5 \\
Silicon & 1.2 & 2.3 \\
Phosphorous & $\ldots$ & 0.03 \\
Magnesium & $\ldots$ & 0.07 \\
Manganese & $\ldots$ & 0.25 \\
Copper & $\ldots$ & 0.1 \\
Nickel & $\ldots$ & 1.0 \\
Chromium & $\ldots$ & 0.07 \\
\hline
\end{tabular}

Table A.2. Designations, minimum mechanical properties, and approximate compositions for ductile iron from ASTM A536-84

\begin{tabular}{|c|c|c|c|c|c|}
\hline Grade & $\begin{array}{c}\text { Composition } \\
\text { (wt.\%) }\end{array}$ & Matrix structure & $\begin{array}{l}\text { Tensile strength } \\
\text { (MPa [ksi]) }\end{array}$ & $\begin{array}{c}\text { Yield strength } \\
\text { (MPa [ksi]) }\end{array}$ & $\begin{array}{c}\text { Ductility } \\
\text { (\% EL) }\end{array}$ \\
\hline $\begin{array}{c}\text { ASTM A536 } \\
60-40-18\end{array}$ & \multirow{3}{*}{$\begin{array}{c}3.5-3.8 \mathrm{C} \\
2.0-2.8 \mathrm{Si} \\
0.05 \mathrm{Mg} \\
<0.20 \mathrm{Ni} \\
<0.10 \mathrm{Mo}\end{array}$} & Ferrite & $414(60)$ & $276(40)$ & 18 \\
\hline $\begin{array}{c}\text { ASTM A536 } \\
100-70-03\end{array}$ & & Pearlite & $689(100)$ & $483(70)$ & 3 \\
\hline $\begin{array}{c}\text { ASTM A536 } \\
120-90-02\end{array}$ & & Tempered martensite & $827(120)$ & $621(90)$ & 2 \\
\hline
\end{tabular}

Source: ASTM. 2014. "Standard A536-84, Standard Specification for Ductile Iron Castings.” American Society for Testing and Materials. 


\section{Rating criteria for soil corrosivity}

Table A.3. AWWA Manual M41: 10 point system to estimate soil corrosivity (AWWA 2009)

\begin{tabular}{lll}
\hline Attribute & \multicolumn{1}{c}{ Soil characteristic } & Points \\
\hline Resistivity $^{a}(\mathrm{ohm} \cdot \mathrm{cm})$ & $<1,500$ & 10 \\
& $\geq 1,500-1,800$ & 8 \\
& $>1,800-2,100$ & 5 \\
& $>2,100-2,500$ & 2 \\
& $>2,500-3,000$ & 1 \\
& $>3,000$ & 0 \\
\hline $\mathrm{pH}$ & $0-2$ & 5 \\
& $2-4$ & 3 \\
& $4-6.5$ & 0 \\
& $6.5-7.5$ & $0^{b}$ \\
& $7.5-8.5$ & 0 \\
& $>8.5$ & 3 \\
\hline Redox potential & $>+100 \mathrm{mV}$ & 0 \\
& +50 to $+100 \mathrm{mV}$ & 3.5 \\
& 0 to $+50 \mathrm{mV}$ & 4 \\
& Negative & 5 \\
\hline Sulfide & Positive & 3.5 \\
& Trace & 2 \\
& Negative & 0 \\
\hline Moisture & Poor drainage, continuously wet. & 2 \\
& Fair drainage, generally moist. & 1 \\
& Good drainage, generally day & 0 \\
\hline
\end{tabular}

${ }^{a}$ Based on water-saturated soil box, the resistivity measurement in water-saturated soil box is available in ASTM G187-12a (ASTM 2012).

${ }^{b}$ If sulfides are present and low or negative redox-potential results are obtained, three points shall be given for this range.

AWWA. 2009. Manual M41, Ductile-Iron Pipe and Fittings. American Water Works Association.

ASTM. 2012. "Standard G187-12a, Standard Test Method for Measurement of Soil Resistivity Using the Two-Electrode Soil Box Method." American Society for Testing and Materials. 
Table A.4. Modified 25-point risk assessment analysis with project-specific assigned point values (Spickelmire 2002)

Criteria 1 to 7 are based on the original 25-point system (Dillon 1994) which has some similar content as AWWA manual M41 (AWWA 2009).

\begin{tabular}{|c|c|c|}
\hline Analysis type & Analysis range & $\begin{array}{l}\text { Point } \\
\text { range }\end{array}$ \\
\hline 1. $\mathrm{pH}$ & $0-2$ & 5 \\
\hline The same criteria with & $2-4$ & 3 \\
\hline \multirow[t]{3}{*}{ AWWA manual M41 } & $4-6.5$ & 0 \\
\hline & $6.5-7.5$ & $0 * *$ \\
\hline & $7.5-8.5$ & 0 \\
\hline **Add 3 if sulfides exist & $>8.5$ & 3 \\
\hline \multirow[t]{5}{*}{ 2. Chloride content } & $>1,000 \mathrm{ppm}$ & 10 \\
\hline & $500-1,000 \mathrm{ppm}$ & 6 \\
\hline & $200-500 \mathrm{ppm}$ & 4 \\
\hline & $50-200 \mathrm{ppm}$ & 2 \\
\hline & $0-50 \mathrm{ppm}$ & 0 \\
\hline \multirow[t]{5}{*}{ 3. Sulfate content } & $>200$ ppm (very severe) & 5 \\
\hline & $150-200 \mathrm{ppm}$ (severe) & 4 \\
\hline & $100-150$ ppm (minimal) & 2 \\
\hline & $50-100$ ppm (little) & 1 \\
\hline & $<50 \mathrm{ppm}$ (none) & 0 \\
\hline 4. Redox potential & Negative (anaerobic conditions) & 5 \\
\hline The same criteria with & 0 to $+50 \mathrm{mV}$ (possible chance of anaerobic) & 4 \\
\hline \multirow{2}{*}{ AWWA manual M41 } & +50 to $+100 \mathrm{mV}$ (minimal chance of anaerobic) & 3.5 \\
\hline & $>+100 \mathrm{mV}$ (aerated soil) & 0 \\
\hline \multirow[t]{10}{*}{ 5. Soil type } & Coal seam or cinders & 15 \\
\hline & Ocean tidal zones & 15 \\
\hline & Highly organic soil, mucks & 10 \\
\hline & Clay (blue-gray or swelling) & 10 \\
\hline & Alkaline salt flats & 10 \\
\hline & Clay/stone & 5 \\
\hline & Clay & 3 \\
\hline & Slit & 2 \\
\hline & Dry loamy soil & 1 \\
\hline & Clean sand & 0 \\
\hline \multirow{6}{*}{ 6. Soil resistivity } & $<1,000 \mathrm{ohm} \cdot \mathrm{cm}$ & 15 \\
\hline & $1,000-1,500 \mathrm{ohm} \cdot \mathrm{cm}$ & 13 \\
\hline & $1,500-2,500 \mathrm{ohm} \cdot \mathrm{cm}$ & 11 \\
\hline & $2,500-5,000 \mathrm{ohm} \cdot \mathrm{cm}$ & 9 \\
\hline & $5,000-10,000 \mathrm{ohm} \cdot \mathrm{cm}$ & 7 \\
\hline & $>10,000 \mathrm{ohm} \cdot \mathrm{cm}$ & 0 \\
\hline 7. Sulfides & Positive & 3.5 \\
\hline The same criteria with & Trace & 2 \\
\hline AWWA manual M41 & Negative & 0 \\
\hline \multirow[t]{7}{*}{ 8. Moisture } & Dry to wet & 6 \\
\hline & Intermittently dry and wet & 5 \\
\hline & Top dry & 4 \\
\hline & Generally moist & 3 \\
\hline & Continuously wet & 2 \\
\hline & Normally dry & 1 \\
\hline & Always dry & 0 \\
\hline
\end{tabular}


Table A.4 (continued)

\begin{tabular}{|c|c|c|}
\hline Analysis type & Analysis range & $\begin{array}{l}\text { Point } \\
\text { range }\end{array}$ \\
\hline 9. Pipe size factor & $\begin{array}{l}\geq 64 \text { inch } \\
50-63 \text { inch } \\
40-49 \text { inch } \\
30-39 \text { inch } \\
24-29 \text { inch } \\
<23 \text { inch }\end{array}$ & $\begin{array}{l}8 \\
6 \\
4 \\
3 \\
2 \\
0\end{array}$ \\
\hline $\begin{array}{l}\text { 10. Maximum design surge } \\
\text { pressure factor }\end{array}$ & $\begin{array}{l}\geq 300 \mathrm{psi} \\
251-259 \mathrm{psi} \\
201-250 \mathrm{psi} \\
151-200 \mathrm{psi} \\
<150 \mathrm{psi}\end{array}$ & $\begin{array}{l}6 \\
4 \\
2 \\
1 \\
0\end{array}$ \\
\hline $\begin{array}{l}\text { 11. Pipe minimum design } \\
\text { life factor }\end{array}$ & $\begin{array}{l}300 \text { years } \\
201-299 \text { years } \\
101-200 \text { years } \\
50-100 \text { years } \\
<50 \text { years }\end{array}$ & $\begin{array}{l}8 \\
6 \\
4 \\
2 \\
0\end{array}$ \\
\hline $\begin{array}{l}\text { 12. Pipe location \& leak } \\
\text { repair difficulty factors }\end{array}$ & $\begin{array}{l}\text { Steep slopes, water crossing } \\
\text { Congested downtown area } \\
\text { Four-lane road } \\
\text { Industrial area } \\
\text { Two-lane concrete road } \\
\text { Two-lane asphalt road } \\
\text { Remote poor access } \\
\text { Cross-country good access }\end{array}$ & $\begin{array}{r}12 \\
10 \\
8 \\
6 \\
4 \\
2 \\
1 \\
0\end{array}$ \\
\hline $\begin{array}{l}\text { 13. Potential interference } \\
\text { sources }\end{array}$ & $\begin{array}{l}\text { A. Within } 1000 \text { feet } \\
\text { Impressed current }>20 \mathrm{~A} \\
\text { Impressed current } 11-20 \mathrm{~A} \\
\text { Impressed current }<11 \mathrm{~A} \\
\text { Light rail station } \\
\text { B. Within } 2500 \text { feet } \\
\text { Impressed current }>20 \mathrm{~A} \\
\text { Impressed current } 11-20 \mathrm{~A} \\
\text { Impressed current }<11 \mathrm{~A} \\
\text { Refinery, tank farm, rail station } \\
\text { C. Light rail tracks or foreign pipe crossing } \\
\text { Long light rail or pipe parallel } \\
\text { Light rail or pipe crossing } \\
\text { D. Oil or gas well field with impressed current systems } \\
\text { Through well field } \\
\text { Multiple track or pipeline crossings } \\
\end{array}$ & $\begin{array}{r}10 \\
8 \\
6 \\
20 \\
\\
8 \\
6 \\
4 \\
10 \\
10 \\
5 \\
15 \\
15\end{array}$ \\
\hline $\begin{array}{l}\text { 14. Pipe zone backfill } \\
\text { materials }\end{array}$ & $\begin{array}{l}\text { Native soil }(<3,000 \mathrm{ohm} \cdot \mathrm{cm} \text { or with angular rock points) } \\
\text { Native soil }(<5,000 \mathrm{ohm} \cdot \mathrm{cm}) \\
\text { Native soil }(<10,000 \mathrm{ohm} \cdot \mathrm{cm}) \\
\text { Rounded select backfill }(<10,000 \mathrm{ohm} \cdot \mathrm{cm}) \\
\text { Rounded select backfill }(>10,000 \mathrm{ohm} \cdot \mathrm{cm})\end{array}$ & $\begin{array}{l}4 \\
3 \\
2 \\
1 \\
0\end{array}$ \\
\hline
\end{tabular}


Table A.4 (continued)

\begin{tabular}{|l|l|c|}
\hline \multicolumn{1}{|c|}{ Analysis type } & \multicolumn{1}{c|}{ Analysis range } & \multicolumn{1}{c|}{$\begin{array}{c}\text { Point } \\
\text { range }\end{array}$} \\
\hline $\begin{array}{l}\text { 15. Future or additional } \\
\text { factors to consider }\end{array}$ & A. Possible soil changes from chemical additives or contaminants & \\
& Heavily salted roads with pipe in drainage area & 10 \\
& Heavily fertilized irrigated field & 8 \\
& Dairies, Feed lots, Barn yards & 6 \\
& B. Previous corrosion leaks on bare or polyethylene-encased (PE) & \\
& ductile or cast iron pipe or fittings & \\
& Within 30 years with PE & 15 \\
& Within 30 years in bare condition & 10 \\
& Within 50 years in bare condition & 5 \\
& Within 100 years in bare condition & 2 \\
& C. Pipeline function & 5 \\
& Sewer force mains & 5 \\
& Single source transmission & 4 \\
& With copper service or grounds & 0 \\
\hline \multicolumn{2}{|c|}{ Distribution type piping } & Total score \\
\hline Risk Assessment Zones 1 \& & Severe & $>25$ \\
2 & & $20-24.5$ \\
\hline Risk Assessment Zone 3 & Appreciable & $15-19.5$ \\
\hline Risk Assessment Zone 4 & Moderate & $15-14.5$ \\
\hline Risk Assessment Zone 5 & Mild & \\
\hline
\end{tabular}

C.P. Dillon. 1994. "Table 20.1, Assessment of Overall Soil Corrosivity to Steel." Corrosion Control in the Chemical Process Industries. Materials Technology Institute of the Chemical Process Industries. 
Table A.5. Normalized penetration rate for the deepest damage on ductile and cast iron (DI \& CI) pipes from five publications (Bonds 2005, Horton 2014, Paris 1975, Ellis 1998, Collins and Padley 1983)

\begin{tabular}{|c|c|c|c|c|c|c|c|c|c|}
\hline Source & Material & $\begin{array}{c}\text { Surface } \\
\text { condition }\end{array}$ & $\begin{array}{c}\text { PE } \\
\text { applied }\end{array}$ & $\begin{array}{c}\text { Burial } \\
\text { duration }\end{array}$ & $\begin{array}{l}\text { Normalized } \\
\text { penetration } \\
\text { rate (mmpy) }\end{array}$ & Location & $\begin{array}{c}\text { Soil } \\
\text { resistivity } \\
(\mathrm{ohm} \cdot \mathrm{cm}) \\
\end{array}$ & $\begin{array}{c}\mathrm{pH} \\
\text { above } 8 \text { or } \\
\text { below } 4.5 \\
\end{array}$ & Sulfide \\
\hline \multirow{22}{*}{$\begin{array}{l}\text { Bonds } \\
(2005)\end{array}$} & DI & $\begin{array}{c}\text { Annealing } \\
\text { oxide }\end{array}$ & & 25 & 1.07 & $\begin{array}{c}\text { Everglade, } \\
\text { FL }\end{array}$ & 110 & & $\mathrm{Y}$ \\
\hline & DI & $\begin{array}{c}\text { Annealing } \\
\text { oxide }\end{array}$ & & 25 & 0.75 & Absecon, NJ & 76 & & $\mathrm{Y}$ \\
\hline & DI & $\begin{array}{c}\text { Annealing } \\
\text { oxide }\end{array}$ & & 25 & 0.565 & \begin{tabular}{|c} 
Birmingham, \\
AL
\end{tabular} & 400 & & $\begin{array}{c}\text { Not } \\
\text { measured }\end{array}$ \\
\hline & DI & $\begin{array}{c}\text { Annealing } \\
\text { oxide }\end{array}$ & & 25 & 0.23 & Casper, WY & 160 & 8.1 & $\begin{array}{c}\text { Not } \\
\text { measured }\end{array}$ \\
\hline & $\mathrm{CI}$ & $\begin{array}{c}\text { Annealing } \\
\text { oxide }\end{array}$ & & 25 & 1.188 & $\begin{array}{c}\text { Everglade, } \\
\text { FL }\end{array}$ & 110 & & $\mathrm{Y}$ \\
\hline & $\mathrm{CI}$ & $\begin{array}{c}\text { Annealing } \\
\text { oxide }\end{array}$ & & 25 & 1.4 & Absecon, NJ & 76 & & $\mathrm{Y}$ \\
\hline & $\mathrm{CI}$ & $\begin{array}{c}\text { Annealing } \\
\text { oxide }\end{array}$ & & 25 & 0.653 & \begin{tabular}{|c} 
Birmingham, \\
AL
\end{tabular} & 400 & & $\begin{array}{c}\text { Not } \\
\text { measured }\end{array}$ \\
\hline & $\mathrm{CI}$ & $\begin{array}{c}\text { Annealing } \\
\text { oxide }\end{array}$ & & 25 & 0.212 & Casper, WY & 160 & 8.1 & $\begin{array}{c}\text { Not } \\
\text { measured }\end{array}$ \\
\hline & DI & $\begin{array}{c}\text { Bare } \\
\text { (sandblast) }\end{array}$ & & 25 & 0.538 & $\begin{array}{c}\text { Watsonville, } \\
\text { CA }\end{array}$ & 960 & & $\mathrm{Y}$ \\
\hline & DI & $\begin{array}{c}\text { Bare } \\
\text { (sandblast) }\end{array}$ & & 25 & 0.45 & $\begin{array}{l}\text { Raceland, } \\
\text { LA }\end{array}$ & 1000 & & \\
\hline & $\mathrm{CI}$ & $\begin{array}{c}\text { Bare } \\
\text { (sandblast) } \\
\end{array}$ & & 25 & 0.803 & $\begin{array}{c}\text { Watsonville, } \\
\text { CA }\end{array}$ & 960 & & $\mathrm{Y}$ \\
\hline & $\mathrm{CI}$ & $\begin{array}{c}\text { Bare } \\
\text { (sandblast) } \\
\end{array}$ & & 25 & 0.98 & $\begin{array}{c}\text { Raceland, } \\
\text { LA }\end{array}$ & 1000 & & \\
\hline & DI or CI & $\begin{array}{c}\text { Annealing } \\
\text { oxide }\end{array}$ & Damaged & 11 & 0.303 & $\begin{array}{c}\text { Everglade, } \\
\text { FL } \\
\end{array}$ & 110 & & $\mathrm{Y}$ \\
\hline & DI or CI & $\begin{array}{c}\text { Annealing } \\
\text { oxide }\end{array}$ & Damaged & 3 & 0.113 & Overton, NV & 68 & & \\
\hline & DI or CI & $\begin{array}{c}\text { Annealing } \\
\text { oxide }\end{array}$ & Damaged & 12 & 0.515 & $\begin{array}{c}\text { Logandale, } \\
\text { NV }\end{array}$ & 70 & & \\
\hline & DI or CI & $\begin{array}{c}\text { Annealing } \\
\text { oxide }\end{array}$ & Damaged & 3 & 0.145 & Hughes, AR & 500 & & \\
\hline & DI or CI & $\begin{array}{c}\text { Annealing } \\
\text { oxide }\end{array}$ & Damaged & 5 & 0 & Aurora, $\mathrm{CO}$ & 1600 & & \\
\hline & DI or CI & Asphalt & & 11 & 0.8 & $\begin{array}{c}\text { Everglade, } \\
\text { FL }\end{array}$ & 110 & & $\mathrm{Y}$ \\
\hline & DI or $\mathrm{CI}$ & Asphalt & & 3 & 0.513 & Overton, NV & 68 & & \\
\hline & DI or CI & Asphalt & & 12 & 0.67 & $\begin{array}{c}\text { Logandale, } \\
\text { NV }\end{array}$ & 70 & & \\
\hline & DI or CI & Asphalt & & 3 & 0.103 & Hughes, AR & 500 & & \\
\hline & DI or CI & Asphalt & & 5 & 0 & Aurora, $\mathrm{CO}$ & 1600 & & \\
\hline
\end{tabular}




\begin{tabular}{|c|c|c|c|c|c|c|c|c|c|}
\hline \multicolumn{10}{|c|}{ Table A.5 (continued) } \\
\hline Source & Material & $\begin{array}{l}\text { Surface } \\
\text { condition }\end{array}$ & $\begin{array}{c}\text { PE } \\
\text { applied }\end{array}$ & $\begin{array}{c}\text { Burial } \\
\text { duration }\end{array}$ & $\begin{array}{l}\text { Normalized } \\
\text { penetration } \\
\text { rate (mmpy) }\end{array}$ & Location & $\begin{array}{c}\text { Soil } \\
\text { resistivity } \\
(\mathrm{ohm} \cdot \mathrm{cm}) \\
\end{array}$ & $\begin{array}{c}\text { pH } \\
\text { above } 8 \text { or } \\
\text { below } 4.5 \\
\end{array}$ & Sulfide \\
\hline \multirow{10}{*}{$\begin{array}{l}\text { Horton } \\
(2014)\end{array}$} & DI & $\begin{array}{c}130 \mathrm{Zn}^{*}+ \\
1 \mathrm{mil} \\
\text { varnish }\end{array}$ & & 8 & 0.114 & $\begin{array}{l}\text { Everglade, } \\
\text { FL }\end{array}$ & 110 & & $\mathrm{Y}$ \\
\hline & DI & $\begin{array}{c}130 \mathrm{Zn}+ \\
1 \mathrm{mil} \\
\text { varnish }\end{array}$ & Intact & 8 & 0 & $\begin{array}{c}\text { Everglade, } \\
\text { FL }\end{array}$ & 110 & & $\mathrm{Y}$ \\
\hline & DI & $\begin{array}{c}130 \mathrm{Zn}+ \\
1 \mathrm{mil} \\
\text { varnish }\end{array}$ & & 9 & 0 & $\begin{array}{c}\text { Watsonville, } \\
\text { CA }\end{array}$ & 960 & & $\mathrm{Y}$ \\
\hline & DI & $\begin{array}{c}130 \mathrm{Zn}+ \\
1 \mathrm{mil} \\
\text { varnish }\end{array}$ & Intact & 9 & 0 & $\begin{array}{c}\text { Watsonville, } \\
\text { CA }\end{array}$ & 960 & & $\mathrm{Y}$ \\
\hline & DI & $\begin{array}{c}130 \mathrm{Zn}+ \\
1 \mathrm{mil} \\
\text { asphalt }\end{array}$ & & 12 & 0.513 & $\begin{array}{c}\text { Everglade, } \\
\text { FL }\end{array}$ & 110 & & $\mathrm{Y}$ \\
\hline & DI & $\begin{array}{c}130 \mathrm{Zn}+ \\
1 \mathrm{mil} \\
\text { asphalt }\end{array}$ & & 12 & 0.248 & $\begin{array}{l}\text { Logandale, } \\
\text { NV }\end{array}$ & 70 & & $\mathrm{Y}$ \\
\hline & DI & $\begin{array}{c}200 \mathrm{Zn}+ \\
4 \text { mil } \\
\text { asphalt }\end{array}$ & & 10.7 & 0.145 & $\begin{array}{c}\text { Everglade, } \\
\text { FL }\end{array}$ & 110 & & Y \\
\hline & DI & $\begin{array}{c}200 \mathrm{Zn}+ \\
4 \text { mil } \\
\text { asphalt }\end{array}$ & Damaged & 10.7 & 0.064 & $\begin{array}{c}\text { Everglade, } \\
\text { FL }\end{array}$ & 110 & & Y \\
\hline & DI & $\begin{array}{c}200 \mathrm{Zn}+ \\
4 \text { mil } \\
\text { asphalt }\end{array}$ & Intact & 10.7 & 0 & $\begin{array}{c}\text { Everglade, } \\
\text { FL }\end{array}$ & 110 & & $\mathrm{Y}$ \\
\hline & DI & $\begin{array}{c}200 \mathrm{Zn}+ \\
2 \text { mil } \\
\text { asphalt }\end{array}$ & Intact & 10 & 0 & $\begin{array}{c}\text { Everglade, } \\
\text { FL }\end{array}$ & 110 & & $\mathrm{Y}$ \\
\hline \multirow{4}{*}{$\begin{array}{l}\text { Paris } \\
(1975)\end{array}$} & DI & $\begin{array}{l}\text { 140Zn + } \\
\text { varnish }\end{array}$ & & 9 & 0 & $\begin{array}{c}\text { Colchester, } \\
\text { England }\end{array}$ & 700 & & $\mathrm{Y}$ \\
\hline & DI & $\begin{array}{l}140 \mathrm{Zn}+ \\
\text { varnish }\end{array}$ & & 9 & 0.086 & $\begin{array}{l}\text { Oldenburg, } \\
\text { Germany }\end{array}$ & 900 & & $\mathrm{Y}$ \\
\hline & DI & $\begin{array}{l}140 \mathrm{Zn}+ \\
\text { varnish }\end{array}$ & & 9 & 0 & $\begin{array}{l}\text { Mont.st.mic } \\
\text { hel, France }\end{array}$ & 110 & & $\mathrm{Y}$ \\
\hline & DI & $\begin{array}{c}\text { Annealing } \\
\text { oxide }\end{array}$ & & 9 & 0.378 & 3 sites & 450 & & $\mathrm{Y}$ \\
\hline \multirow{2}{*}{$\begin{array}{l}\text { Ellis } \\
(1998)\end{array}$} & DI & $\begin{array}{c}* * \text { As- } \\
\text { manufactured }\end{array}$ & Intact & 5 & 0.38 & $\begin{array}{c}\text { South } \\
\text { Australia }\end{array}$ & $\begin{array}{c}\text { Not } \\
\text { measured }\end{array}$ & $\begin{array}{c}\text { Not } \\
\text { measured }\end{array}$ & $\begin{array}{c}\text { Not } \\
\text { measured }\end{array}$ \\
\hline & DI & $\begin{array}{c}\text { As- } \\
\text { manufactured }\end{array}$ & & 5 & 0.64 & $\begin{array}{c}\text { South } \\
\text { Australia }\end{array}$ & $\begin{array}{c}\text { Not } \\
\text { measured }\end{array}$ & $\begin{array}{c}\text { Not } \\
\text { measured }\end{array}$ & $\begin{array}{c}\text { Not } \\
\text { measured }\end{array}$ \\
\hline \multirow{5}{*}{$\begin{array}{l}\text { Collins } \\
\text { and } \\
\text { Padley } \\
(1983)\end{array}$} & DI & $\begin{array}{c}\text { As- } \\
\text { manufactured }\end{array}$ & & 5 & 0.56 & $\begin{array}{c}\text { Varel, } \\
\text { Germany }\end{array}$ & $\begin{array}{c}\text { Low } \\
\text { resistivity }\end{array}$ & $\begin{array}{c}\text { Not } \\
\text { measured }\end{array}$ & $\begin{array}{c}\text { Not } \\
\text { measured }\end{array}$ \\
\hline & DI & $\begin{array}{c}\text { As- } \\
\text { manufactured }\end{array}$ & Intact & 5 & 0.2 & $\begin{array}{c}\text { Varel, } \\
\text { Germany }\end{array}$ & $\begin{array}{c}\text { Low } \\
\text { resistivity }\end{array}$ & $\begin{array}{c}\text { Not } \\
\text { measured }\end{array}$ & $\begin{array}{c}\text { Not } \\
\text { measured }\end{array}$ \\
\hline & DI & $\begin{array}{c}\text { As- } \\
\text { manufactured }\end{array}$ & & 9 & 0.21 & $\begin{array}{c}\text { Colchester, } \\
\text { England }\end{array}$ & $\begin{array}{c}\text { Low } \\
\text { resistivity }\end{array}$ & $\begin{array}{c}\text { Not } \\
\text { measured }\end{array}$ & $\begin{array}{c}\text { Not } \\
\text { measured }\end{array}$ \\
\hline & DI & $\begin{array}{c}\text { As- } \\
\text { manufactured }\end{array}$ & Intact & 9 & 0.078 & $\begin{array}{c}\text { Colchester, } \\
\text { England }\end{array}$ & $\begin{array}{c}\text { Low } \\
\text { resistivity }\end{array}$ & $\begin{array}{c}\text { Not } \\
\text { measured }\end{array}$ & $\begin{array}{c}\text { Not } \\
\text { measured }\end{array}$ \\
\hline & DI & $\begin{array}{c}\text { As- } \\
\text { manufactured }\end{array}$ & & 9 & 0.62 & $\begin{array}{l}\text { Michel, } \\
\text { France }\end{array}$ & $\begin{array}{c}\text { Low } \\
\text { resistivity }\end{array}$ & $\begin{array}{c}\text { Not } \\
\text { measured }\end{array}$ & \begin{tabular}{|c|} 
Not \\
measured
\end{tabular} \\
\hline
\end{tabular}

*The number before $\mathrm{Zn}$ indicates the density of $\mathrm{Zn}$ coating in $\mathrm{g} / \mathrm{m}^{2}$. **As-manufactured condition may refer to as-annealed or asphalt-finished. 


\section{Additional analyses of soil corrosivity based on NBS dataset}

The analysis of the NBS corrosion database presented here focuses on the effect of ionic concentration, $\mathrm{pH}$ and resistivity of soils on the corrosion of ferrous pipes. In the NBS database, the most and least aggressive soils were chosen based on the highest and lowest mass loss values of 6 " pipes buried for approximately 12 years. The mass loss normalized by surface area reflects the degree of corrosion damage on those pipes. Figure A.1 shows the comparison of resistivity, $\mathrm{pH}$ and ionic concentration of the most aggressive (mass loss $\geq 0.29 \mathrm{~g} / \mathrm{cm}^{2}$ ) and least aggressive (mass loss $\leq 0.13 \mathrm{~g} / \mathrm{cm}^{2}$ ) soils. The soil identification numbers marked on the plot in Figure A.1 represent the numbers assigned to different soil types in the NBS dataset. The concentration of salts in the plot is reported in milligram-equivalents per $100 \mathrm{~g}$ of soil.

The analysis of data in Figure A.1 shows a significant scatter in ionic concentration for the most aggressive soils. On the other hand, ionic concentrations of the least aggressive soils showed less data scatter. Overall, it was difficult to distinguish any noticeable effect of ionic concentration on soil corrosivity. Obviously, less aggressive soils have much smaller concentrations of soluble salts. The values of $\mathrm{pH}$ for both the most and least aggressive soils also have large data scatter. The resistivity was much higher for the least aggressive soils compared to the most aggressive soils.

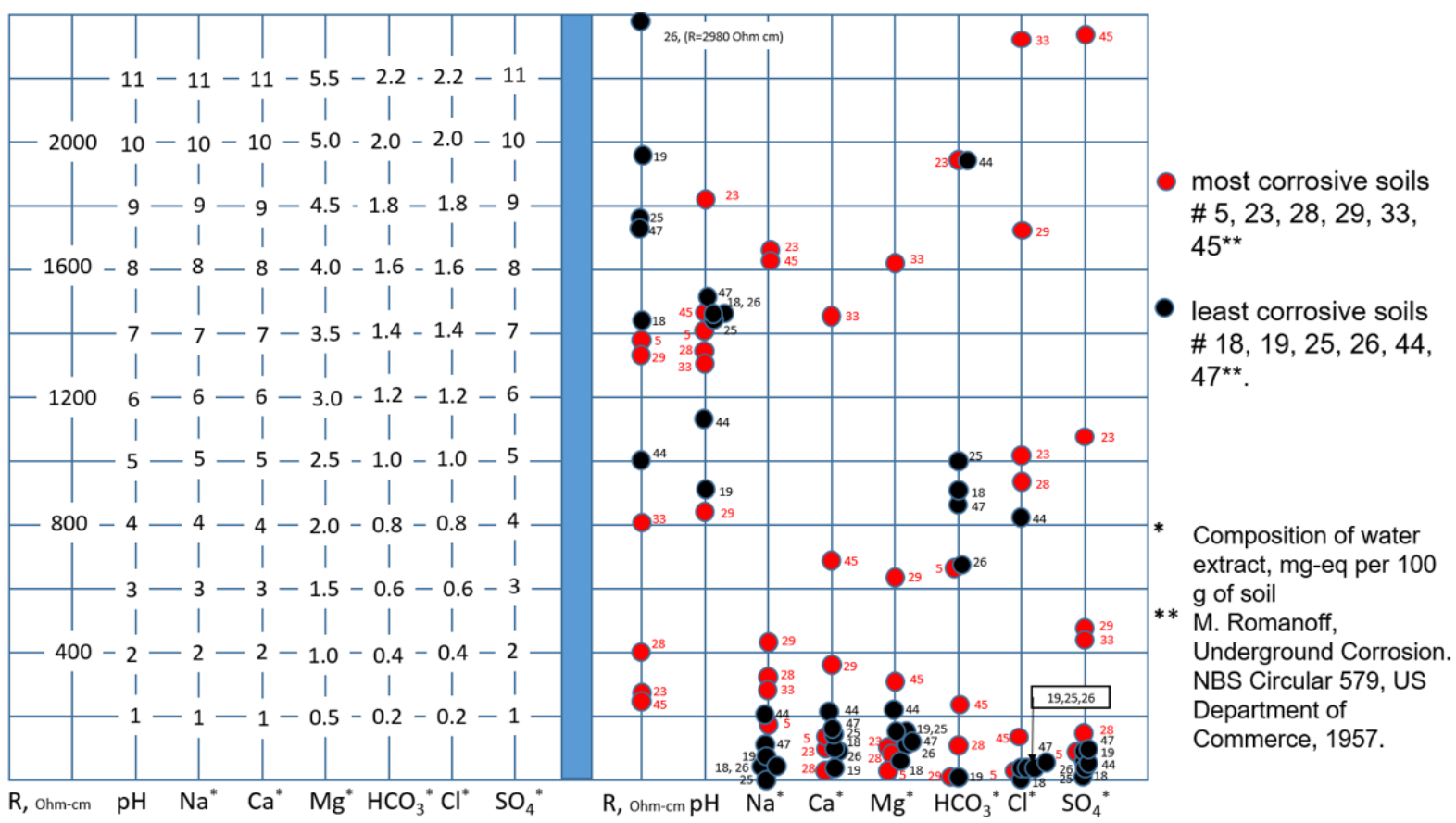

Figure A.1. Summary of chemical and physical properties of the six most and least corrosive soils based on the corrosion mass loss on 6-in. ferrous pipe. These soil data were collected from the NBS corrosion study (Romanoff 1957).

In addition, the most and least aggressive soils based on the deepest penetration were selected from the same NBS dataset. The maximum penetration is associated with the susceptibility of material to local perforation. Figure A.2 shows the comparison of resistivity, $\mathrm{pH}$ and ionic concentration of the most aggressive (maximum penetration $\geq 4.9 \mathrm{~mm}$ ) and least aggressive (maximum penetration $\leq 1.75 \mathrm{~mm}$ ) soils. The analysis indicates a large scatter in $\mathrm{pH}$ value and ionic concentration for the most and least aggressive soils. The soil resistivity for the least aggressive soils was much higher compared to the most corrosive soils based on maximum penetration. 


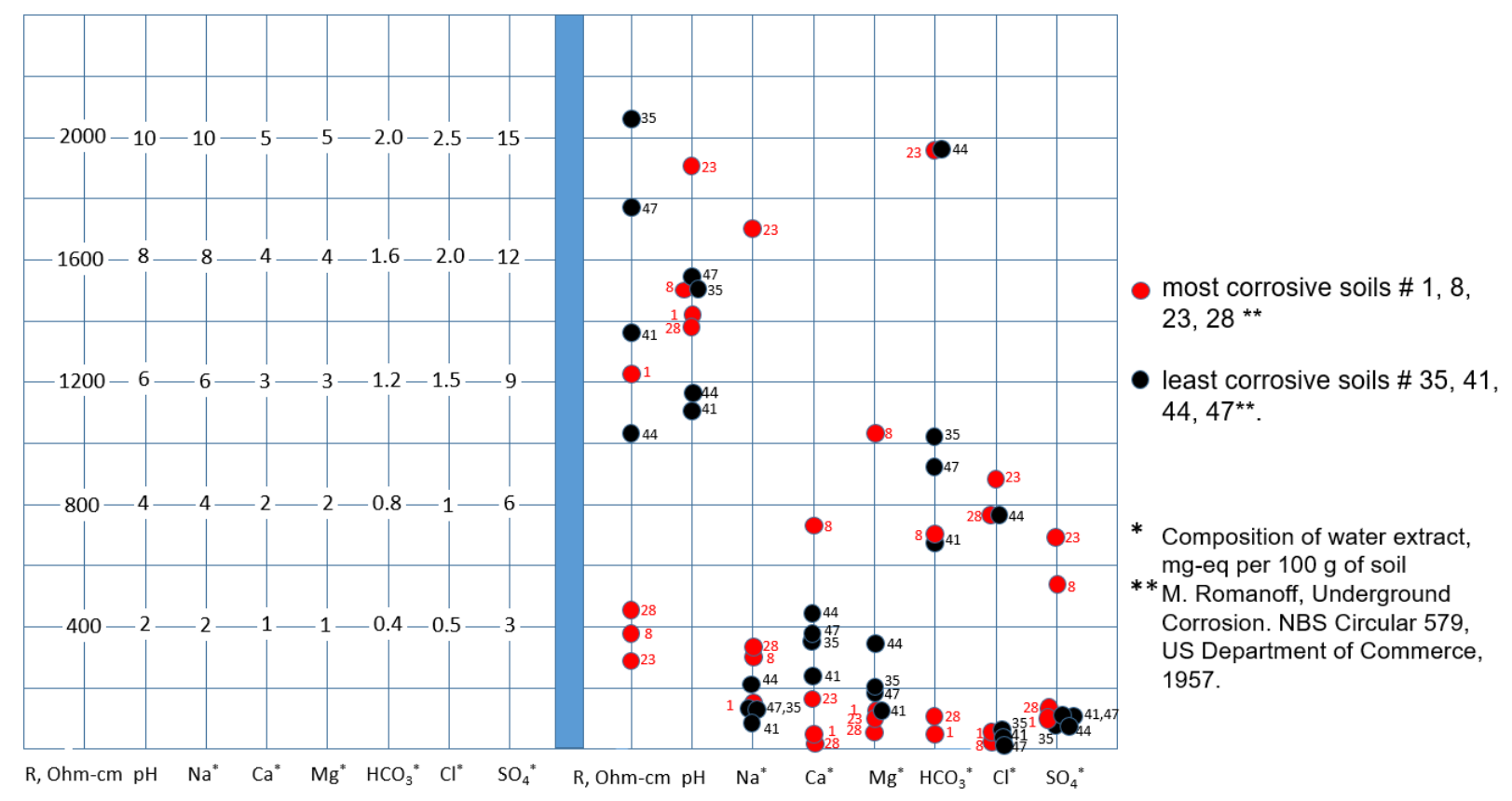

Figure A.2. Summary of chemical and physical properties of the four most and least corrosive soils based on the deepest penetration on 6-in. ferrous pipe. These soil data were collected from the NBS corrosion study

(Romanoff 1957).

\section{Compositions of different soil-simulating solutions}

Table A.6. Synthetic solutions used to study microbiologically influenced corrosion (MIC)

\begin{tabular}{|c|c|c|c|c|c|}
\hline \multirow{2}{*}{$\begin{array}{r}\text { Recipe source } \\
\text { Composition }(\mathrm{g} / \mathrm{L})\end{array}$} & \multicolumn{2}{|c|}{$\begin{array}{l}\text { Sherar } \\
\text { (2013) }\end{array}$} & \multirow{2}{*}{$\begin{array}{c}\text { Newman } \\
(1992) \\
\# 3^{(B)}\end{array}$} & \multicolumn{2}{|c|}{$\begin{array}{l}\text { Sherar } \\
\text { (2011) }\end{array}$} \\
\hline & $\# 1^{(\mathrm{A})}$ & $\# 2^{(\mathrm{A})}$ & & $\# 4$ & $\# 5$ \\
\hline $\mathrm{NaHCO}_{3}$ & 16.8 & 0.437 & & 4.2 & \\
\hline $\mathrm{Na}_{2} \mathrm{CO}_{3}$ & & 0.657 & & & \\
\hline $\mathrm{NaHCO}_{3} / \mathrm{Na}_{2} \mathrm{CO}_{3}$ & & & & & $19^{(\mathrm{C})}$ \\
\hline $\mathrm{Na}_{2} \mathrm{SO}_{4}$ & 14.2 & 0.071 & & & 14.2 \\
\hline $\mathrm{NaCl}$ & 5.8 & 0.035 & 35.06 & & 5.84 \\
\hline $\mathrm{NaClO}_{4}$ & & 12.24 & & & \\
\hline $\mathrm{NaH}_{2} \mathrm{PO}_{4}+\mathrm{Na}_{2} \mathrm{HPO}_{4}$ & & & $13.1^{(\mathrm{C})}$ & & \\
\hline $\mathrm{H}_{2} \mathrm{~S}$ & & & & & 0.034 \\
\hline $\mathrm{Na}_{2} \mathrm{~S} \cdot 9 \mathrm{H}_{2} \mathrm{O}$ & & & & 0.24 & \\
\hline $\mathrm{pH}$ & $8.9 \pm 0.5$ & $8.9 \pm 0.5$ & 7.2 & & 9.5 \\
\hline
\end{tabular}

(A) Preconditioning solution of $1 \mathrm{M} \mathrm{NaHCO}_{3} / \mathrm{Na}_{2} \mathrm{CO}_{3}$ was used to pre-form a siderite film.

(B) $0.6,3$, and $15 \mathrm{mM} \mathrm{H}_{2} \mathrm{~S}$ was added as saturated, pre-analyzed solution after purging $200 \mathrm{~mL}$ of the base solution with gold spot nitrogen for $4 \mathrm{~h}$.

(C) Assuming equal amount of both substances. 


\section{Fact sheet}

- There are 876,000 miles of municipal water mains in the US - more than 5 times longer than the national highway system. Moreover, community water systems include over 1.8 million miles of network pipes (2002).

- The average age of drinking water infrastructure in the US is over 40 years of a 50-year design life. Some pipes date back to the 1880 s.

- The conditions of many of these pipes are unknown, as they are buried underground out of sight and are owned and operated by various local entities.

- Up to 20,000 miles of pipe will need to be replaced annually, beginning 2035 .

- The nationwide system of wastewater infrastructure includes 600,000 miles of sanitary sewers and 200,000 miles of storm sewers. Aging sewer systems spill about 1.26 trillion gallons of untreated sewage every single year.

- Since 2000, the US suffered over 5.1 million broken water mains (240,000 breaks per year), most of them caused by corrosion.

- Failures in drinking water infrastructure result in water disruption, impediments to emergency response, health issues, and damage to other types of infrastructure, such as roadways.

- In 2013 the American Society of Civil Engineers (ASCE), in its Report Card for America's Infrastructure, gave an overall grade of "D" for the state of critical water/wastewater infrastructure.

- According to ASCE, "Every day, six billion gallons of drinking water disappears, mostly due to old, leaky pipes and water mains. That is enough water to serve the population of a state the size of California" (2005).

- The US Conference of Mayors in their "Open Letter to the Next President of the United States" of September 2008 expressed alarm that " $35 \%$ of cities in a Conference of Mayors survey do not know where their water supply will come from by 2025."

- Leaking pipes are a concern for most cities, which can lose anywhere from 5 to $40 \%$ of their water.

- On December 14, 2015, a state of emergency due to "out-of-control corrosion" was declared in Flint, MI, after state and local government officials ignored, for more than 18 months, irrefutable evidence that the water pumped from the Flint River exposed residents to extreme toxicity. "There are potential Flints all over the Northeast and Midwest," Rep. Duncan (R-TN) said in August 2016. 

